\title{
CAMA
}

Centre for Applied Macroeconomic Analysis

\section{Slowdown in Emerging Markets: Rough Patch or Prolonged Weakness?}

\section{CAMA Working Paper 1/2016 January 2016}

Tatiana Didier

World Bank, Operations and Strategy Group

\section{Ayhan Kose}

World Bank, Development Prospects Group

Brookings Institution

CEPR and

Centre for Applied Macroeconomic Analysis (CAMA), ANU

\section{Franziska Ohnsorge}

World Bank, Development Prospects Group

\section{Lei Sandy Ye}

World Bank, Development Prospects Group

\section{Abstract}

Emerging markets (EM) face their fifth consecutive year of slowing growth and a possibly longer period of sluggish performance than previously thought. This paper presents a comprehensive analysis of the nature of and the appropriate policy responses to the growth slowdown in EM. It reports three main results. First, the slowdown is synchronous and protracted, affecting a sizable number of EM, especially large ones. Second, it has been driven by both external factors, including weak world trade, low commodity prices, and tightening financial conditions; and domestic factors, including slowdown in productivity growth, bouts of policy uncertainty, and an erosion of policy buffers. Both structural and cyclical factors have contributed to the slowdown. Third, the room for accommodative cyclical fiscal and monetary policies is limited in many EM, lending urgency to putting in place structural reforms to upgrade governance structures, improve business environments, raise human and physical capital, and manage demographic pressures. 


\section{Keywords}

Emerging markets, growth slowdown, policy space, monetary policy, fiscal policy, structural reforms.

\section{JEL Classification}

E60, F6, F43, O4, O43

\section{Address for correspondence:}

(E) cama.admin@anu.edu.au

ISSN 2206-0332

The Centre for Applied Macroeconomic Analysis in the Crawford School of Public Policy has been established to build strong links between professional macroeconomists. It provides a forum for quality macroeconomic research and discussion of policy issues between academia, government and the private sector.

The Crawford School of Public Policy is the Australian National University's public policy school, serving and influencing Australia, Asia and the Pacific through advanced policy research, graduate and executive education, and policy impact. 


\title{
Slowdown in Emerging Markets: Rough Patch or Prolonged Weakness?
}

\author{
Tatiana Didier, M. Ayhan Kose, Franziska Ohnsorge, and Lei Sandy Ye ${ }^{1}$
}

\begin{abstract}
Emerging markets (EM) face their fifth consecutive year of slowing growth and a possibly longer period of sluggish performance than previously thought. This paper presents a comprehensive analysis of the nature of and the appropriate policy responses to the growth slowdown in EM. It reports three main results. First, the slowdown is synchronous and protracted, affecting a sizable number of EM, especially large ones. Second, it has been driven by both external factors, including weak world trade, low commodity prices, and tightening financial conditions; and domestic factors, including slowdown in productivity growth, bouts of policy uncertainty, and an erosion of policy buffers. Both structural and cyclical factors have contributed to the slowdown. Third, the room for accommodative cyclical fiscal and monetary policies is limited in many EM, lending urgency to putting in place structural reforms to upgrade governance structures, improve business environments, raise human and physical capital, and manage demographic pressures.
\end{abstract}

JEL Classification Numbers: E60, F6, F43, O4, 043.

Keywords: emerging markets, growth slowdown, policy space, monetary policy, fiscal policy, structural reforms.

\footnotetext{
1 Didier (World Bank, Operations and Strategy Group; tdidier@worldbank.org); Kose (World Bank, Development Prospects Group; Brookings Institution; CEPR; CAMA; akose@worldbank.org); Ohnsorge (World Bank, Development Prospects Group; fohnsorge@worldbank.org); Ye (World Bank, Development Prospects Group; lye1@worldbank.org). The paper was produced with inputs from Marcio Cruz, Raju Huidrom, Ergys Islamaj, Eung Ju Kim; Jaime de Jesus Filho, Bryce Quillin, Naotaka Sugawara, and Tianli Zhao. Anh Mai Bui and Xinghao Gong provided research assistance. It has benefited from useful comments from Kaushik Basu, Vandana Chandra, Christian Eigen-Zucchi, Mark Felsenthal, Poonam Gupta, David Rosenblatt, and Dana Vorisek, and valuable conversations with Ursel Baumann, Eduardo Borenzstein, Charles Collyns, Don Hanna, Michael Hanson, Li Lian Ong, Ramon Gomez-Salvador, Bernd Schnatz, Hung Tran and Ine van Robays.
} 


\section{Slowdown in Emerging Markets: Rough Patch or Prolonged Weakness?}

\section{CONTENTS}

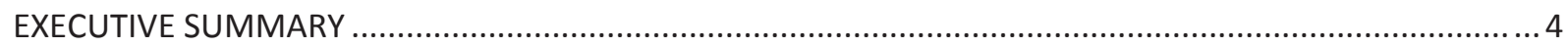

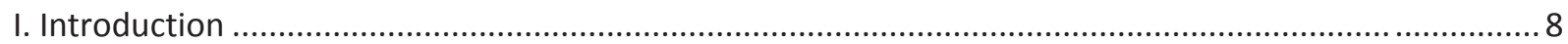

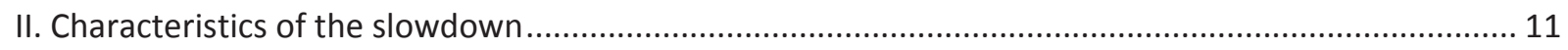

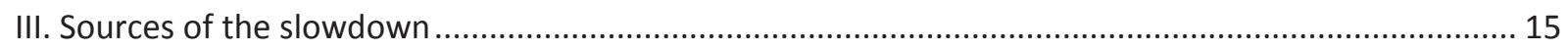

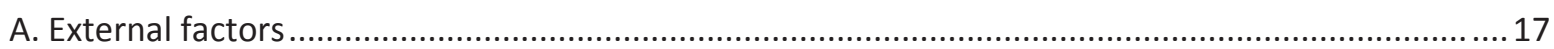

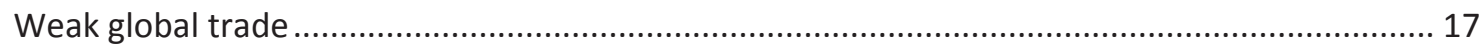

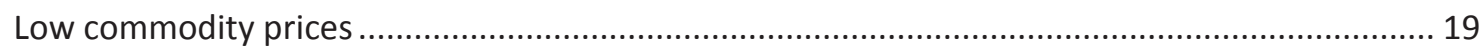

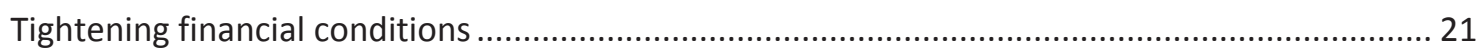

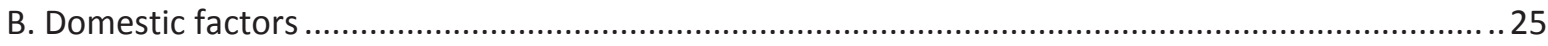

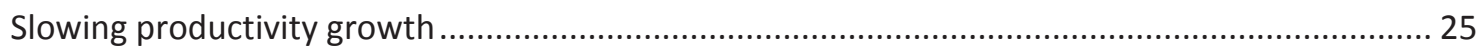

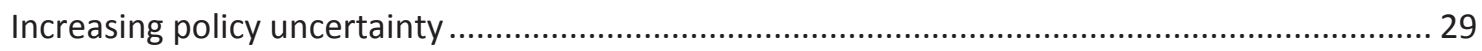

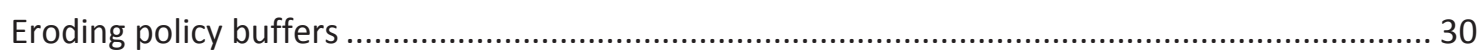

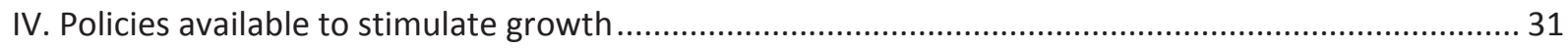

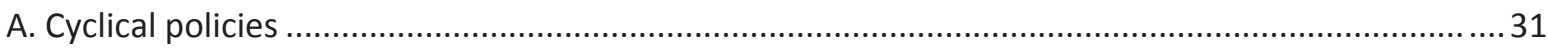

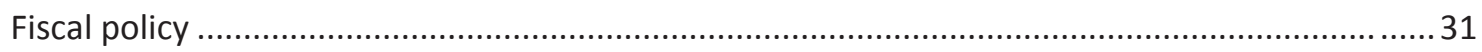

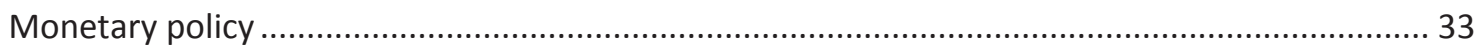

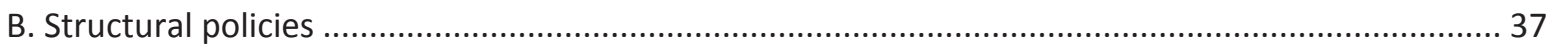

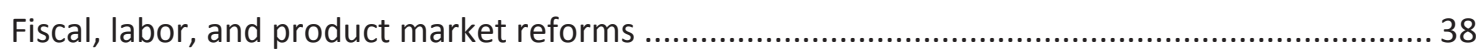

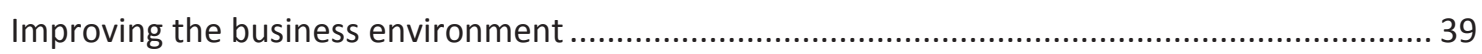

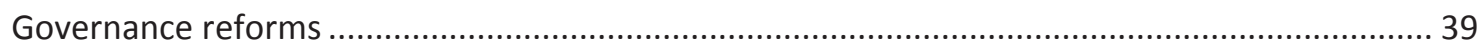

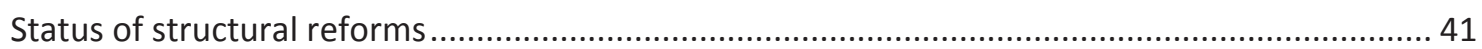

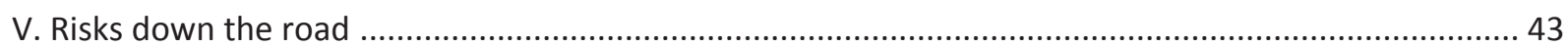

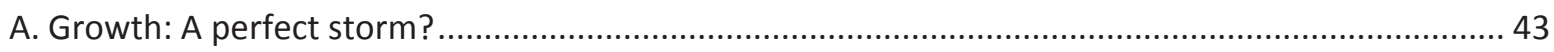

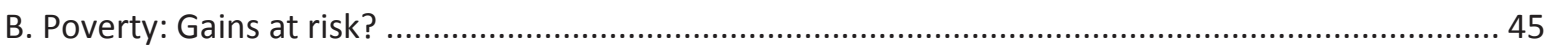

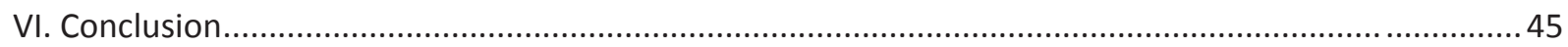

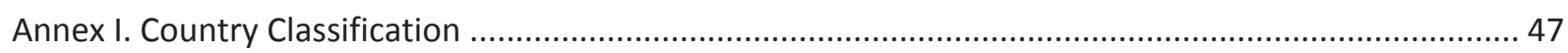

Annex II. The Middle-Income Trap: A Brief Literature Review ..................................................... 48

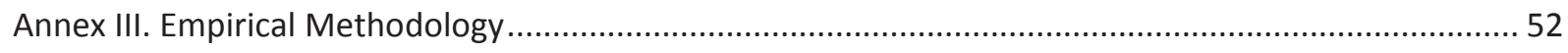

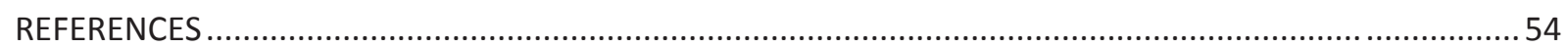




\section{Figures}

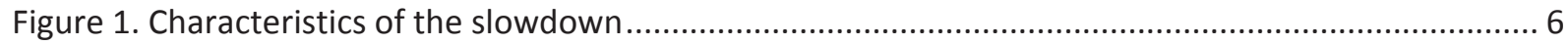

Figure 2. Policy options to cope with the slowdown .................................................................... 7

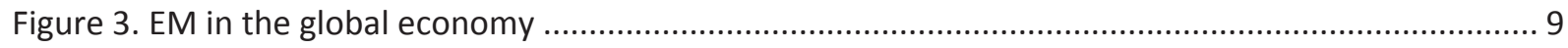

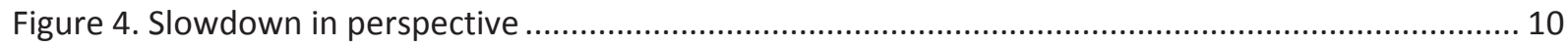

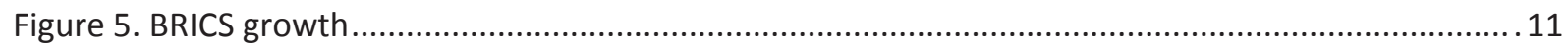

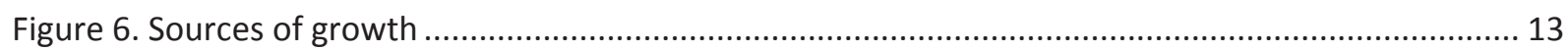

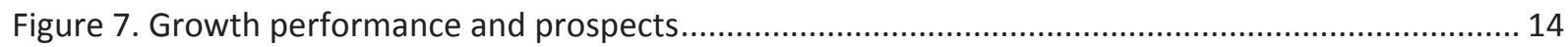

Figure 8. External and domestic drivers of the slowdown ........................................................... 16

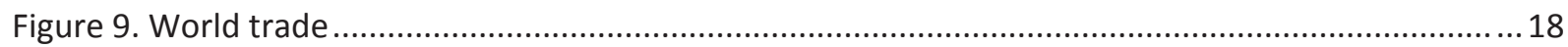

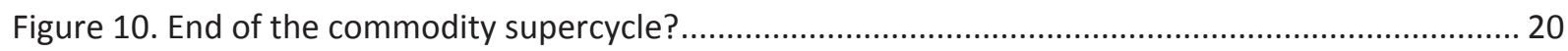

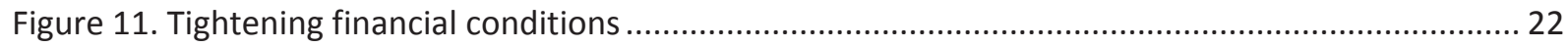

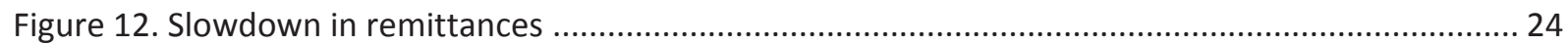

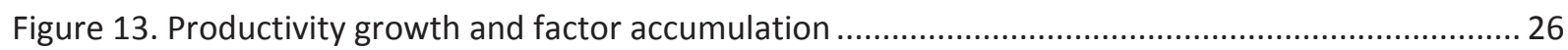

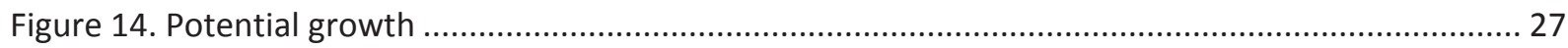

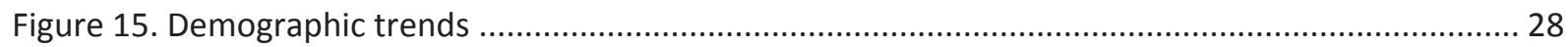

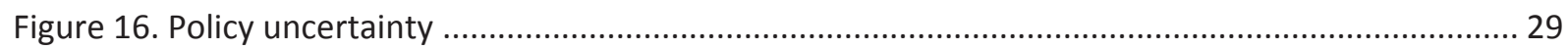

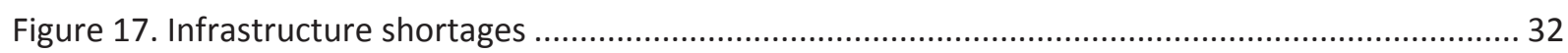

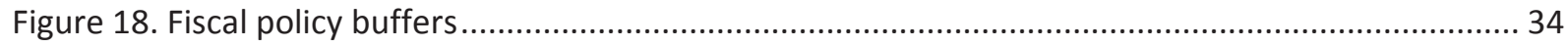

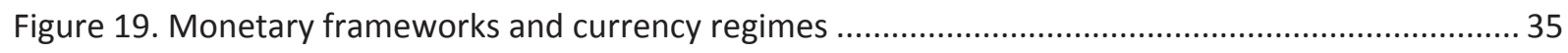

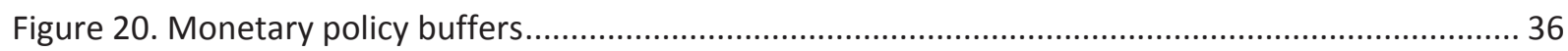

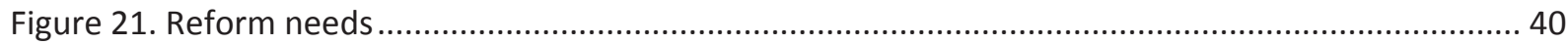

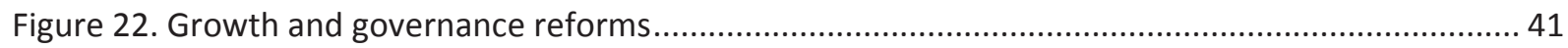

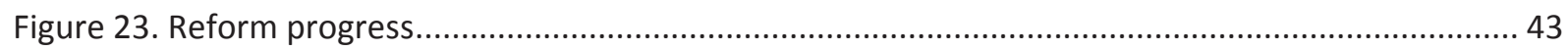

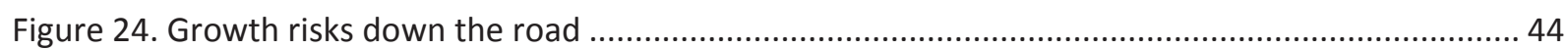

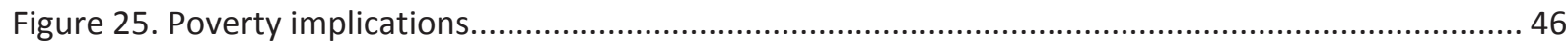

\section{Tables}

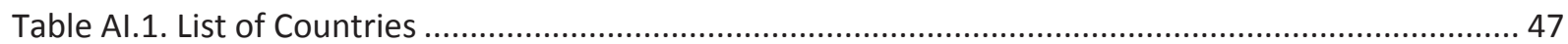

Table All.1. Middle-Income Trap: Selected Studies ................................................................. 49 
"Nirvana" is defined as the state of freedom from suffering. For emerging markets, that state is over...

Andres Velasco, September 11, 2013

The real question is what will happen when the turmoil moves to debt markets. Many countries have built up substantial reserves, and are now issuing far more debt in domestic currency... there is surely more drama to come over the next few years.

Kenneth Rogoff, February 6, 2014

In the medium term, ... the potential for technological catch-up growth and secular convergence remains strong in most emerging countries. The pace of a country's convergence will depend... on the quality of governance and the pace of structural reforms.

Kemal Dervis, February 17, 2014

The most likely scenario is that most major emerging markets ... will experience a transitional growth slowdown but will not be derailed by shifts in monetary policy in the West, with high growth rates returning in the course of the coming year...

Michael Spence, February 20, 2014

But, again, these problems are self-inflicted, and many emerging economies do have stronger macro and structural fundamentals, which will give them greater resilience when the Fed starts hiking rates. When it does, some will suffer more than others; but, with a few exceptions lacking systemic importance, widespread distress and crises need not occur.

Nouriel Roubini, June 29, 2015

As global investors navigate the uncertain waters of emerging markets in the next few years, they should remember that, for these economies, the wave of industrialization and urbanization and the associated productivity gains are far from over. With their faster-growing populations and productivity, they will enjoy a growth advantage over developed economies for some time to come.

Laura Tyson, June 30, 2015

With hindsight, it has become clear that there was in fact no coherent growth story for most emerging markets. Scratch the surface, and you found high growth rates driven not by productive transformation but by domestic demand, in turn fueled by temporary commodity booms and unsustainable levels of public or, more often, private borrowing.

Dani Rodrik, August 13, 2015

Something has gone badly wrong in the emerging economies... The search for culprits is under way: commodity prices, fracking, US interest rates... But the answer is simpler and more traditional. It is politics.

Bill Emmott, August 17, 2015

In short, though emerging economies' debts seem largely moderate by historic standards, it is likely that they are being underestimated, perhaps by a large margin. If so, the magnitude of the ongoing reversal in capital flows ... may be larger than is generally believed-potentially large enough to trigger a crisis.

Carmen Reinhart, October 9, 2015 


\section{EXECUTIVE SUMMARY}

Slowdown in emerging markets after a golden decade. Since 2010, growth has been slowing in emerging market economies (EM). EM growth has remained well below pre-crisis (2003-08) rates and, by 2014, had fallen below its long-term (1990-2008) average. This follows half a decade during which EM as a group achieved its highest growth since the 1980s and became the main engine of global activity, accounting for about 52 percent of global growth. The protracted deceleration in EM growth contrasts with the weak but steady recovery in advanced economies (AE) from a 2012 trough.

There has been intense debate about the nature of and appropriate policy responses to the growth slowdown in EM. The objective of this Policy Research Note is to shed light on this debate by addressing the following questions:

- What are the main characteristics of the slowdown?

- What are the key drivers of the slowdown?

- Which policies are available to stimulate growth?

A synchronous and protracted slowdown. The slowdown has been unusually synchronous and protracted (Figure 1). It has affected a sizeable number of EM, especially large ones. Although the slowdown is taking place against a backdrop of a weak, but not stressed, external environment, its breadth is comparable to previous episodes of global turmoil. By 2014, the number of EM slowing for three consecutive years reached the levels seen during the global financial crisis of 2008-09. The deceleration in EM growth has been broad-based, with concurrent declines in growth in most components of demand. Growth rates of investment and exports suffered especially sharp cutbacks, falling to less than half of their 2003-08 average levels. The slowdown has been associated with repeated downward revisions in EM growth forecasts. Recent growth forecasts for 2015 are slightly below 4 percent, down from as high as 7.6 percent in 2010. Repeated forecast downgrades and high-frequency indicators suggest that the slowdown might not be simply a pause, but the beginning of an era of weak growth for EM.

Caused by external and domestic factors. The EM growth slowdown was initially driven by external factors but domestic factors have increasingly weighed on growth since 2014. External factors holding back growth since 2011 include weak world trade, low commodity prices, and tightening financial conditions. Domestic factors include a steady slowdown in productivity growth, bouts of policy uncertainty, and an erosion of policy buffers that has made it difficult to support activity with fiscal and monetary stimulus.

Part cyclical, part structural. Decelerating potential growth has, on average, accounted for one-third of the slowdown in EM growth since 2010. However, the degree to which structural factors contributed to the slowdown varies widely across countries. Much of the decline in potential growth resulted from a slowdown in productivity growth.

Appropriate policy response. Policies can play an important role in mitigating the adverse effects of the slowdown and promoting growth (Figure 2). Since the growth deceleration has both cyclical and structural components, both cyclical and structural policies need to be employed, but their relative importance varies across countries. Even where cyclical factors appear predominant and policy space is ample, the uncertainties around the underlying drivers of the slowdown imply that the optimal policy mix requires the adoption of structural policies to improve medium- and long-term growth prospects in addition to the use of any cyclical policies. 
Fiscal and monetary policies. To the extent that the slowdown reflects, at least in part, a cyclical deceleration, expansionary fiscal and monetary policies could support growth.

- Fiscal policy. Crisis-related fiscal stimulus, both during the crisis and in its wake, has reduced the maneuvering space in several EM. Persistently low oil prices have further narrowed fiscal policy room in most oil-exporting countries but widened it in some oil-importing countries. Provided there is sufficient policy space, infrastructure investment can be a particularly effective instrument for fiscal stimulus to help lift activity and boost employment. Fiscal multipliers can range from nil in countries with large fiscal deficits (in excess of 7 percent of GDP) to 2.5 in countries with sizable fiscal surpluses (around 2 percent of GDP).

- Monetary policy. Monetary policy options diverge between commodity-importing and commodity-exporting countries: while most of the latter EM have limited monetary policy room to maneuver, many in the former group should have some space to counteract shocks and stimulate activity. In commodity-exporting EM, depreciating currencies have increased inflation pressures and weakened balance sheets with foreign exposures. This has compelled several inflation-targeting central banks to tighten their monetary policy stance. Even after these interest rate hikes, real policy rates appear to remain low in several commodity-exporting countries. In oil-importing countries, the drop in oil prices has reduced inflation and allowed central banks to cut rates. However, inflation pressures may resume once the effect of lower oil prices dissipates.

Structural reforms. Reforms could mitigate the sources of the growth slowdown in the medium- and longterm, especially those associated with structural factors. Since the 2008 global financial crisis, EM's record with respect to structural reforms has been mixed. Although there has been progress in strengthening infrastructure and reducing administrative obstacles in some EM, governance reforms have been lagging. Corruption and infrastructure gaps remain key obstacles to doing business in many EM. Policies to improve the investment climate, enhance the functioning of labor markets, and raise human and physical capital could boost productivity. Past episodes of governance reforms appear to have been associated with more than one-percentage-point higher growth compared with non-reform periods.

Larger risks down the road? Three major risks arise from the slowdown in EM. First, in a context of already weakening capital flows, slow growth could combine with bouts of global financial market volatility and lead to sudden stops in major EM. Sudden stops have been associated with sharp output and investment contractions: historically, GDP growth has declined, on average, by almost 7 percentage points and investment growth plummeted by more than 21 percentage points in the two years following a sudden stop episode. Second, in light of the growing importance of EM in the world economy, a persistent slowdown or hard landing in EM could derail a fragile global recovery. Third, weak EM growth would make it difficult to reduce poverty and improve standards of living.

A rough patch or prolonged weakness? EM have come a long way over the past two decades: they have been able to improve their macroeconomic policy frameworks, reduce debt and inflation levels, diversify their production and exports, and establish stronger global trade and financial linkages. In a nutshell, the EM of today are surely not the crisis-prone EM of the 1980s or 1990s. However, after enjoying years of strong growth, EM find themselves at a crossroads. While the growth slowdown since 2010 could simply be a rough patch, it could also signal the start of an era of slow growth given the persistent nature of the factors that have driven the slowdown so far. In light of the significant global risks going forward, EM urgently need to put in place an appropriate set of policies to address their cyclical and structural challenges and promote growth. 
Figure 1. Characteristics of the slowdown

A synchronous and persistent slowdown has been underway in EM since the post-crisis rebound of 2010, narrowing the growth differential between AE and EM. The slowdown has been driven by both external and domestic factors, and has had both cyclical and structural components. Repeated short-and long-term forecast downgrades suggest that EM may continue to suffer from weak growth in the coming years.

A. Growth

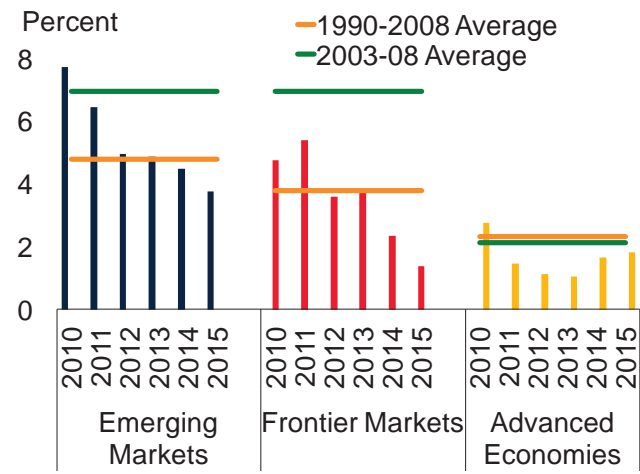

C. Actual and potential growth: EM

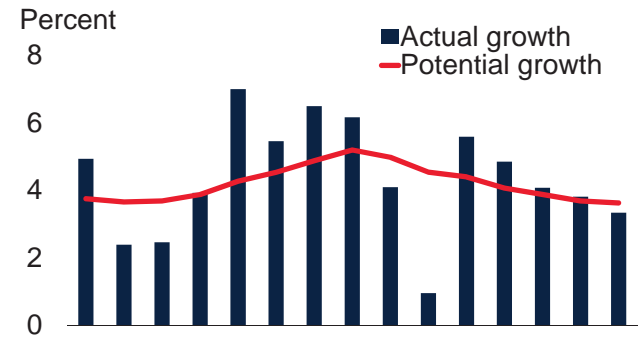

$-2$

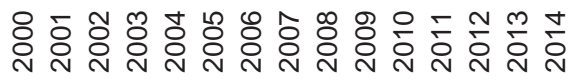

\section{E. EM growth forecasts for 2015}

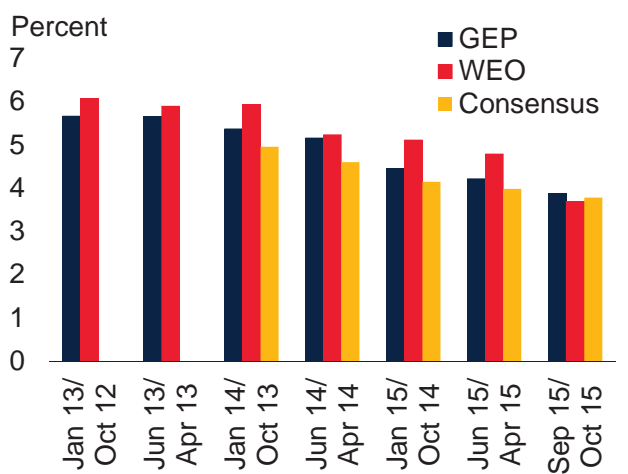

\section{B. EM-AE growth differential}

Percentage points

8

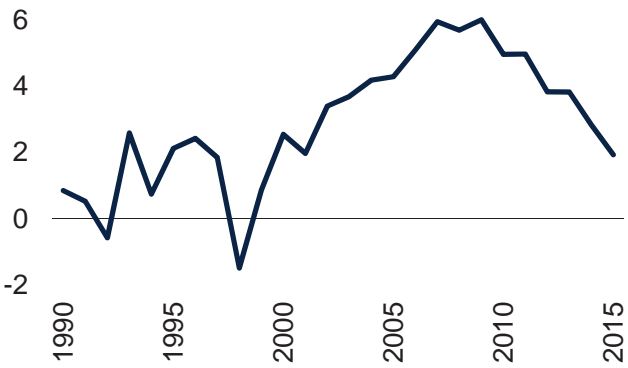

D. External and domestic drivers of slowdown: BRICS Percentage points

3

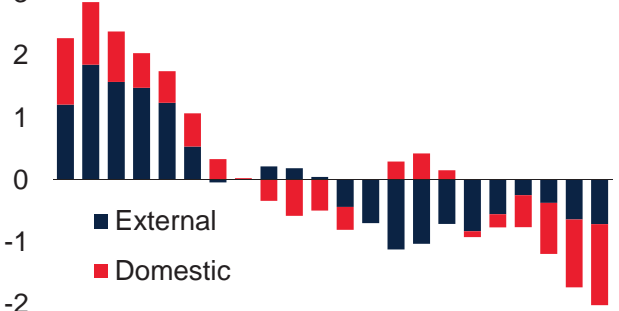

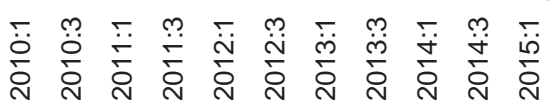

F. Long-term growth expectations: BRIC

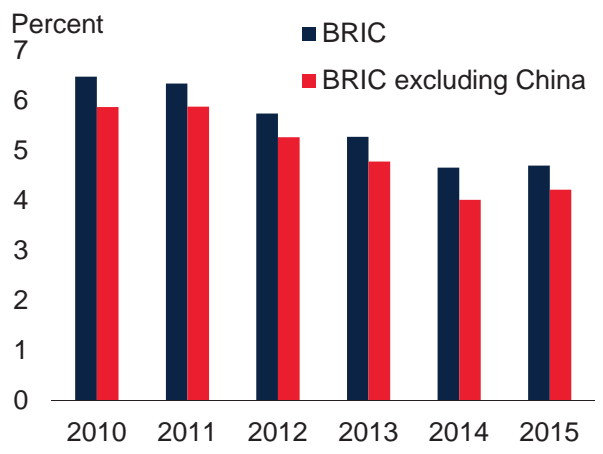

Source: World Bank Global Economic Prospects (GEP), IMF World Economic Outlook (WEO), Consensus Forecasts, World Bank, Haver Analytics. A. Weighted average growth.

B. Difference between weighted average EM growth and weighted average AE growth.

C. Unweighted averages to reflect the full universe of EM.

D. Based on a Bayesian vector autoregression estimation using data for 1998:1 to 2015:2 for 18 EM. Each bar shows the percentage point deviation of growth from the sample mean. See Figure $8 \mathrm{E}$ for additional details.

E. Consensus Forecasts for 2015 growth are only available from January 2014. In each column, the first date refers to the edition year of the World Bank GEP and the month-year of Consensus Forecasts, and the second date refers to the edition year of the IMF WEO. September 2015 forecasts for GEP are working assumptions. All columns show growth forecasts for 2015 as of the date shown in the column.

F. Each column shows five-year ahead Consensus Forecasts as of the latest available month in the year denoted. Unweighted averages. Five-yearahead Consensus Forecasts for South Africa are not available. 


\section{Figure 2. Policy options to cope with the slowdown}

The infrastructure gap in EM remains large, suggesting that expansionary fiscal policy could be an effective stimulus tool. Fiscal space has shrunk in many EM, reducing fiscal multipliers. Monetary policy space has narrowed for commodity exporters. With room for countercyclical policies narrowing in many EM, structural reforms should be employed to promote growth.

\section{A. EM fiscal sustainability}

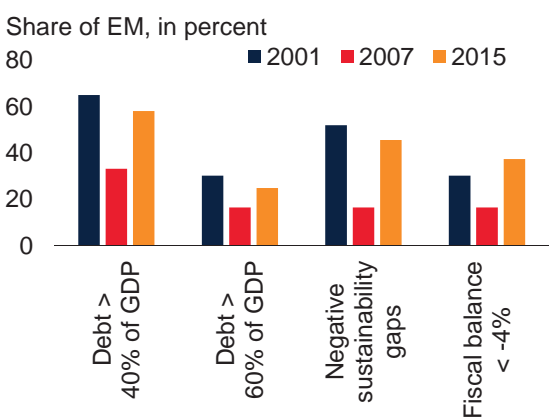

\section{Monetary policy rate changes in EM}

Number of hikes and cuts

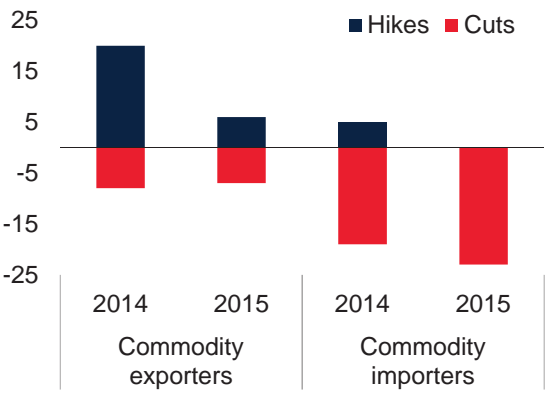

E. Growth differential during reforms and setbacks Growth differential

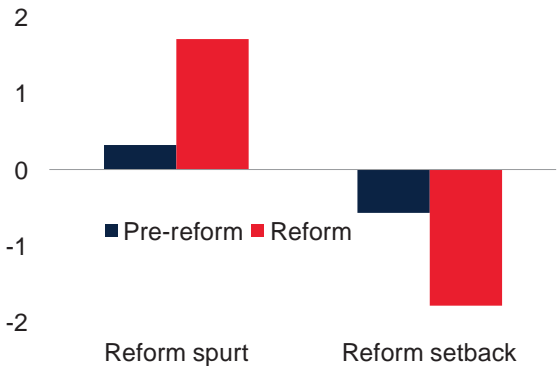

\section{B. Fiscal multipliers after two years}

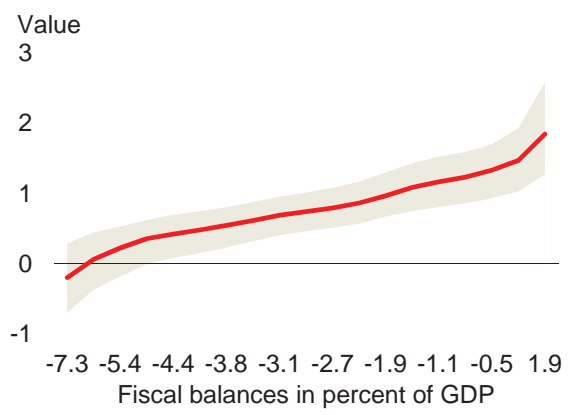

\section{Access to electricity}

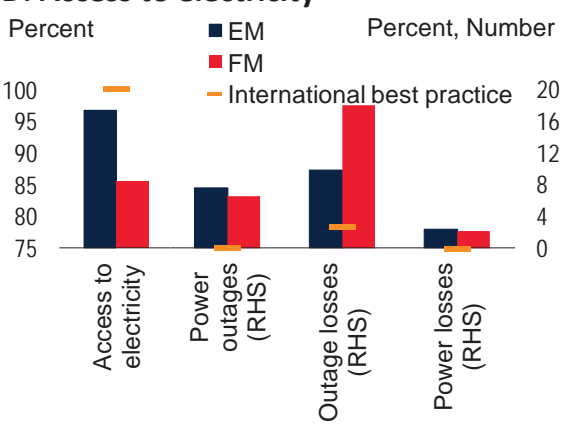

F. Changes in growth and governance quality: 2010-14 Percentage points

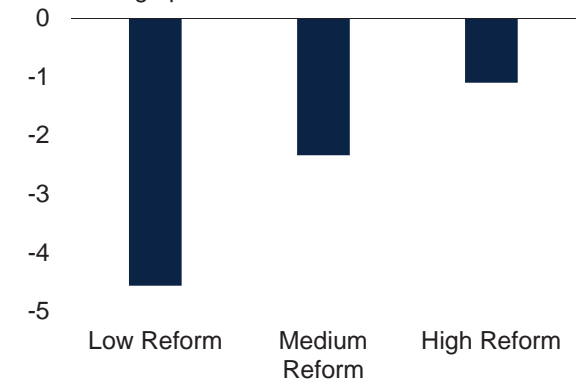

Source: World Bank (2015a), Central Banking News, Haver Analytics, World Bank Country Policy and Institutional Assessment (CPIA) and Worldwide Governance Indicators (WGI).

A. EM with general government debt above $60 \%$ of GDP in 2015 include Brazil, Egypt, Hungary, India, Morocco, Pakistan. See Figure 18B for details. B. Fiscal multipliers after two years for different levels of fiscal balance (in percent of GDP), estimated from an IPVAR model using a sample of 15 emerging and frontier markets. Values on the $\mathrm{x}$-axis correspond to percentiles of the fiscal balance; solid line represents the median; shaded area is the $16-84$ percent confidence band.

C. Hikes and cuts refer to central banks' rate decisions, including base rates, policy rates, repo rates, Selic rates, discount rates, reference rates, lending rates, refinancing rates and benchmark rates. The number of rate cuts is presented with a negative sign. There are 11 commodity exporters and 13 commodity importers.

D. Access to electricity is in percent of population; power outages of firms in a typical month (number); power outages value loss in percent of sales; electricity transmission and distribution losses in percent of total output. International best practice ("frontier") is the average for the top $5^{\text {th }}$ percentile for access to electricity and for the bottom $5^{\text {th }}$ percentile for power outages, value lost to power outages, and power losses.

E. Based on an event study of episodes of significant reform spurts and setbacks (two standard-error change in at least one of four WGI ratings) for 1996-2014 of EM and FM. See Figure 22A for additional details.

F. Magnitude of slowdown is the change in growth during 2010-14. Low, medium, and high reform refer to the $25^{\text {th }}, 25^{\text {th }}-75^{\text {th }}$, and $75^{\text {th }}$ percentiles of the distribution in change in average governance of EM from 2010-2014. See Figure 22B for additional details. 


\section{Introduction}

A synchronous growth slowdown has been underway in emerging markets (EM) since $2010 .^{2}$ Growth in these countries is now markedly slower than, not just the pre-crisis average, but also the long-term average. As a group, EM growth eased from 7.6 percent in 2010 to 4.5 percent in 2014, and is projected to slow further to below 4 percent in 2015. This moderation has affected all regions (except South Asia) and is the most severe in Latin America and the Caribbean. The deceleration is highly synchronous across countries, especially among large EM. By 2015, China, Russia, and South Africa had all experienced three consecutive years of slower growth. The EM-AE growth differential has narrowed to two percentage points in 2015, well below the 2003-08 average of 4.8 percentage points and near the long-term average differential of 1990-2008.

The disappointing growth performance comes after a "golden era" for EM, especially during the early 2000s. From the early 1980 s to 2008, EM were able to deliver record-high growth rates while transforming the world economic landscape and becoming truly global players. By 2014, emerging markets accounted for 34 percent of global GDP, more than one-and-a-half times as much as they did in 1980 (Figure 3). Moreover, during the 2000s, emerging economies, especially the larger ones, were a main source of global growth, accounting for about 52 percent of world growth during the pre-crisis period and 60 percent during 2010-2014.

The rising importance of emerging markets in the global economy was also reflected in their rapid integration into international trade and finance. The share of global trade attributable to EM doubled between 1994 and 2014, from 16 percent to 32 percent. In global finance, gross private capital flows to emerging economies exceeded \$1 trillion in 2014 (about 20 percent of private inflows to all economies). EM deepened their economic ties not only with AE, but with each other. For instance, from 2000 to 2014, the share of EM exports to other EM nearly doubled, to 30 percent.

EM economies surprised most commentators by weathering the global financial crisis better than advanced economies and bouncing back rapidly in 2010. This was driven by a variety of factors, including the size and strength of their domestic demand, ample policy buffers built up prior to the crisis and the increased importance of intra-EM trade. While fluctuations in growth have become more synchronous among EM since the mid-1980s, growth in EM seems to have become less sensitive to growth in AE. Their successful performance during the crisis combined with their newfound business cycle independence led some to argue that emerging market economies had decoupled from $\mathrm{AE} .{ }^{3}$

After enjoying years of enviable growth, however, EM are at a crossroads. While the recent growth slowdown could be a rough patch, it could also be the beginning of an era of sluggish growth. In light of the growing importance of EM economies, a persistent slowdown or hard landing in EM could derail a fragile global recovery. Conversely, renewed growth momentum in EM could buoy activity in many of their trading partners and the world economy.

\footnotetext{
2 For a list of $24 \mathrm{EM}$ economies, please see Annex I. The group of EM generally includes countries with significant access to international capital markets, as defined by being classified as an EM by two of the three stock indexes of S\&P, FTSE, and MSCI.

${ }^{3}$ A number of studies analyze the growth performance of EM economies and how their dependence on advanced economies has evolved over time (King 2010; Kose and Prasad 2010; Magnus 2010; Spence 2011; O’Neill 2011; World Bank 2011a; Sharma 2012; Henry 2013; De la Torre et al. 2015).
} 


\section{Figure 3. EM in the global economy}

Over the past two decades, EM have generated a rising share of global output and became a major source of global growth.
A. Share of world output
B. Contribution to world growth
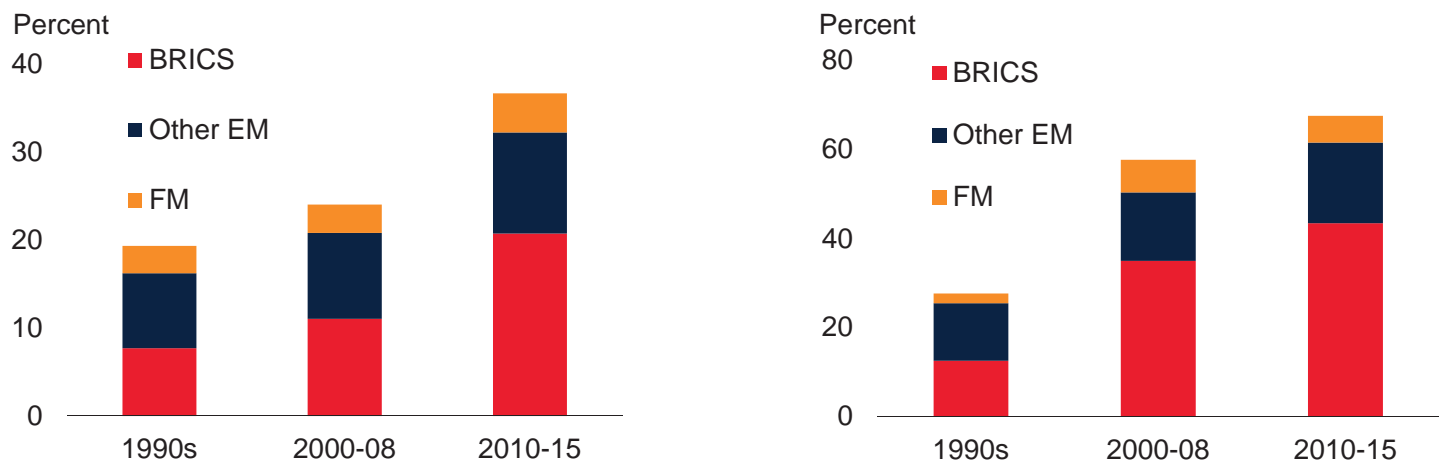
Source: World Bank, IMF World Economic Outlook, World Development Indicators.
A. Each column shows the period average of the share of global output contributed by each group denoted. 1990s average starts in 1992. Data for 2015 are forecasts.
B. The columns denote the percent contribution of each group to global growth over the periods denoted. Data for 2015 are forecasts.

The recent slowdown in EM has been a source of a lively debate, as evident from the quotations at the beginning of this Note. Some economists paint a bleak picture for the future of EM and argue that the impressive growth performance of EM prior to the crisis was driven by temporary commodity booms and rapid debt accumulation, and will not be sustained. Others emphasize that a wide range of cyclical and structural factors are driving the slowdown: weakening macroeconomic fundamentals after the crisis; prospective tightening in financial conditions; resurfacing of deep-rooted governance problems in EM; and difficulty adjusting to disruptive technological changes. Still others highlight differences across EM and claim that some of them are in a better position to weather the slowdown and will likely register strong growth in the future. ${ }^{4}$

This Policy Research Note seeks to help move the debate forward by examining the main features, drivers, and implications of the recent EM slowdown and provides a comprehensive analysis of available policy options to counteract it. Specifically, it addresses the following questions:

- What are the main characteristics of the EM growth slowdown?

- What are the key drivers of the slowdown?

- Which policies are available to stimulate growth?

\footnotetext{
${ }^{4}$ For details about these debates, see Hausmann (2013), Velasco (2013), Rogoff (2014), Spence (2014), Dervis (2015), Emmott (2015), Reinhart (2015), Rodrik (2015), Roubini (2015), and Tyson (2015).
} 


\section{Figure 4. Slowdown in perspective}

Emerging market growth has slowed steadily since 2010, and coincided with a gradual recovery in advanced economies. The slowdown has been wide-reaching across regions and affecting an unusually large number of EM for several years, comparable only to previous crisis periods. Unprecedented since the 1980s, the majority of BRICS economies are slowing simultaneously. Growth forecasts for 2015 have been revised downward repeatedly.

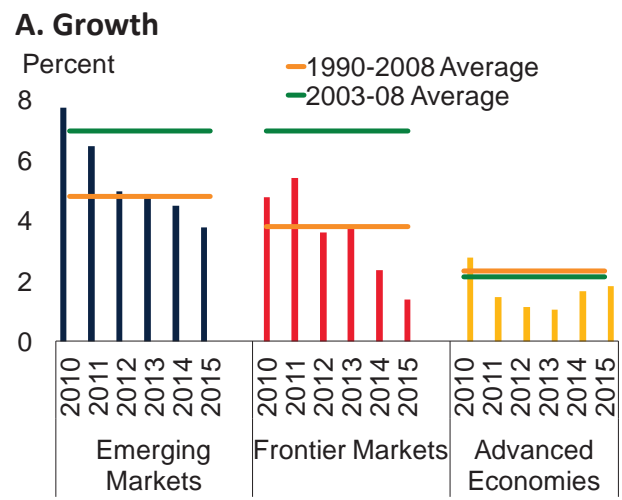

\section{EM growth}

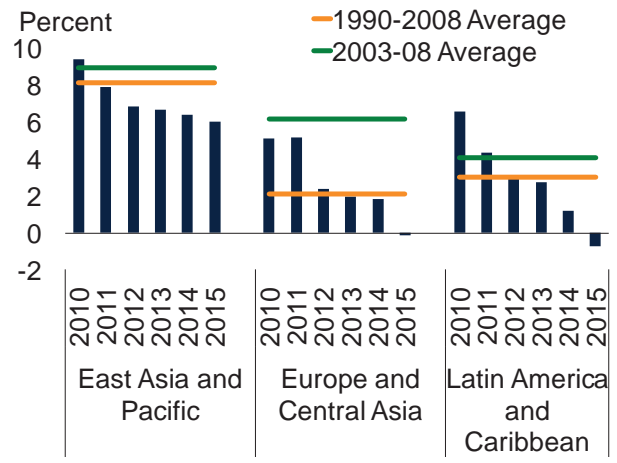

E. EM slowing for three consecutive years Number of countries

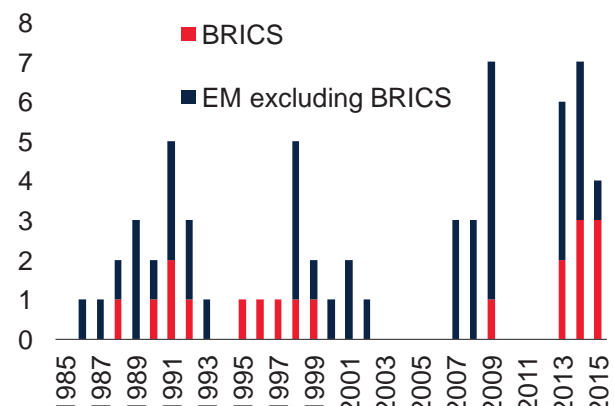

\section{B. EM-AE growth differential}

Percentage points

$$
8
$$

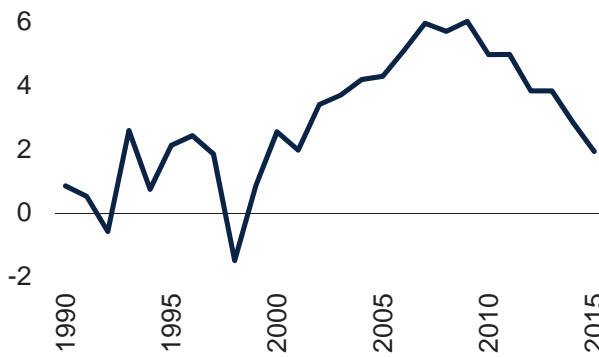

D. EM growth (cont.)

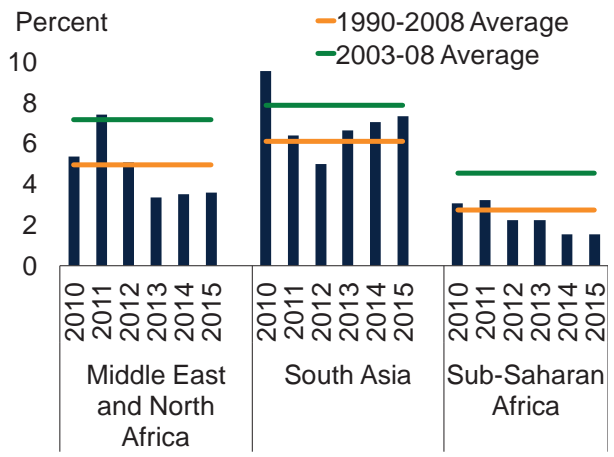

\section{F. EM growth forecasts for 2015}

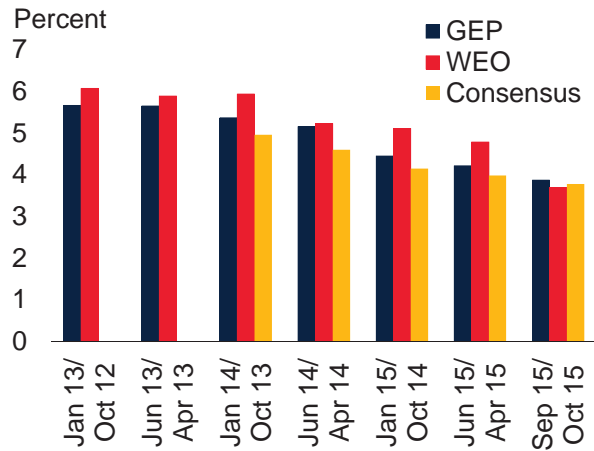

Source: World Bank Global Economic Prospects and World Development Indicators, IMF World Economic Outlook, Consensus Forecasts, Haver Analytics.

Note: Due to data availability, FM long-run average for 1990-2008 starts in 1993. EM, FM, and AE as defined in Annex I.

A. C. D. Weighted average growth. Regional growth numbers are for EM

B. Difference between weighted average EM growth and weighted average AE growth

E. Number of EM countries in which growth slowed for three consecutive years by the year denoted. BRICS refers to Brazil, Russia, India, China, and South Africa. Economies expected to slow for three consecutive years in 2015 are China, Indonesia, Russia, and South Africa.

F. Consensus Forecasts for 2015 growth are only available from January 2014. In each column, the first date refers to the edition year of the World Bank GEP and the month-year of Consensus Forecasts, and the second date refers to the edition year of the IMF WEO. September 2015 forecasts for GEP are working assumptions. Bars show growth forecasts for 2015 as of the date shown in the figure. 


\section{Figure 5. BRICS growth}

Growth in BRICS, with the exception of India, has been slowing significantly after 2010. These slowdowns are expected to continue over the near term.

\section{A. China and India}

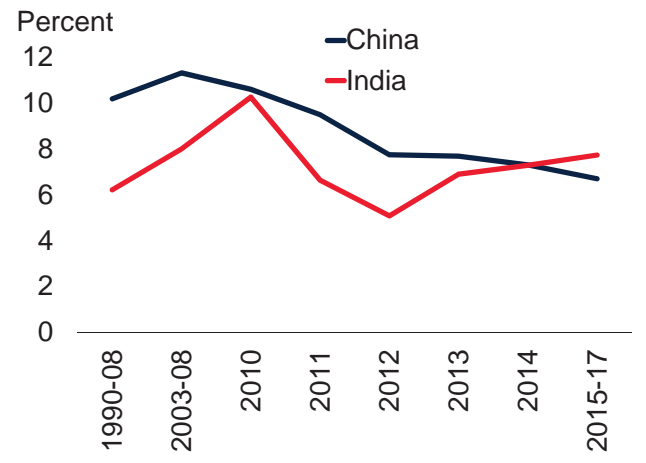

\section{B. Brazil, Russia, and South Africa}

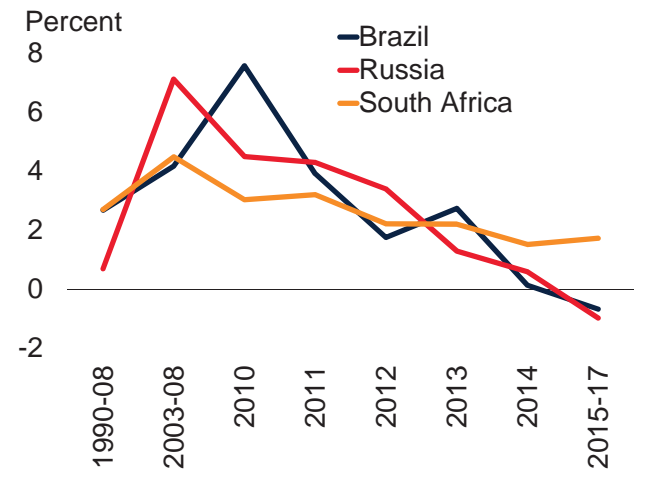

Source: World Bank, IMF World Economic Outlook, World Bank (2015b, c, d).

A. B. Period averages of annual real GDP growth rates. Data for 2015-17 are forecasts.

\section{Characteristics of the slowdown}

Since the post-crisis rebound of 2010, EM growth has slowed steadily (Figure 4). Since 2011, EM growth has been well below pre-crisis rates and, by 2014, had fallen below its long-term average. As a result, the growth differential between emerging markets and advanced economies has begun to narrow, and is expected to fall below its historical average by 2015 . The slowdown currently underway is:

- Synchronous and protracted. The growth slowdown among emerging markets since 2010 has been unusually synchronous and protracted and has affected a sizeable number of EM. The share of EM growing below their 1990-2008 long-term average has increased from about one-fifth in 2010 to about 80 percent in 2014. The slowdown has affected all regions except South Asia. The most severe slowdown has taken place in Latin America and Caribbean.

- Especially among large EM. BRICS (Brazil, Russia, India, China, and South Africa) account for about two-thirds of emerging market GDP and MIMT (Mexico, Indonesia, Malaysia, and Turkey) for another one-eighth. Unprecedented since the 1980s, four of the nine largest emerging marketsthe BRICS and the MIMT-appear to be simultaneously headed for a slowdown in 2015 for at least the third consecutive year. After 2010, all BRICS have been growing at rates below their 2003-08 average (Figure 5). Similar synchronous and protracted EM growth slowdowns had only occurred during the global and regional turmoil periods of the early and late 1990s as well as the 2008 global financial crisis. 
- Repeatedly disappointing. The EM slowdown has surprised most forecasters and caused repeated downward revisions, especially because the deceleration is taking place amid a backdrop of a weak but not stressed external environment. Growth forecasts have been revised downwards, on average and in virtually the majority of EM, in every forecast round since mid-2011. For example, in early 2013, EM growth was expected to be 5.6 percent in 2015, but, by June 2015, this projection had been revised to 4.2 percent (World Bank 2013; World Bank 2015f). ${ }^{5}$

- Broad-based domestically. The growth slowdown has been broad-based, reflecting simultaneous decelerations in all components of demand (Figure 6). Investment and exports slowed most sharply to well below their long-term average growth rates (excluding the transition recession in Russia in the early 1990s). In contrast, private and government consumption fell more modestly. As a result, GDP growth has fallen below the long-term average and well below pre-crisis growth rates.

- Amid gradual recovery in AE. The slowdown in EM contrasts with the anemic but steady recovery in advanced economy growth. Starting in 2012, AE growth has on average risen from 1.1 percent to 1.7 percent, and is forecasted to strengthen to 1.8 percent by the end of 2015. This trend suggests that in 2015, AE growth would again be in line with its long-term average from 19902008 , contrary to EM. About 54 percent of AE had experienced consecutive years of higher growth from 2012-2014.

- Along with slowing growth in FM and other developing economies. A similar slowdown set in among FM in 2011, a year later than in EM. Growth in FM decelerated from 5.4 to 2.3 percent during 2011-2014, and is expected to slow further to 1.4 percent by the end of 2015. More broadly, the share of developing economies slowing below their 1990-2008 long-term average has increased from about one-third in 2010 to one-half in 2014.

- Likely to continue over the short term. Both industry and consumer confidence indicators suggest that the growth slowdown in EM appears set to continue over the near term. ${ }^{6}$ On average, over 2010-14, emerging markets' manufacturing Purchasing Managers' Indices (PMI) have deteriorated sharply, from levels indicating robust expansion to levels indicating contraction. As of October 2015, they remain below the threshold for a contraction in all EM except India, Mexico, Poland, and Russia (Figure 7). Consumer confidence has similarly fallen steadily since 2014. In more than half of EM, consumer confidence is now at a level indicating that consumers expect a deterioration of economic conditions (i.e. below 50).

\footnotetext{
5 Similar downward revisions took place among Consensus Forecasts and IMF World Economic Outlook forecasts.

${ }^{6}$ Purchasing Managers' Indices are based on monthly surveys from private firms and measure managers' current sentiment and confidence on production, inventory, new orders, supplier deliveries, and employment. These surveys are available for almost half the EM sample.
} 


\section{Figure 6. Sources of growth}

The growth slowdown in EM was reflected in all components of demand, with the sharpest slowdowns in investment and exports. Investment, export, and GDP growth have fallen below long-term averages while consumption has been more resilient.

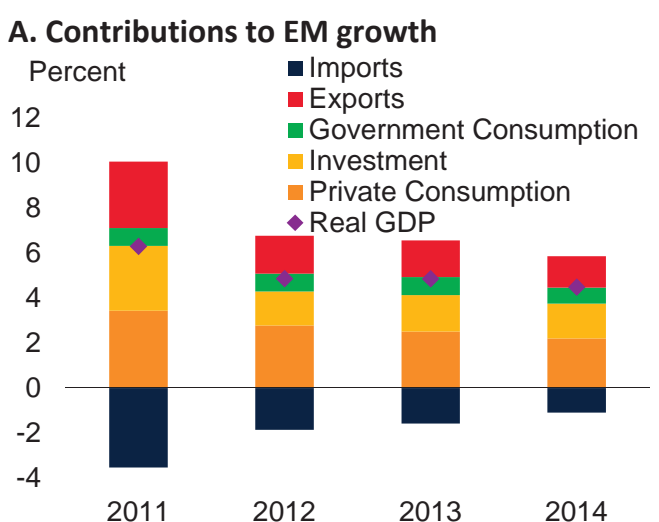

C. Private consumption growth
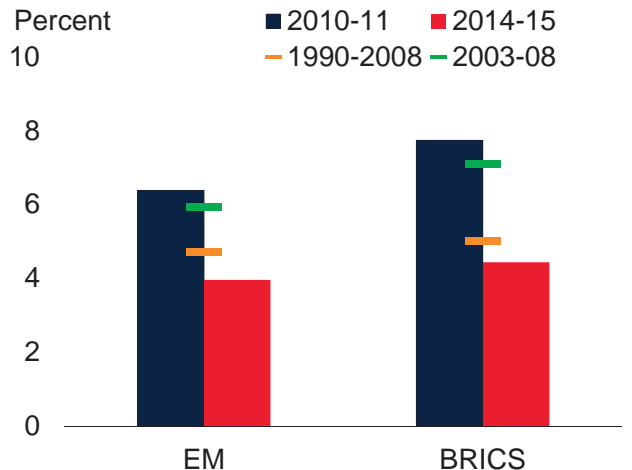

E. Investment growth

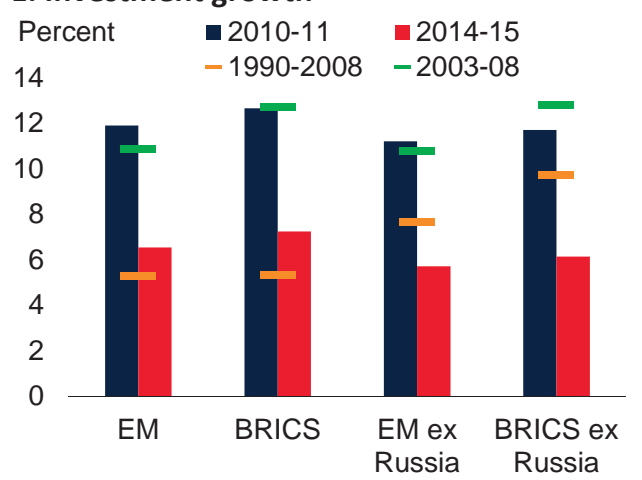

\section{B. GDP growth}

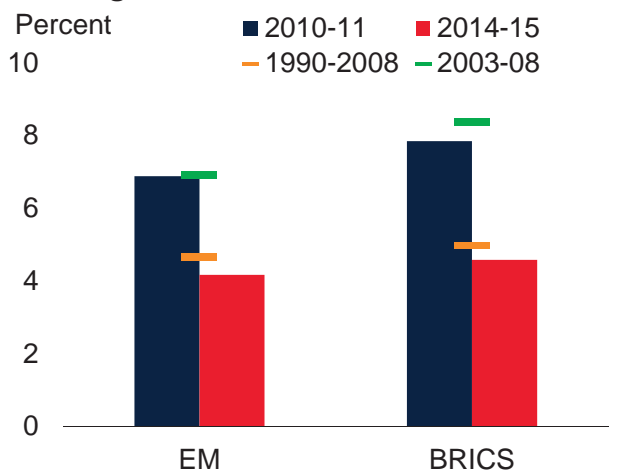

D. Government consumption growth

$\begin{array}{ll}\text { Percent } & \text {-2010-11 }=2014-15 \\ 8 & -1990-2008-2003-08\end{array}$

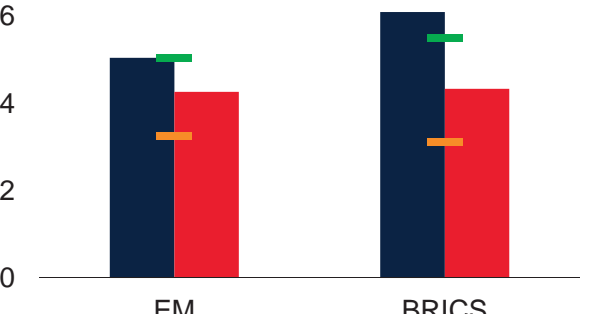

EM

BRICS

\section{F. Export growth}

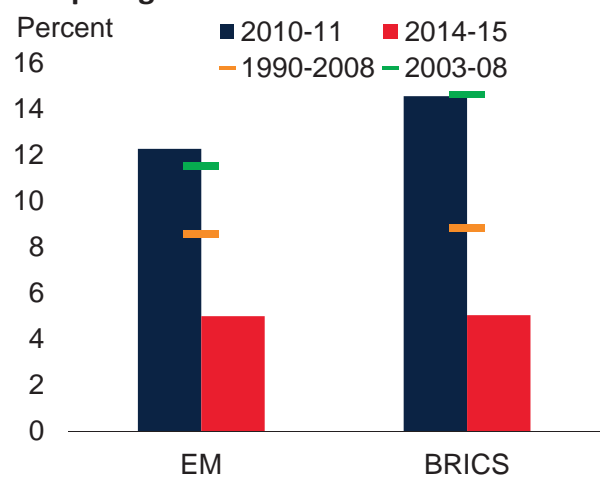

Source: World Bank.

Note: Due to lack of data, Qatar is excluded. EM as defined in Annex I.

E. EM ex Russia and BRICS ex Russia are shown separately due to Russia's status as an outlier in investment growth. 
Figure 7. Growth performance and prospects

Purchasing Managers' Indices have been, on average and in the majority of EM with available data, below the threshold indicating recession since early 2015. Consumer confidence indicators suggest further deterioration ahead. As growth has fallen below its long-term average, long-term expectations of growth have been declining.

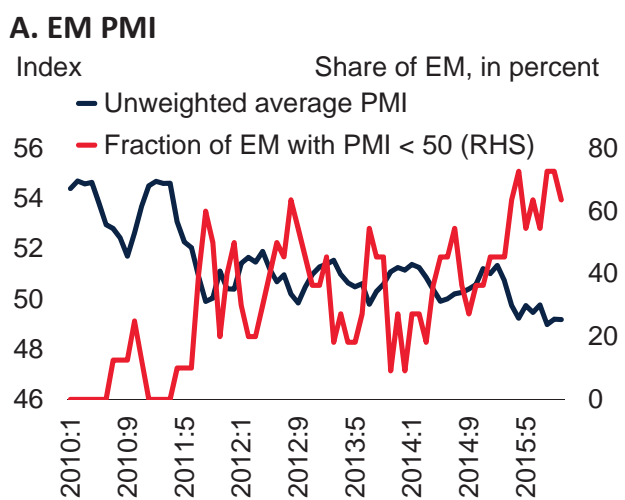

C. EM growing less than the long-term average Share of $E M$, in percent 100

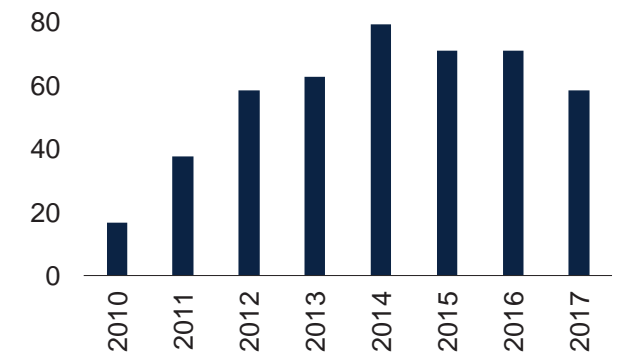

E. Long-term growth expectations: EM

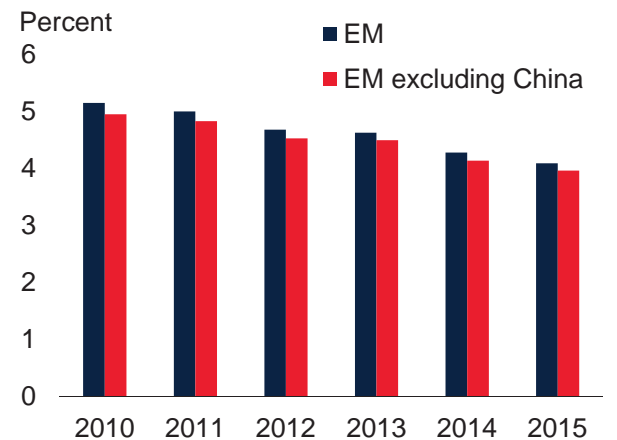

\section{B. PMI: Major EM}

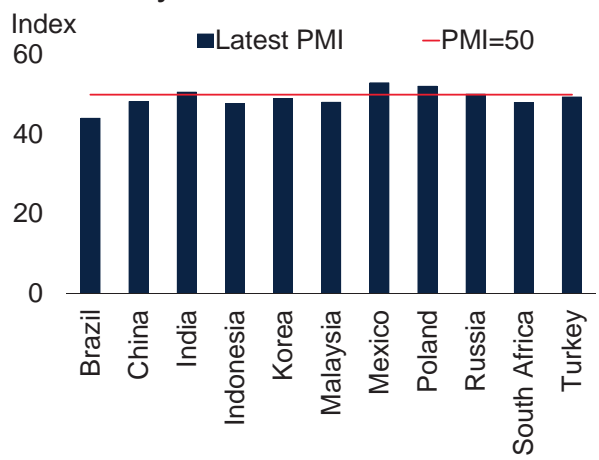

D. Consumer confidence

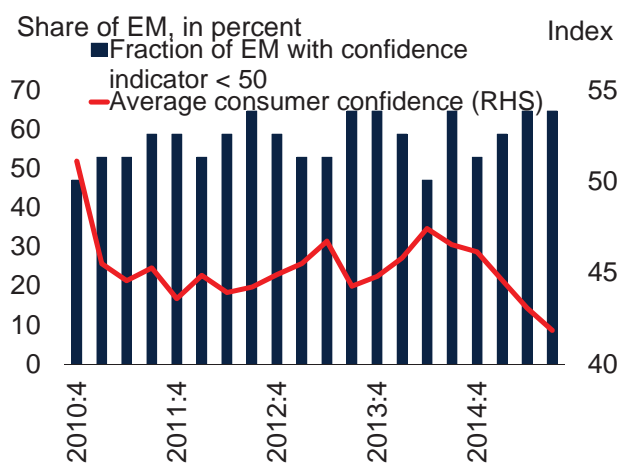

F. Long-term growth expectations: BRIC

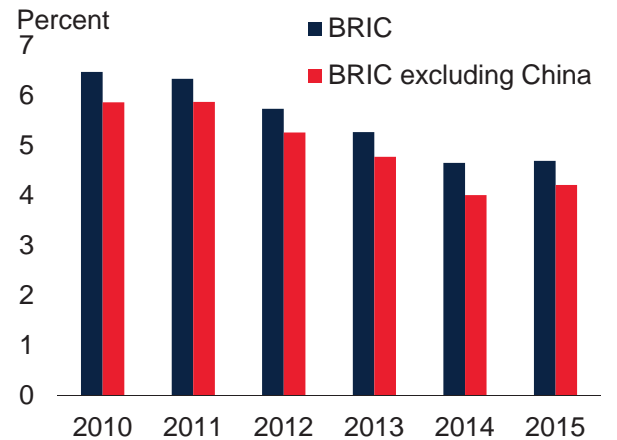

Source: World Bank, Haver Analytics, JP Morgan, Consensus Forecasts.

A. Unweighted average PMI for Brazil, China, India, Indonesia, Korea, Malaysia, Mexico, Poland, Russia, South Africa, Turkey. A PMI below 50 indicates contraction. The latest data is as of Oct 2015.

B. Latest PMI is as of Oct 2015.

C. Long-term averages are country-specific for 1990-2008. Long-term average for the Czech Rep. starts in 1991.

D. Consumer confidence indicators for Brazil, Chile, China, Colombia, Czech Republic, Hungary, India, Indonesia, Korea, Malaysia, Mexico, Philippines, Poland, Russia, South Africa, Thailand, Turkey. "Average" indicates unweighted average (rebased to $50=$ neutral). A value below 50 indicates that consumers expect a deterioration in economic conditions.

E.F. Each column shows five-year ahead Consensus Forecasts as of the latest available month in the year denoted. Unweighted averages. Five-year-ahead Consensus Forecasts are not available for EM in the Middle East and North Africa, Pakistan, and South Africa. 


\section{Sources of the slowdown}

The synchronous nature of the growth slowdown in emerging and frontier markets suggests that common factors may be at work. These factors could be associated with either external factors or a coincidence of similar domestic developments. An extensive literature has documented the predominant role of external factors in lifting EM growth during the 2000s until the global financial crisis (Fayad and Perrelli 2014; IMF 2014a). The slowdown since 2010 has been attributed to sliding commodity prices (Gruss 2014); financial system strains (Aslund 2013); and weaker trading partner demand (Cubeddu et al. 2014; Fayad and Perrelli 2014; IMF 2014a). Alternatively, common factors could reflect a coincidence of domestic developments, including policy tightening (Fayad and Perrelli 2014), political uncertainty, demographic trends, and slowing productivity growth (Dabla-Norris et al. 2013).

Country-specific Bayesian vector autoregression models are estimated to identify key external and domestic factors weighing on growth in $18 \mathrm{EM}$ economies. External factors include U.S. growth and 10year bond yields, Chinese growth, the EMBI spread, and the terms of trade. Domestic factors include inflation, the real exchange rate, and short-term interest rates. ${ }^{7}$

Since 2010, the drivers of the EM growth slowdown have pivoted from predominantly external towards more domestic ones. Between 2010 and 2013, an unfavorable global macro-financial environment was the main driver of the EM growth slowdown (excluding China, Figure 8). This included, especially, a terms of trade deterioration since 2011, U.S. growth setbacks in 2013 and a steady slowdown in China's growth since 2010. From 2014, domestic factors have become increasingly more important in driving growth. In addition to unfavorable domestic shocks, China's growth slowdown and deteriorating terms of trade have weighed especially heavily on growth in commodity exporters. In BRICS, domestic factors were the predominant source of downward pressure on growth in 2014. These factors reflected rising short-term interest rates and real appreciation in China. Underneath these short-term factors, a trend slowdown in productivity growth has been underway. Although not easily measured on a high-frequency basis for a large number of countries, bouts of political uncertainty have raised political risk in some large EM.

\footnotetext{
7 The methodology follows Litterman (1986). The sample includes quarterly data for 1998 Q1 to 2015 Q2 for 18 EM (all EM excluding Egypt, Morocco, Pakistan, Qatar, Saudi Arabia, and the United Arab Emirates). In the analysis for the EM sample, China is excluded, as its growth is an external factor. In the analysis for BRICS, China is included, in which the estimation for China does not separately include its growth as an external factor. The external variables are assumed to be contemporaneously exogenous to variables in the domestic block. The Cholesky ordering is in the order the variables are listed in the text. See Annex III for additional details.
} 
Figure 8. External and domestic drivers of the slowdown

Since 2010, the drivers of the EM growth slowdown have pivoted from predominantly external towards more domestic drivers. External drivers included a terms-of-trade deterioration since 2011, U.S. growth setbacks in 2013, and a steady slowdown in China's growth since 2014. From 2014, domestic factors increasingly slowed growth, especially in BRICS. China's growth slowdown and deteriorating terms of trade have weighed especially heavily on growth in commodity exporters since 2014.

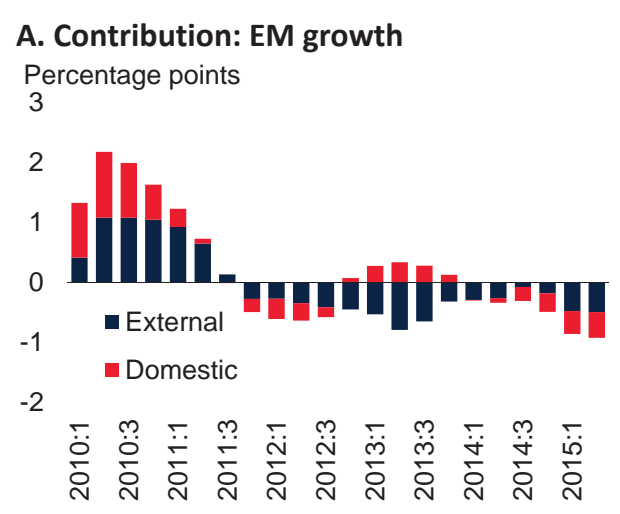

C. Contribution: Commodity-exporting EM growth

Percentage points

3
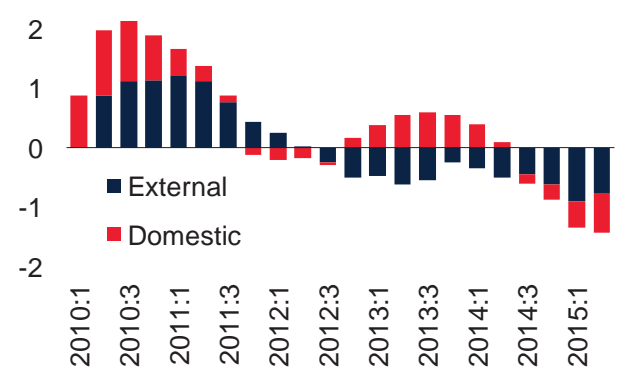

\section{E. Contribution: BRICS growth}

Percentage points

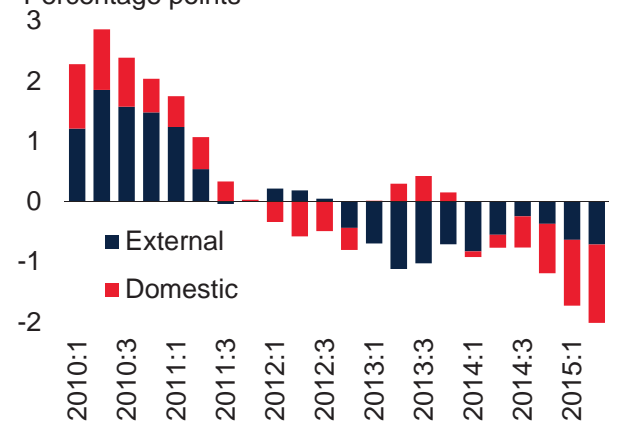

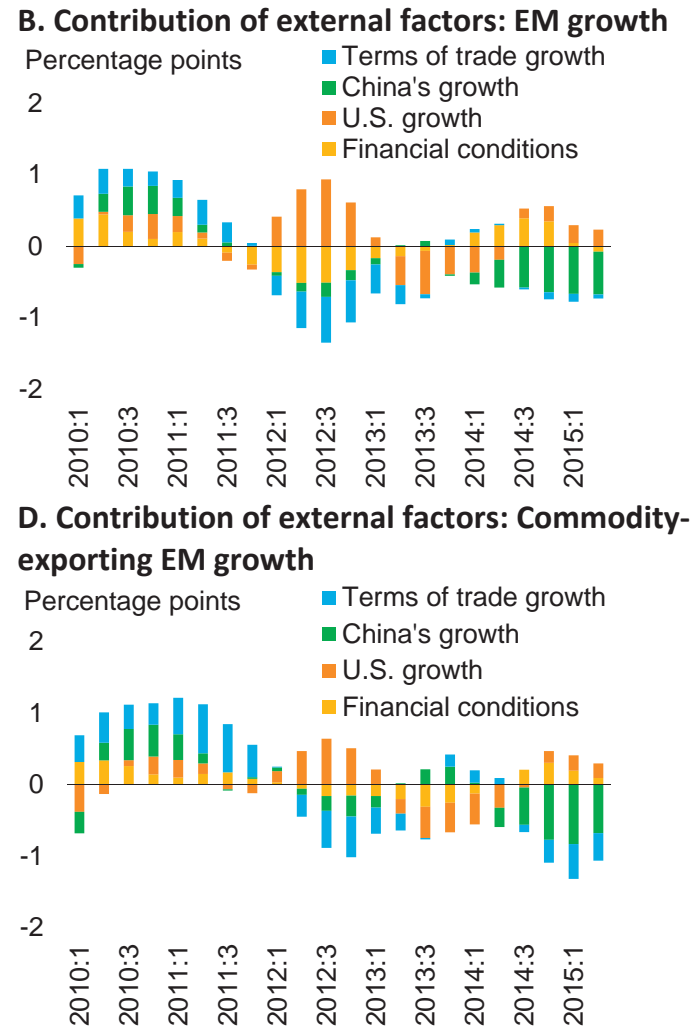

F. Contribution of domestic factors: BRICS growth

Percentage points $\quad$ Short-term interest rate

$2 \quad \square$ Real appreciation

1. Domestic inflation

|

$-2$

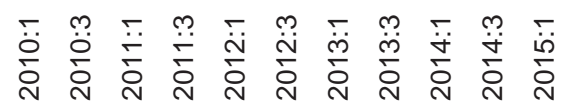

Source: World Bank estimates.

Note: Each bar shows the percentage point deviation of growth from the sample mean.

A.-D. Based on a Bayesian vector autoregression estimation using data for 1998:1 to 2015:2 for $18 \mathrm{EM}$. External factors include U.S. growth and 10-year bond yields, Chinese growth, EMBI spreads, and terms of trade. Domestic factors include domestic inflation, the real exchange rate, and short-term interest rates. All charts show the unweighted average contribution to EM growth excluding China, since China's growth is considered an external factor.

E.F. Based on the same Bayesian vector autoregression estimation as in A-D. In estimates for China, its growth is not separately included as an external factor. Unweighted average contribution to BRICS growth, including China. 


\section{A. External factors}

\section{Weak global trade}

During 2000-07, global trade grew at an annual average rate of about 7 percent. Much of this growth in trade originated in EM, as annual growth in EM trade averaged 11 percent over the same period. The rapid increase in global trade during the 2000s was an important driver of growth in a number of small open EM. Contributions to growth from external demand reflected a combination of increased trade openness and higher trading partner growth (IMF 2014b).

Since 2010, however, global trade growth has slowed significantly (Figure 9). And, given many EM are highly open economies, the slowdown in world trade has weighed heavily on their growth. By 2014, global trade had fallen 20 percent short of its pre-crisis trend (World Bank 2015a). The first half of 2015 saw the slowest growth in global trade since 2009, reflecting a significant contraction in import demand from emerging markets, including from Asia and Central and Eastern Europe. This deceleration in trade has been broad-based, affecting a wide range of commodity-exporting and importing EM.

This post-crisis trade slowdown has been attributed to five factors (World Bank 2015a):

- Anemic advanced economy growth. Advanced economies constitute about 60 percent of global import demand (and, of this, the EU accounts for 35 percent) and receive just under half of all EM exports. From 2010-2015, advanced economy real GDP growth remained below 2 percent and import growth below 4.8 percent-well below pre-crisis growth rates. By 2014, real GDP in the United States and the Euro Area was 8-13 percent below pre-crisis trend and import demand 2223 percent below pre-crisis trend, respectively.

- Changing composition of global demand. The composition of global demand has shifted away from highly trade-intensive commodities. The recovery has been particularly anemic in investment. As a result, by 2014, global investment demand was almost 10 percent below precrisis trend (and in the Euro Area, 30 percent below trend). Private and government consumption have returned near to their pre-crisis trends. Since capital goods are typically the most importsensitive among all components of aggregate demand, the income elasticity of trade has declined.

- Slowing expansion of global value chains. The maturation of global value chains has further reduced the elasticity of trade flows to activity. During the 1990s, a decline in shipping times and cost and trade liberalization encouraged rapid fragmentation of production across borders. As production processes expanded across countries, trade grew substantially among the members of the production chain. With maturing supply chains, this trade growth has slowed. ${ }^{8}$ As a result, trade has become less sensitive to both activity and exchange rate movements (Constantinescu, Mattoo, and Ruta 2014; Ahmed, Appendino and Ruta 2015).

- Weak trade finance. While conclusive evidence remains elusive, there are concerns that higher capital requirements and tightened financial regulations have reduced banks' willingness to extend trade finance (World Bank 2015a).

- Slowing momentum towards further liberalization. The pace of trade liberalization-or, at least, of easing impediments to trade-has slowed since the crisis (see more on this in Section IV.B).

\footnotetext{
8 Some supply chains may even have begun to shorten again as higher-value added activity moved to EM. For example, China's imports of parts and components has declined from a peak of 60 percent of its total merchandise exports in the 1990s to about 35 percent in 2012, as foreign inputs were replaced with domestic ones (Kee and Tang 2014). This has contributed to a particularly pronounced decline in China's elasticity of trade to activity.
} 


\section{Figure 9. World trade}

After being a key driver of global trade until the crisis, EM export growth has slowed sharply since 2010. This reflects weak global demand, especially among advanced economies; a shifting demand composition away from investment; slowing growth in global value-chains, including in China; and modest momentum in trade liberalization.

\section{A. EM and world exports value growth}

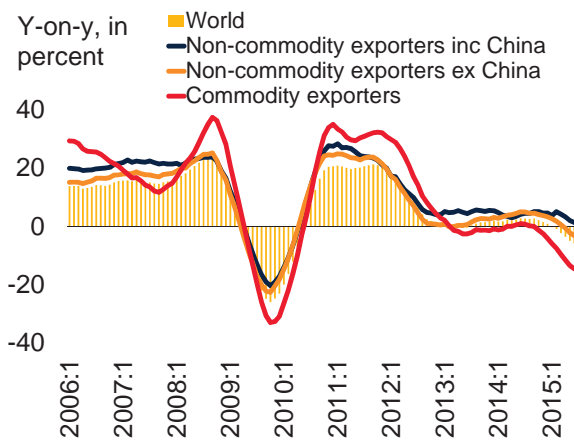

C. GDP and imports

Index of trend volume in 2014

if crisis had not occurred $=100$

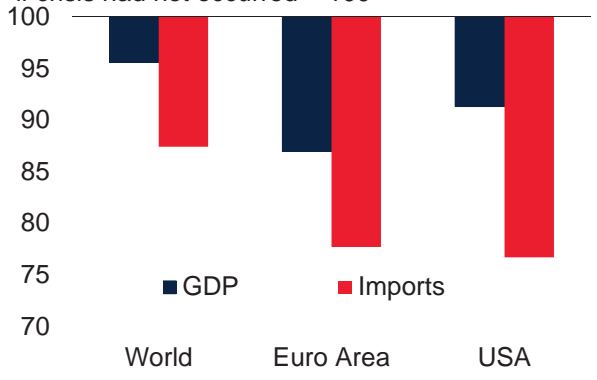

E. China's imports of parts and components

Share of merchandise exports, in percent

70

60

50

40

30

20

10

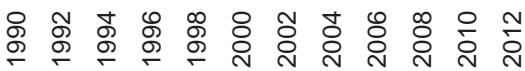

\section{B. EM exports to $E M$ and $A E$}

Share of exports, in percent

Exp. to EM Exp. to AE Exp. to ROW

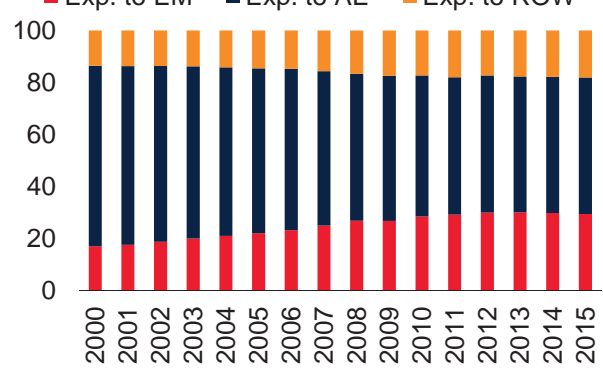

D. Investment, consumption, and government

\section{expenditure}

Index of trend volume in 2014

if crisis had not occurred $=100$

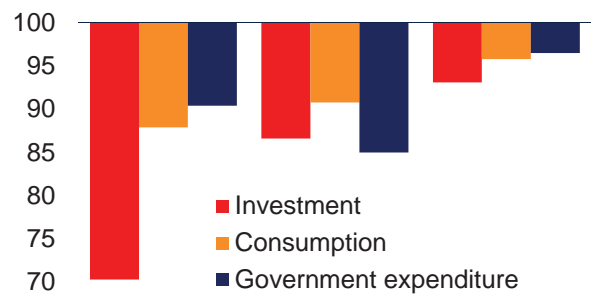

65

Euro Area USA World

\section{F. Temporary trade barriers}

Share of imported products, in percent 2.0

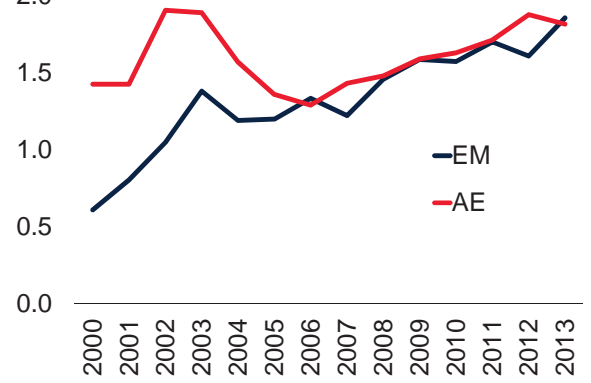

Source: Bown (2014), IMF Direction of Trade Statistics, WTO, World Bank, Constantinescu, Mattoo and Ruta (2014), World Bank, using UN Comtrade Data.

A. Annualized monthly year-on-year growth rates of goods exports. Latest data is for June 2015.

B. Annual shares of EM goods exports. Data for 2015 is share of annualized exports as of June. ROW stands for rest of the world.

C. D. The post-crisis trend growth is assumed to be equivalent to the average growth rate during 1980-2008. Using this, the trend level for 2014 is rebased to 100 . The 100 mark reflects where GDP, imports, investment, government expenditure and consumption would have been in 2014 if pre-crisis trends continued into the post-crisis period. Hence, bars below 100 show deviations from trends in 2014.

E. Share of total merchandise exports. Parts and components are the sum of three UN Comtrade broad economic categories: 42 (parts and accessories of capital goods, except transport equipment), 53 (parts and accessories of transport equipment), and 22 (processed industrial supplies not elsewhere specified).

F. Stock of imported products under temporary trade barriers, including antidumping, global safeguards, countervailing duties, and Chinaspecific transitional safeguard measures. Sample includes thirteen EM and five AE. 
While some recovery in global trade growth is projected over the next two years, it is expected to remain significantly below pre-crisis averages, both in absolute terms and in relation to global GDP growth. On the upside, the recent oil price plunge reduces the cost of transport, and hence could encourage global trade flows. On net, however, the structural impediments to trade are expected to have more persistent effects, and hence global trade growth is likely to remain weak.

\section{Low commodity prices}

Prices of oil and metals have declined by 50-60 percent from their 2011 peaks and are expected to remain low for the next decade (World Bank 2015e; Baffes et al. 2015). Agricultural prices have declined somewhat less, but are more than 20 percent below their 2011 peaks (Figure 10).

Since about half of emerging markets are commodity exporters, they are among the countries most affected by the broad-based declines in commodity prices. ${ }^{9}$ In several commodity markets, Brazil (iron ore, and soybeans), Chile (copper), Indonesia (nickel and aluminum), or Russia (oil) account for more than one-quarter of global exports. With falling export proceeds, the growth prospects of these countries have dimmed considerably.

Behind this persistent and sharp decline in commodity prices is a series of supply shocks, which have coincided with weak global growth. These have included faster-than-anticipated expansion of oil and metals supplies (e.g., from shale oil in the United States and new mining projects across the world), repeated downward revisions of demand projections, and U.S. dollar appreciation. Since 2014, oil market supplies, in particular, have increased well beyond earlier expectations as a result of less-than-expected disruptions from political uncertainty in the Middle East and an apparent switch in OPEC policy from targeting global oil prices to targeting market share (Baffes et al. 2015). Slowing growth in major emerging economies is contributing to softening commodity prices. For example, China accounts for more than onefifth of global demand for many metals (nickel, iron ore, aluminum, copper, tin, and zinc) as well as soybeans.

As discussed below, procyclical policy tightening since the large oil price drop in the second half of 2014 has further dampened growth in several commodity-exporting EM. For instance, government revenues from the resources sector have fallen sharply in commodity-exporting EM since current prices are well below fiscal break-even prices (i.e. prices that would generate fiscal balance). Several commodityexporting EM have tightened fiscal policy to reduce financing needs. In some of them, currencies have depreciated sharply (Brazil, Colombia, Peru, Russia) and central banks have raised policy rates-despite weak growth - to anchor inflation expectations and financial stability risks.

\footnotetext{
${ }^{9}$ Commodity exporters are, for the purposes of the study, defined as countries whose commodity exports account for 30 percent or more of exports or whose exports of a single commodity account for 20 percent or more of exports in 2010-14, on average. They include Brazil, Chile, Colombia, Indonesia, Malaysia, Peru, Qatar, Russia, Saudi Arabia, South Africa, and the United Arab Emirates.
} 
Figure 10. End of the commodity supercycle?

Commodity prices have fallen sharply from 2011 peaks and are expected to remain low. This has particularly affected growth in several emerging markets that account for a sizeable share of global exports of commodities. Slowing growth in China, a major source of demand for commodities, contributes to lower commodity prices.

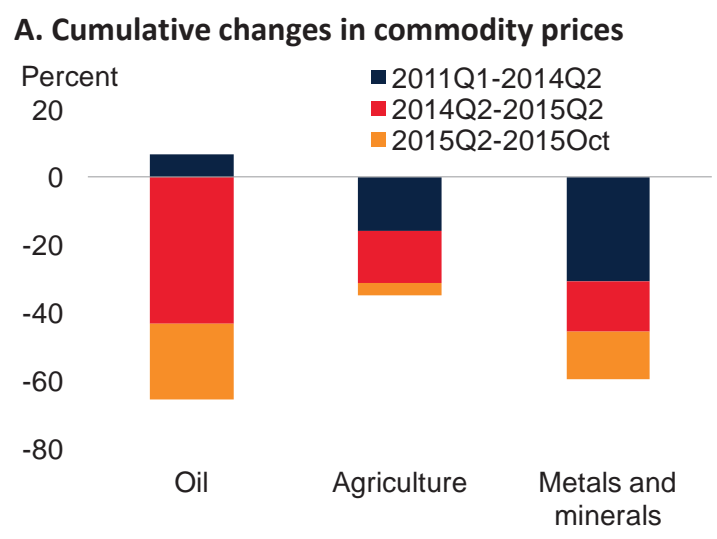

C. Oil production and fuel exports, 2013

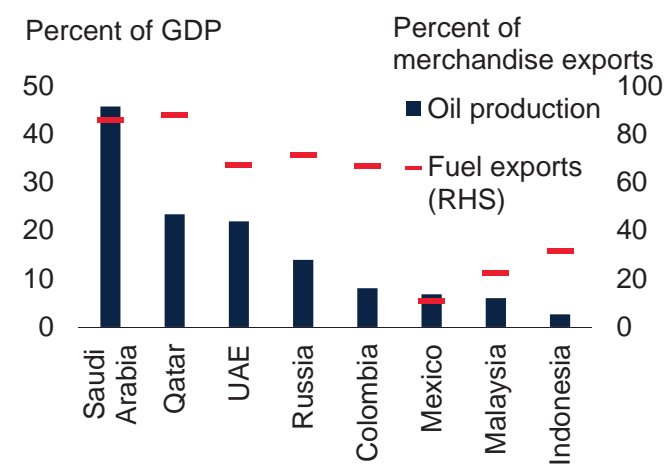

\section{B. Major EM in global commodity exports}

Share of global commodity exports, in percent - Brazil Indonesia - Russian Federation $₫$ South Africa

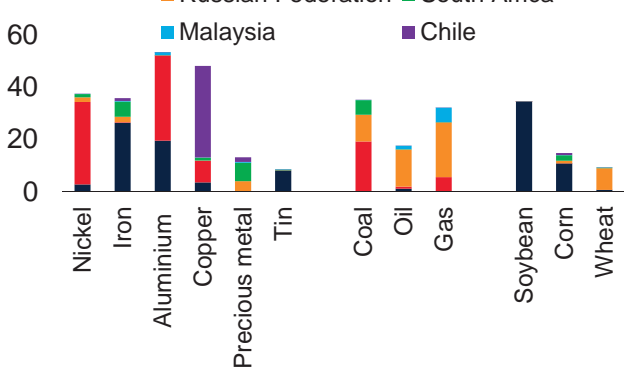

D. Metals and primary energy consumption: China Million metric tons $\quad$ Million tons of

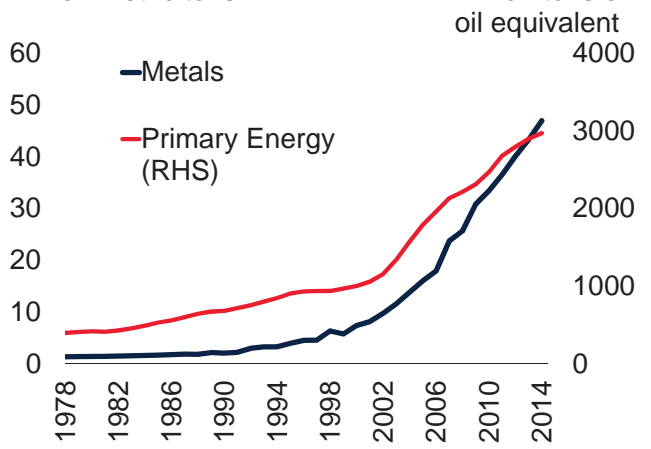

Source: World Bank, Haver Analytics, BP Statistical Review, World Bureau of Metal Statistics.

A. Includes unweighted averages of WTI, Brent, and Dubai oil prices, 21 agricultural goods and 7 metal and mineral commodities.

B. The world aggregate represents the sum of reporting and non-reporting countries. For non-reporting countries, data is based on the partner reported data (mirror data). Average over 2008-14. Includes exports of ores (e.g. bauxite) and oil products.

C. Oil production is estimated as oil rents, which are defined as the difference between the value of crude oil production at world prices and total costs of production. Estimates are based on sources and methods described in World Bank (2011b).

D. Metals include Aluminum, Copper, Lead, Nickel, Tin, and Zinc.

Among commodity-importing EM, the growth benefits from lower commodity prices (especially low oil prices), as a result of rising real incomes, have yet to materialize fully. A number of country-specific factors, (e.g. political uncertainty, droughts, disruptions to power supply) have thus far offset much of the growth benefit of lower oil prices. However, low oil and gas prices have presented opportunities to reduce vulnerabilities in some commodity-importing EM. For example, inflation has subsided in a number of EM, such as the Czech Republic, Hungary, India, and the Philippines. This has helped them maintain stronger current account balances. Several EM reduced or eliminated fuel-subsidies (Indonesia, Malaysia), raised energy taxes (India), or deregulated local fuel prices (Egypt, India). Fiscal windfalls from these measures have been used for countercyclical savings.

Oil prices may have begun to find some support after the sharp decline since the second half of 2014, but are expected to remain well below their 2013 levels over the medium-term. Second-round effects of low oil prices on other commodities, together with robust supplies and soft demand, are also expected to keep prices low for most other commodities over the medium-term. 


\section{Tightening financial conditions}

Global capital inflows (including direct, portfolio and other investment) have declined steadily from the immediate post-crisis rebound, to about three quarters their 2010 levels by $2014 .^{10}$ Within this global aggregate, net capital inflows to EM have been highly volatile (Figure 11). From their 2011:2 post-crisis peak - which matched broadly their pre-crisis peak-they plunged by three-quarters in a new low in 2012:3, only to more-than-double again to a new peak in 2013:4. Since 2013:4, net capital flows to EM have steadily declined from about 2 percent of GDP in 2014:1 to virtually zero by 2015:2 (Figure 11). This has coincided with higher volatility in capital flows and larger swings in EM credit default swap (CDS) spreads.

In 2015, net capital flows stalled to virtually zero-despite continued benign global financing conditions: record-low interest rates in advanced economies and a significant balance sheet expansion by the European Central Bank and the Bank of Japan. During the first half of 2015, net capital inflows into EM shrank to less than one-tenth of their level in the second half of 2014. Although portfolio inflows remained robust, portfolio outflows increased by one-third and other investment net inflows fell by two-thirds between the second half of 2014 and the first half of 2015. The declines in net capital inflows largely reflected developments in China: in the first half of 2015, portfolio outflows from China rose ten-fold and net other investment inflows fell by four-fifths from the second half of 2014. Net capital flows to other EM have been broadly stable at modest levels but were accompanied by a considerable increase in corporate bond yields for EM.

The volatility of capital inflows to EM may have weighed on investment. Since 2010, investment growth has slowed sharply in EM. In the BRICS, for example, investment growth has slowed from double-digits in 2010 to 5 percent in 2014. A variety of country-specific factors have contributed to this: policy uncertainty in Brazil and Russia, structural bottlenecks in South Africa and India, and uncertainty about a reform push to rebalance growth in China.

Looking ahead, EM will likely face increasingly tighter financing conditions as the U.S. Federal Reserve is expected to soon raise interest rates for the first time since the global financial crisis. This is likely to initiate a gradual tightening cycle from currently record-low interest rates and is expected to slowly lift global financing cost. In addition, prospects of increasingly divergent monetary policies between the United States Federal Reserve and other major central banks increase the potential for further appreciation of the U.S. dollar and elevated currency risk.

\footnotetext{
10 By 2014, portfolio inflows into equity and bond markets and direct investment flows had risen well above crisis levels; by 2014, portfolio flows into EM were 50 percent above their 2007 levels. In contrast, deleveraging by EU banks dampened bank lending flows to emerging markets as parent bank deleveraging of EU banks has raised funding cost and increased lending rates for EM subsidiaries and affiliates, especially in emerging Europe and Central Asia (Feyen, Kibuuka, and Ötker-Robe 2012). For a discussion of the volatility of bond flows to EM and its implications, see Ramos-Francia and Garcia-Verdu (2015).
} 
Figure 11. Tightening financial conditions

Global capital flows, as well as EM CDS spreads, have been highly volatile since 2010. Since 2014, net capital flows to EM have steadily declined, but this mostly reflected sharp portfolio and net other investment outflows from China. The prospect of rising interest rates has contributed to depreciation in commodity exporting countries and those with high current account deficits.

\section{A. EM capital flows, including China

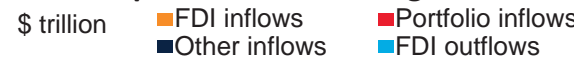 Portfolio outflows =Other outflows -Total net flows}

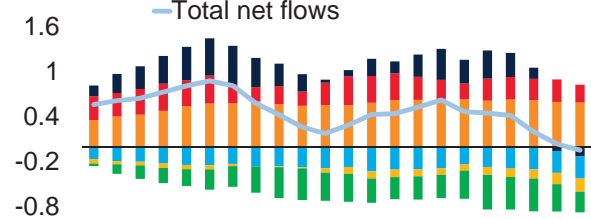

$-1.4$

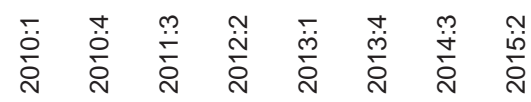

\section{EM portfolio flows and CDS spreads}

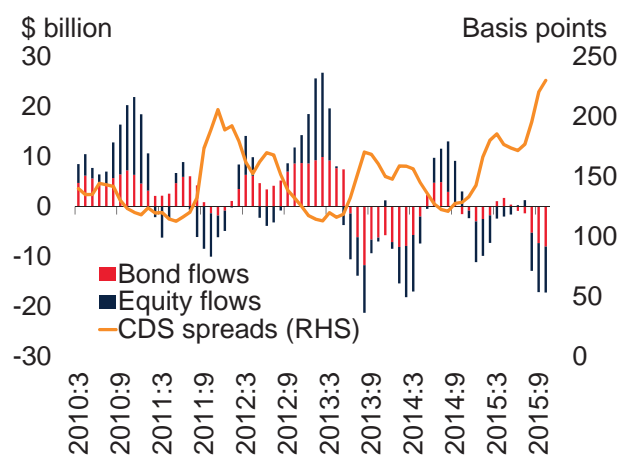

E. Currency Index: Current account status

Nominal effective exchange rate, $2010=100$

105

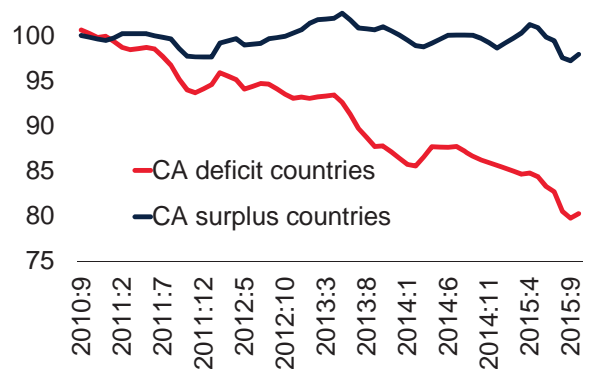

B. EM capital flows, excluding China

$$
\begin{array}{lll}
\text { \$ trillion } & \text { FDI inflows } & \text { Portfolio inflows } \\
& \text { FDI outflows } & \text { Portfolio outflows } \\
& \text { Other outflows } & \text {-Other inflows } \\
& - \text { Total net flows } &
\end{array}
$$

1.2

0.9

0.6

0.3

0

$-0.3$

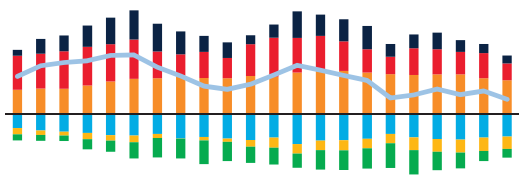

\section{EM bond yields}

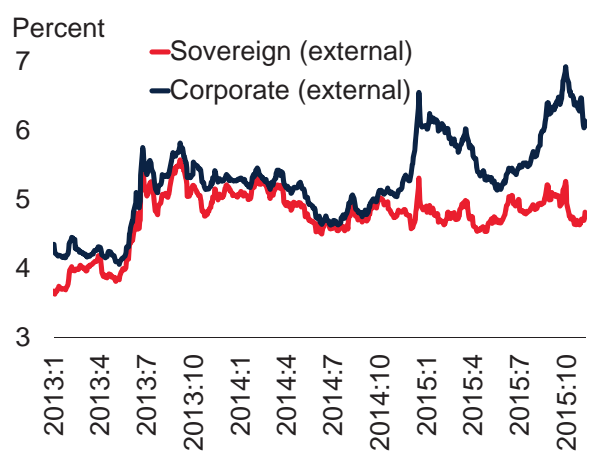

F. Currency Index: Commodity exporting status

Nominal effective exchange rate, $2010=100$ 105

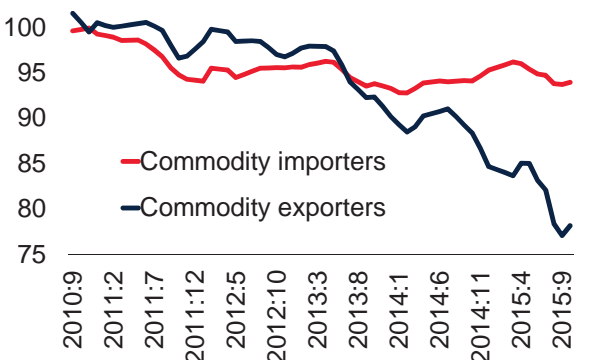

Source: World Bank Global Economic Prospects and World Development Indicators, EPFR, Bloomberg, Federal Reserve Bank of St. Louis, JP Morgan.

A.B. Four-quarter rolling sums. Other inflows and outflows refer to liabilities and assets, respectively, of the other investments (including bank flows) category of balance of payments.

C. Three-month moving average of bond and equity flows, and simple average of 5-year sovereign credit-default swap spreads for Brazil, China, Colombia, Indonesia, Kazakhstan, Malaysia, Mexico, Peru, Philippines, Russia, South Africa, Thailand, and Turkey. The latest observation is Oct 2015.

D. Market-value weighted average. The latest observation is 6 Nov 2015

E.F. CA stands for "Current account". Unweighted averages. The latest observation is Oct 2015. EM excludes Qatar and the UAE. 
In all likelihood, the liftoff or subsequent rate increases will proceed smoothly. Faced with rising financing cost and currency risk, however, investors are likely to increasingly differentiate among country prospects and vulnerabilities. For example, both during the financial market turmoil of May-June 2013 and during the broad-based U.S. dollar appreciation since mid-2014, exchange rates depreciated sharply against the U.S. dollar in the more vulnerable EM and in those with weaker growth prospects, in particular commodity exporters (Arteta et al. 2015).

Slowing remittance inflows have further tightened financial conditions in several EM. Growth in remittance inflows (expressed in U.S. dollars) to EM has slowed, from 12.5 percent in 2010 to a projected 4.4 percent in 2015 (World Bank 2015i). This has reflected a growth slowdown in several important source countries as well as a sharp depreciation in host country currencies, especially the Russian ruble.

During the last decade, remittances have been sizeable for EM, comparable to FDI and ODA. Since 2000, total remittances have averaged about 44 percent of the size of total FDI (Figure 12). Several EM (Egypt, India, Morocco, Pakistan, Philippines) have received substantial inflows of capital as well as remittances over the last decade. Compared with capital flows, remittances tend to be a resilient source of foreign exchange, as they are weakly correlated with capital flows and the domestic business cycle. As such, remittances have the potential to provide some stability for the balance of payments, and hence for the overall economy more generally, when capital inflows decline (World Bank 2015a).

Several large EM, especially commodity exporters in the Middle East and Russia, are important sources of remittances to other EM. Their growth slowdown, or recession in the case of Russia, could continue to weigh on remittance outflows from these sources. In addition, it may encourage the early return of migrants who may have difficulty reintegrating into local labor markets (EBRD 2015).

The external factors driving the EM growth slowdown are likely to remain in place. As global supply chains mature and the AE recovery remains hesitant, world trade is likely to stay weak. Large investments over the past decade to boost the supply of commodities and prospective weakness in demand continue to keep downward pressure on commodity prices. The normalization of US monetary policy will likely coincide with increasingly tighter global financial conditions and more volatile capital flows to EM. 
Figure 12. Slowdown in remittances

Growth of remittances has decelerated in recent years. Remittance flows are a sizeable and stable source of foreign exchange for EM. They tend to be uncorrelated with domestic business cycles and capital flows, including during episodes of sudden stops.

\section{A. EM remittances and other flows}

Billions USD

800

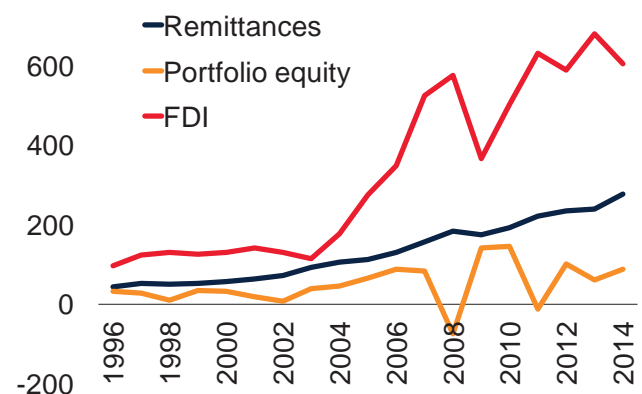

C. Cyclicality of remittances with capital inflows and GDP

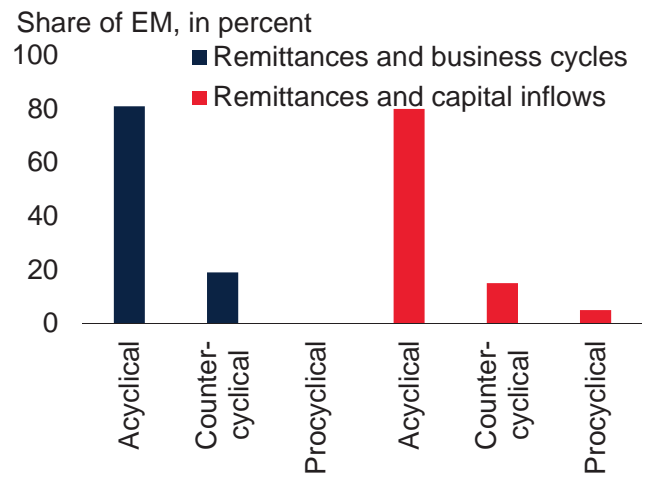

\section{B. Volatility of capital flows}

Standard deviation, in percent

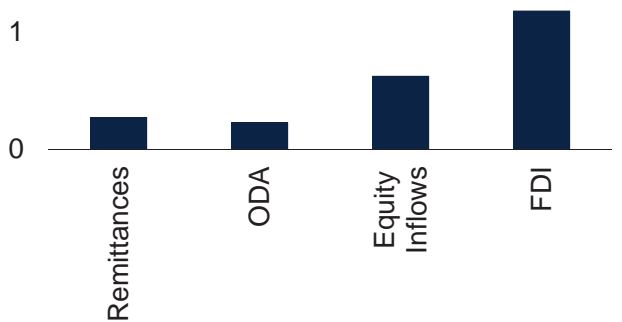

D. Remittances and business cycles: Sudden stops

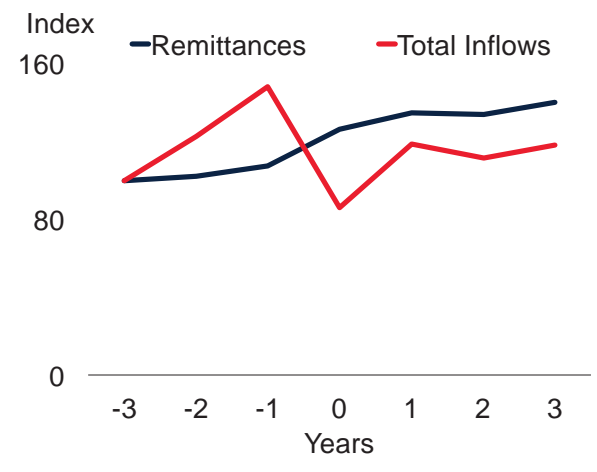

Source: World Bank (2015a, 2015i), World Development Indicators, IMF Balance of Payments data, Haver Analytics.

A. Remittances are based on IMF Balance of Payments Manual 6; FDI is foreign direct investment, net inflows.

B. Volatility is defined as the standard deviation of the detrended ratio of the relevant inflow to GDP. ODA is net official development assistance and official aid received.

C. The bars show the percentage of emerging markets in each category in which remittances have been acyclical, procyclical or countercyclical during 1980-2012. Remittances (remittances relative to capital flows) are considered as: (i) procyclical if the correlation between the cyclical components of remittances and output is positive and statistically different from zero, (ii) countercyclical if it is negative and statistically different from zero and (iii) acyclical if the correlation is not statistically different from zero.

D. Values are averages of remittances and net capital inflows for emerging markets that have experienced sudden stop episodes. Index numbers are calculated with a base of 100 for the period three years before the sudden stop year (-3). Capital Inflows are net, i.e. the difference between amounts brought in by foreign entities and the amounts sent out by domestic entities. The horizontal axis denotes years. 0 (zero) refers to the year of the sudden stop episode. 


\section{B. Domestic factors}

\section{Slowing productivity growth}

In a number of emerging markets, productivity growth has declined substantially. To estimate productivity, GDP is decomposed into total factor productivity (TFP) and factors of production using a production function approach. ${ }^{11}$ This decomposition suggests that the growth slowdown in emerging markets since 2010 has predominantly reflected slowing TFP growth (Figure 13). Factor accumulationboth capital and labor-has contributed about three-quarters to growth. By 2014, on average across emerging markets, TFP growth had reached well below its historical (1990-2008) average. This decline was particularly pronounced among smaller emerging and frontier markets. In the BRICS, TFP growth declined less and appears to have stabilized below its historical average. These findings are in line with those of other studies who document that emerging market TFP growth has slowed by about 2 percentage points from 2006-2007 to 2013-2014 (IMF 2015a).

The productivity slowdown since 2010 has been most pronounced in the Middle East and North Africa, Latin America and Caribbean, and Eastern Europe and Central Asia (Figure 13). Productivity growth ground to a virtual halt in Eastern Europe and Central Asia in 2012 and in Latin America in 2014, from 2-21/2 percent in 2010-11. ${ }^{12}$ In the Middle East and North Africa, productivity has been falling since 2007 and, since 2012, at an accelerating pace. In contrast, productivity growth has held steady in Sub-Saharan Africa and risen in South Asia.

A similar decomposition is conducted for potential growth to illustrate the degree to which the growth slowdown has reflected structural factors or a cyclical weakening from the immediate post-crisis rebound (Figure 14). ${ }^{13}$ Since the global financial crisis, potential growth in EM has declined steadily below historical average levels. Softening potential growth accounted for about one-third of the growth slowdown in emerging markets from peak growth in 2010 to 2014, and about half of this reflected a slowdown in productivity growth. However, the degree to which structural and cyclical factors contributed to the slowdown varies widely, ranging from a share of one-tenth to more than the entire decline in growth. A large literature, using varying samples, also finds that both cyclical and structural factors have contributed to the post-crisis EM growth slowdown. ${ }^{14}$

\footnotetext{
11 GDP is assumed to be characterized by a Cobb-Douglas production function of total factor productivity, labor proxied by employment, and the capital stock derived using the perpetual inventory method, assuming a labor share of national income of 0.7 (Burns et al. 2014). Total factor productivity is derived as the residual.

12 In both regions, growth has been supported by capital accumulation and, in Latin America, also by labor accumulation (Sosa, Tsounta, and Kim 2013; Tsounta 2014).

${ }_{13}$ Potential output growth is calculated as a function of the growth rates of potential labor and capital inputs as well as potential TFP. The estimates for potential labor growth assume full employment, with the unemployment rate and the labor force participation at equilibrium values. Potential labor input growth is thus calculated as the growth rate in working age population. The stock of capital is constructed using a simplified version of the perpetual inventory methodology from investment data, assuming a depreciation rate of 7 percent (IMF 2005; Burns et al. 2014). Implicitly, this assumes that there are no shifts over time in the productivity of investment, e.g. as a result of a shift from non-housing into housing investment (D'Auria et al. 2010). Potential TFP growth is the growth rate of the HP-filtered actual TFP (calculated as the Solow residual). While IMF (2015) calculates potential growth in the BRICS based on a multivariate filter, they obtain similar estimates of both potential growth and the slowdown in potential TFP growth.

${ }^{14}$ However, underneath this average, the relative contribution of structural and cyclical factors differs across countries (Anand et al. 2014; Cubeddu et al. 2014; Tsounta 2014; and De Gregorio 2015). For example, structural factors have been considered prominent in emerging Europe as well as in China. On the other hand, cyclical factors have played more important roles in LAC and other parts of emerging Asia.
} 
Figure 13. Productivity growth and factor accumulation

The emerging market growth slowdown since 2010 has mainly reflected slowing total factor productivity (TFP) growth. TFP growth in EM has slipped from its strong 2000s levels to rates below its long-term average over 1990 2008. The TFP growth slowdown in the BRICS was pronounced from 2010-12, but has stabilized since then.

\section{A. Contribution to EM growth} Percent

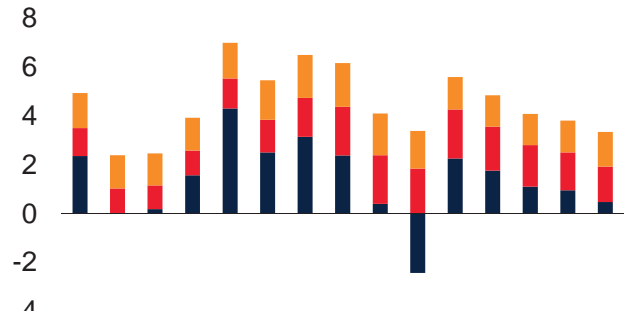

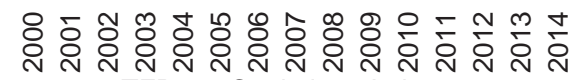
-TFP —Capital $\square$ Labor

\section{TFP growth in EM}

Percent

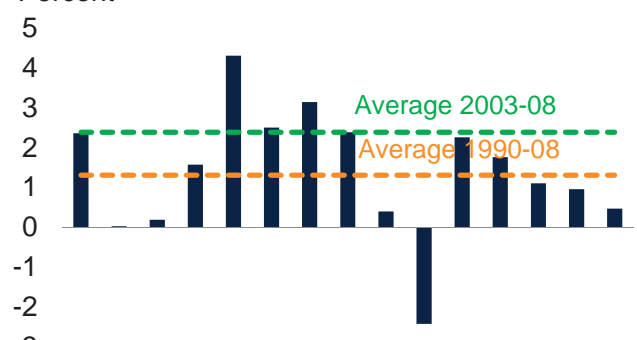

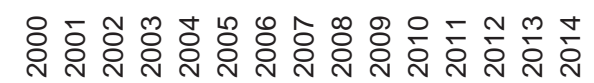

E. Contribution to growth: regional dimensions

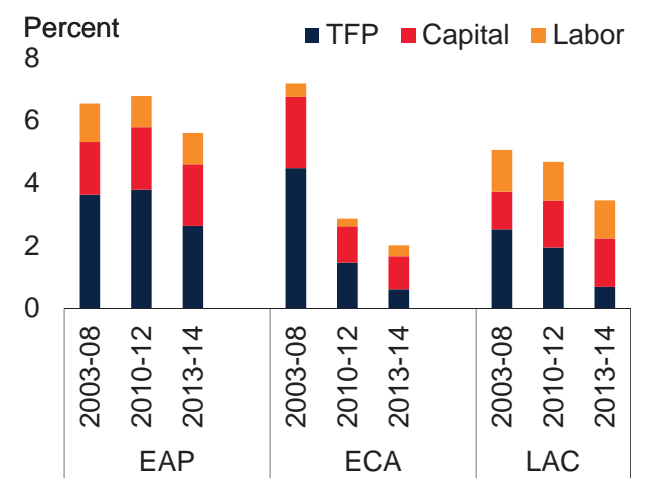

\section{B. Contribution to BRICS growth}

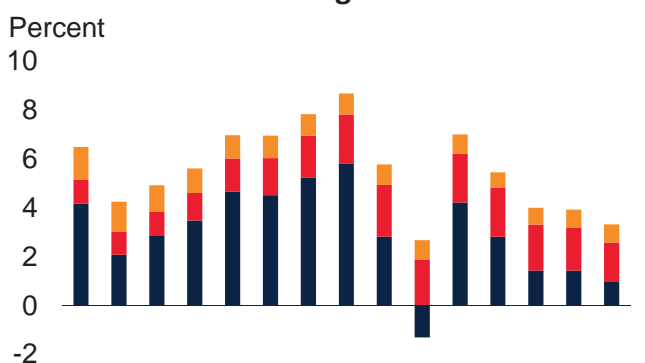

$-2$

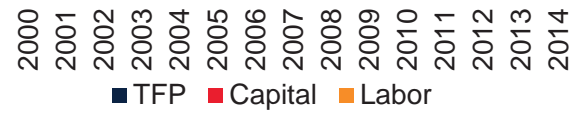

D. TFP growth in BRICS

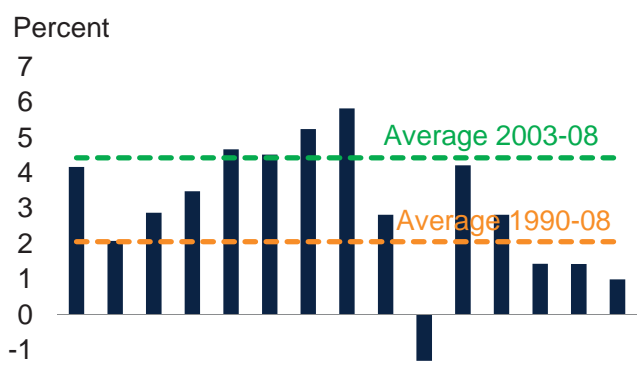

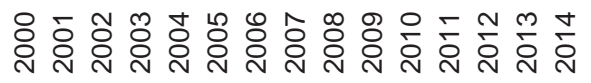

F. Contribution to growth: regional dimensions (cont.)

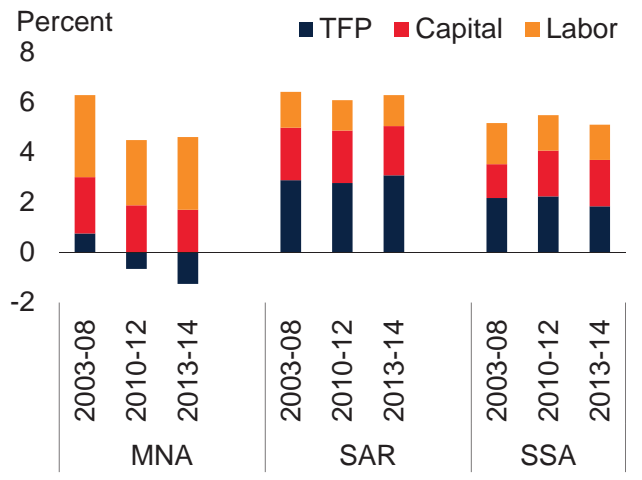

Source: World Bank, Haver Analytics.

A-D. Unweighted averages to reflect the full universe of EM

E.F. EAP stands for East Asia and Pacific, ECA stands for Europe and Central Asia, LAC stands for Latin America and Caribbean, MNA stands for Middle East and North Africa, SAR stands for South Asia, and SSA stands for Sub-Saharan Africa. Since each region has one economy that accounts for one-third or more of regional GDP, all data are unweighted averages to reflect trends across the region more broadly. To ensure a sufficiently large sample, each region indicated includes both EM and FM. 
Figure 14. Potential growth

Since the crisis, potential growth has steadily slowed in EM and appears to have shifted to a lower level in FM. Potential growth in EM and BRICS has now fallen below its long-term average over 1990-2008.

A. Actual and potential growth: EM

Percent
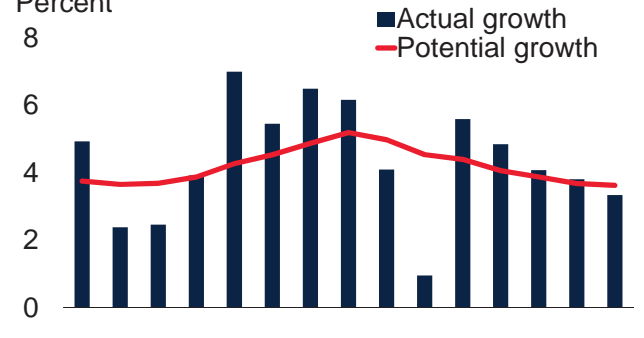

$-2$

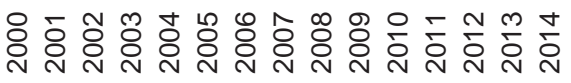

C. Potential growth: EM

Percent

8

-•Average 1990-2008

6

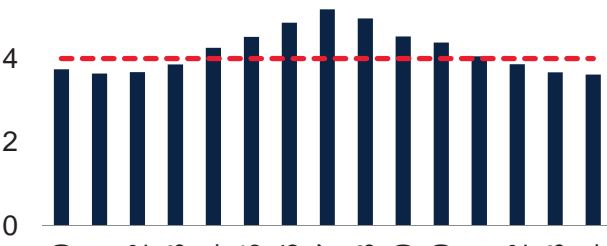

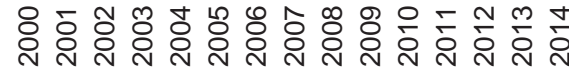

E. Contribution to potential growth: EM

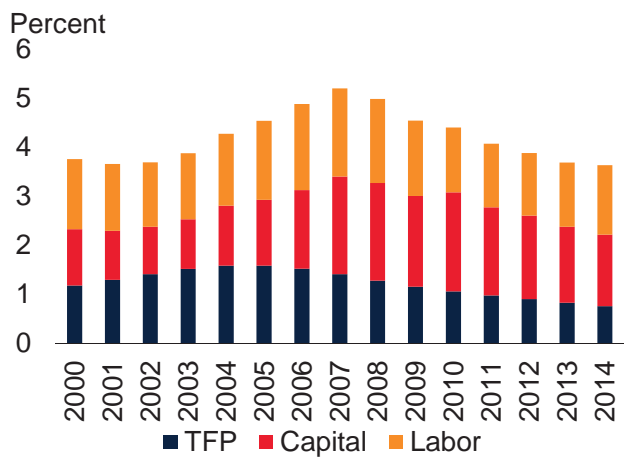

Source: World Bank, Haver Analytics.

A-F. Unweighted averages.
B. Actual and potential growth: FM Percent

8 Actual growth

-Potential growth

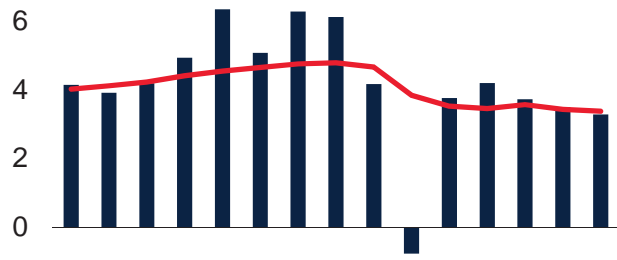

$-2$

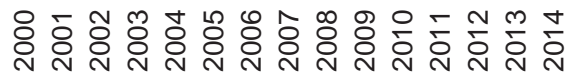

D. Potential growth: BRICS

Percent

8

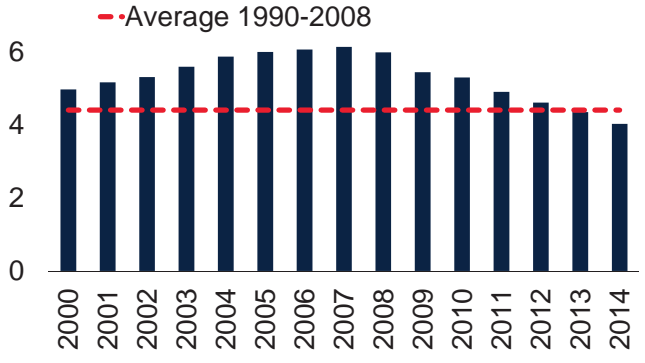

F. Contribution to potential growth: BRICS

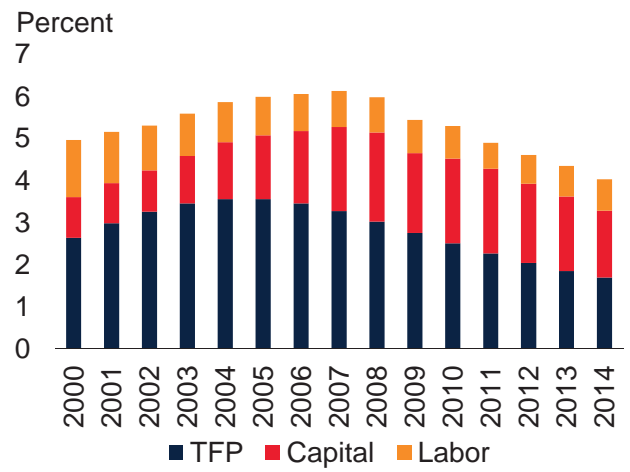




\section{Figure 15. Demographic trends}

In EM, working-age population share has been declining, along with slowing population growth rate.

\section{A. Share of working-age population}

Share in total population, aged 15-64, percent 70

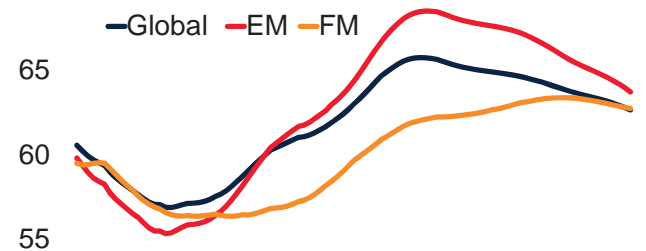

50

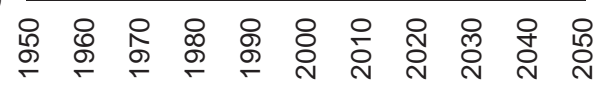

\section{B. Population growth rate}

Annual population growth rate, in percent 3

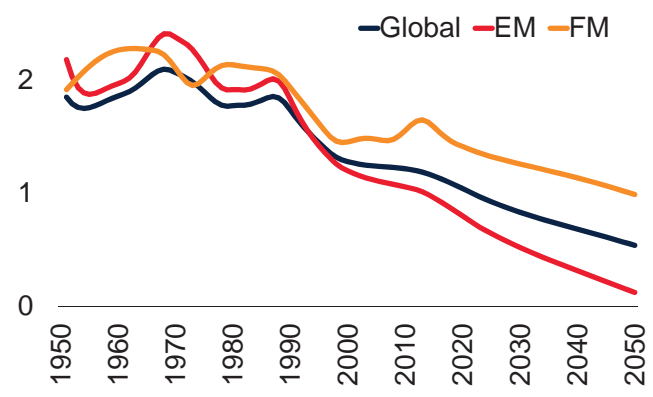

Source: World Bank estimates, based on data from UN (2015)

A. Share of population aged $15-64$ as a ratio to total population.

B. Annual growth rate of total population.

Part of the slowdown in potential output and productivity growth across the emerging world reflects demographic trends, which have passed a turning point since the global crisis with potentially profound implications for growth (Figure 15). Since 2010, working-age population growth has slowed from pre-crisis rates in EM in all regions. The slowdown has been most marked in Europe and Central Asia and the Middle East and North Africa. As a result, the share of the working age population has risen only marginally or fallen in all EM regions other than Sub-Saharan Africa (World Bank 2015g).

These trends have contributed to slowing potential output and reduced the "demographic dividend" in two ways. First, slowing growth of the working-age population has reduced growth in labor inputs. Second, a shift in the age structure of the labor force has been associated with lower innovation, productivity growth, and savings. ${ }^{15}$

Looking ahead, falling fertility rates and rising life expectancy will intensify these trends and may put additional pressures on productivity growth in particular and GDP growth more broadly. In particular, by 2025, outright declines in the working age populations are expected in Europe and Central Asia-partly as a result of emigration-and in East Asia and the Pacific. South Asia and Sub-Saharan Africa are exceptions, since still-high population growth will lead to an increase in the share of the working-age population.

\footnotetext{
15 See Higgins (1998); Bloom, Canning, and Sevilla (2003); Bloom and Canning (2004); and Aksoy et al. (2015). For example, among advanced countries, a shrinking share of the working age population may explain a slowdown in average annual growth from 2000-09 to 2010-19 of some 0.6 percentage points in Japan and 1.3 percentage points in the United States (Aksoy et al. 2015). In contrast, In India, almost half of the increase in per capita income since the 1970s may be attributed to the "demographic dividend" (Aiyar and Mody 2011).
} 
Figure 16. Policy uncertainty

There have been multiple episodes of elevated policy uncertainty in EM and AE since the global financial crisis.

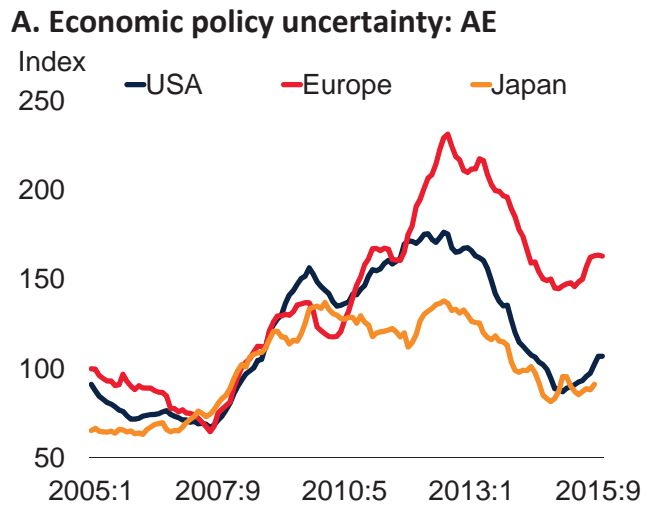

\section{Political Risk}

Political risk (Lower number $=$ higher risk) 68

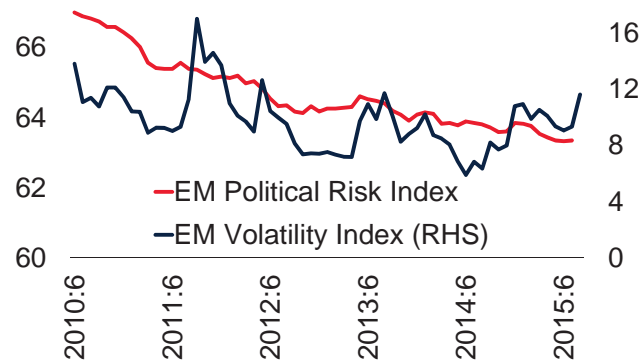

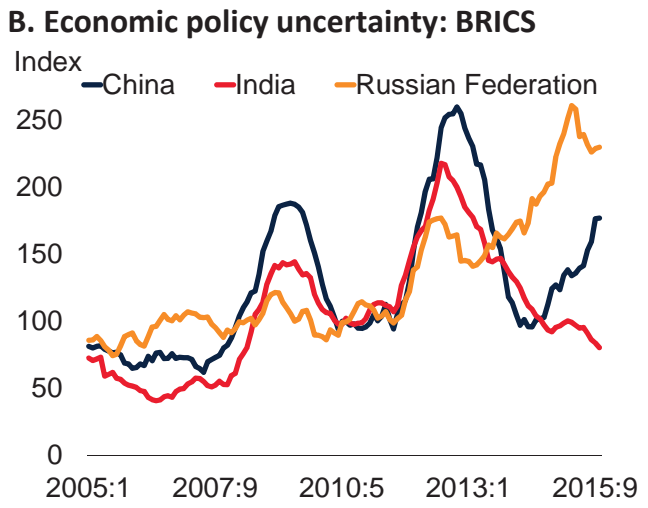

D. EM with presidential or parliamentary elections Average annual share, in percent

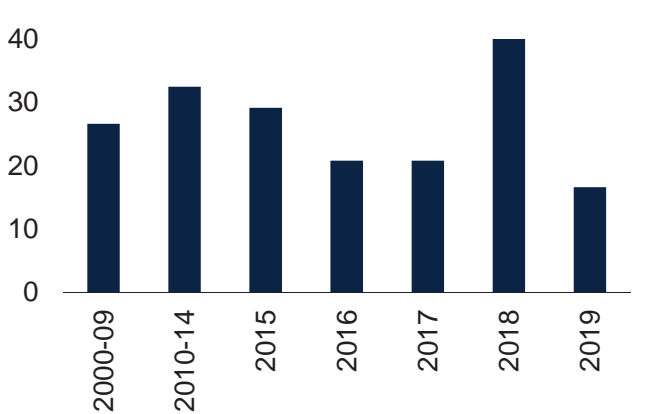

Source: Baker, Bloom, and Davis (2013), International Country Risk Group, various country reports from Economist Intelligence Unit, Bloomberg, and Consensus Forecasts.

A.B. 12-month moving averages of Economic Policy Uncertainty Indices (Baker, Bloom, and Davis 2013). The Economic Policy Uncertainty Index is a weighted average of newspaper coverage of policy-related economic uncertainty and, depending on the country, the disagreement among forecasters and, for the United States, the number of federal tax provisions set to expire in future years. A higher value indicates more uncertainty in economic policy. The latest observation for Japan is as of Aug 2015, and those for all other economies are as of Oct 2015.

C. Unweighted averages of Political Risk Rating for EM. A higher Political Risk Rating indicates lower political risk. Political Risk Ratings are a weighted average of ratings of government stability, socioeconomic conditions, investment profile, corruption, the role of the military in politics, law and order, external and internal conflict, religious and ethnic tensions, democratic accountability and bureaucratic quality. The EM volatility index refers to JPMorgan's emerging market volatility index, which tracks the level of implied volatility of emerging market currencies.

D. Annual average shares of the cumulative number of emerging market countries for which a presidential or parliamentary election has been held over the intervals 2000-09 and 2010-14.

\section{Increasing policy uncertainty}

Since the global financial crisis, there have been repeated bouts of economic policy uncertainty in major advanced economies and EM. In advanced economies, it began to surge in 2008 to a peak in 2013 and has remained above pre-crisis levels since then (Figure 16). Discussions about debt ceilings, government shutdowns and the timing of interest rate liftoff in the United States, the euro area sovereign debt crisis, and concerns about the effectiveness of Abenomics in Japan have contributed to this uncertainty. Bouts of policy uncertainty have also swept across EM since the global financial crisis. In BRICS, policy uncertainty intensified around new Five-Year plans in China, elections in India and geopolitical tensions in Russia. More broadly among EM, political risk as measured by ICRG's political risk index has steadily 
increased. ${ }^{16}$ The underlying steady rise in political risk and episodes of policy uncertainty have been reflected in bouts of stock market and currency volatility.

By dampening consumer and business confidence, policy uncertainty can set back growth and recoveries or deepen recessions. Waiting for a resolution of uncertainty, firms and households delay or reduce investment and consumption of durable goods. ${ }^{17}$ This adverse impact of policy uncertainty can be larger in countries with less-developed financial markets, as is the case in many EM. In addition, financial institutions facing uncertainty typically increase risk premia and limit lending, which reduce firms' access to credit and, in turn, firms' investment spending. ${ }^{18}$ Concerns about policy direction can also dampen foreign direct investment as well as other types of capital flows. ${ }^{19}$ Uncertainty shocks have accounted for as much as 50 percent of cyclical volatility in EM and other developing countries. ${ }^{20}$

Looking ahead, if heightened policy-especially political-uncertainty persists, it may severely constrain policymakers' ability to support growth. Countercyclical fiscal and monetary policies may be harder to implement when investors focus on rising uncertainty and/or widening vulnerabilities. Capital outflows and depreciations amidst weakening confidence may limit the effectiveness of countercyclical policies in lifting activity (Chinn 2014). Structural reforms also often stall amidst political uncertainty.

\section{Eroding policy buffers}

During the global financial crisis and its immediate aftermath, a number of EM employed expansionary fiscal and monetary policies to support activity. Their ability to employ effective countercyclical policy during the crisis was a major accomplishment. However, the erosion of policy buffers has made it increasingly difficult to stem the growth slowdown through fiscal and monetary stimulus in many countries. A comprehensive discussion of available space for cyclical and structural policies is provided in the next section.

Domestic factors that have been driving the slowdown so far are likely to continue to weigh on growth. With aging populations, labor inputs are expected to shrink and productivity growth is likely to slow as the demographic dividends of the 1990s and 2000s fade. This trend will be most pronounced in major EM (but may still lag in some FM by a generation). Unless EM implement credible medium-term policy and reform programs, policy uncertainty will likely persist, weakening investor confidence and slowing investment growth. This will in turn impede the long-run technological progress that is the foundation of sustained growth. Moreover, the longer growth weakness persists, the more domestic policy buffers will likely erode and limit the use and effectiveness of cyclical policies to support activity. Countercyclical fiscal and monetary policies may become more difficult to implement when investors focus on shrinking policy space, rising uncertainty, and widening vulnerabilities.

\footnotetext{
16 The International Country Risk Guide (ICRG) political risk index is a weighted average of ratings of government stability, socioeconomic conditions, investment profile, corruption, the role of the military in politics, law and order, external and internal conflict, religious and ethnic tensions, democratic accountability and bureaucratic quality.

17 Carrière-Swallow and Céspedes (2013) find that, in comparison to the U.S. and other developed countries, emerging economies experience more severe declines in investment and private consumption following policy uncertainty shocks, endure longer recovery, and do not have a subsequent overshoot in activity.

18 See Barro (1991), Rodrik (1991), and Julio and Yook (2012).

19 See Julio and Yook (2013), Gourio, Siemer, and Verdelhan (2014), and Karolyi (2015). On the other hand, elections may provide incentives for policymakers to implement growth-enhancing policies, as growth has been shown to help generate incumbent electoral wins (Brender and Drazen 2008; Gupta and Panagariya 2014).

20 See Carrière-Swallow and Céspedes (2013). In advanced markets, a sizeable real impact of uncertainty has also been estimated: for example, an increase in policy uncertainty-as defined by the Economic Policy Uncertainty Index (Baker, Bloom, and Davis 2013)-similar in size to the increase between 2006 and 2011, could reduce U.S. real GDP by almost 2.5 percent below baseline (Kose and Terrones 2015).
} 


\section{Policies available to stimulate growth}

\section{A. Cyclical policies}

To the extent that the growth slowdown in EM is partly a cyclical deceleration, fiscal and monetary policy could support growth-provided there is sufficient policy space. This section discusses countercyclical fiscal and monetary policy options.

\section{Fiscal policy}

Fiscal stimulus could help promote activity. Fiscal multipliers - the increase in real GDP generated by a 1 percent increase in fiscal spending - for emerging markets are up to 0.6 in the short-term and up to 0.9 in the medium-term. Fiscal multipliers tend to be larger during recessions than expansions, in countries with ample fiscal space, in less open economies, and for fiscal stimulus conducted through expenditure increases, especially public investment, rather than tax cuts (Ilzetzki, Mendoza, and Végh 2013; World Bank 2015a).

Sizeable infrastructure needs may warrant public investment, especially since infrastructure investment can be a particularly effective instrument for fiscal stimulus to lift activity in the short run. Using public investment as a proxy for infrastructure investments, multipliers have been estimated to range from 0.25 to 1 in EM (IMF 2014b). Using measures of physical capital stock, a 1 percent increase in physical capital stock has been estimated to raise short-run growth in Sub-Saharan Africa and Latin America and Caribbean by 1-2 percentage points (Calderón and Servén 2008, 2010). In addition to raising short-term activity, infrastructure investment can help raise long-term capital stocks and increase productivity (Fernald 1999; Gonzalez-Navarro and Quintana-Domeque 2010). However, estimates of long-term output effects of public investment vary widely (Bom and Ligthart 2014). ${ }^{21}$ In addition to raising domestic growth, infrastructure investment may also foster trade (and thus growth of partner countries), boost employment, and help reduce income inequality. ${ }^{22}$

While some of the largest infrastructure deficits have been identified for low-income countries and frontier markets, EM also lag by global comparison. Access to water and sanitation remains incomplete, power outages are common, access to communications networks is limited, and rail infrastructure is underdeveloped (Figure 17).

\footnotetext{
21 The output effects of public infrastructure have also been shown at the subnational level. For example, Indian states with greater electricity supply in agriculture have grown faster (Rud 2012).

22 Infrastructure bottlenecks may lower trade between developing countries by about one-quarter and exports from developing to high-income countries by more than half (Francois and Manchin 2013). Micro- as well as macroeconomic studies suggest sizeable employment gains from infrastructure investment. For example, an electrification program in South Africa may have raised female employment by nine hours per week (Dinkelman 2011). Separately, every \$1 billion increase in infrastructure in MENA countries has been estimated to potentially generate 11,000 jobs in oil-importing economies and 49,000 jobs in oilexporting economies (Estache et al. 2013). Rural road development has raised worker and household incomes in Bangladesh and Vietnam by facilitating mobility among the poorest households (Khandker and Koolwal 2007, 2010; Mu and van de Walle 2007; Calderón and Servén 2014).
} 


\section{Figure 17. Infrastructure shortages}

Infrastructure needs remain significant in emerging and, especially, frontier markets. Access to water and sanitation remains incomplete, power outages are common, access to communications networks is limited, and rail infrastructure is underdeveloped.

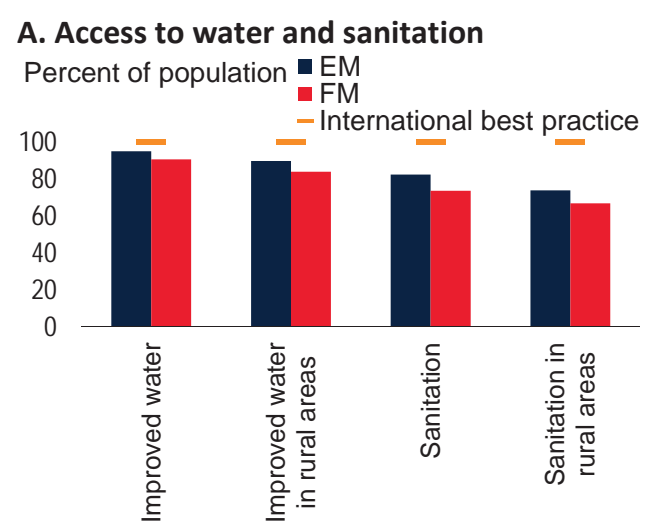

C. Access to communications network

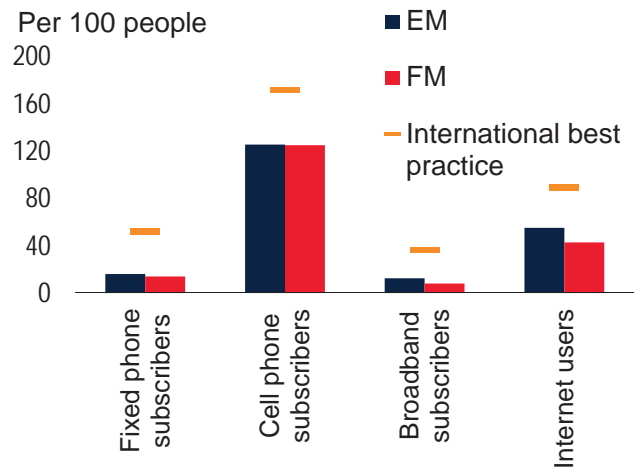

\section{B. Access to electricity}

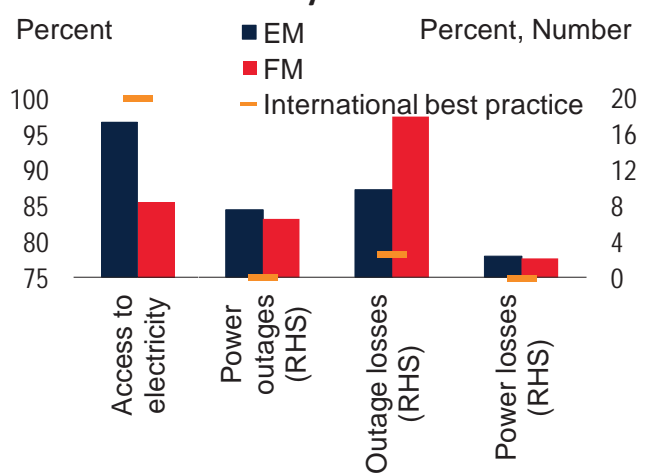

D. Rail and port network

Index, million tons per km 23

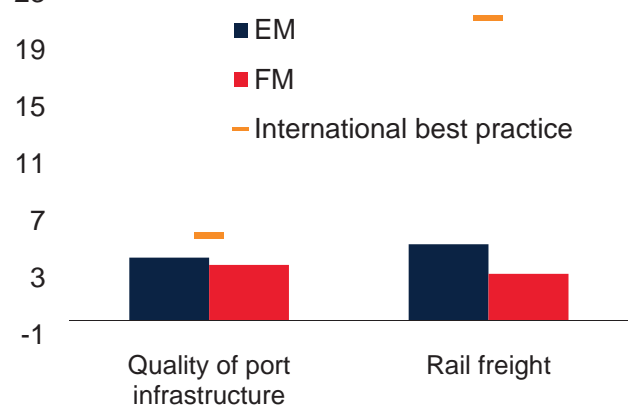

Source: World Bank CPIA.

Note: Unweighted averages for latest available data (varies by country and indicator but typically for 2012).

A. Percent of population with access to improved water and sanitation facilities.

B. Access to electricity in percent of population; power outages of firms in a typical month (number); value lost due to power outages in percent of sales; electricity transmission and distribution losses in percent of total output. International best practice ("frontier") is the average of values for the top $5^{\text {th }}$ percentile for access to electricity and the average of the bottom $5^{\text {th }}$ percentile for power outages, value lost to power outages, and power losses.

D. Rail freight stands for goods transported by rail in million tons per km of rail lines. Quality of port infrastructure ranked from 1 to 7 where $1=$ extremely underdeveloped and $7=$ well developed and efficient by international standards.

Infrastructure investment needs, however, have to be assessed against financing cost and implementation capacity (Kraay and Servén 2013). In advanced economies, public investment has been shown to raise growth without significantly raising public debt ratios. In contrast, because of less economic slack and lower efficiency of investment in emerging and frontier markets than in advanced economies, growth benefits in the former are smaller, subject to significant uncertainty, and entail rising public debt (Gupta et al. 2014; IMF 2014b).

The effectiveness of stimulus measures such as infrastructure spending also depends on the availability of fiscal space. High public debt or deficits can turn fiscal multipliers nil or even negative as households and firms save to prepare for subsequent fiscal consolidation and as investors require higher risk premia. For example, two-year multipliers in emerging and frontier markets can range from negative when the fiscal balance is in the bottom quartile of EM to 2 when the fiscal balance is in the top quartile (Estevao and Samake 2013; World Bank 2015a). 
Since the crisis, fiscal positions of EM have deteriorated considerably (Figure 18). Their fiscal balances have weakened from, on average, a surplus of 1.2 percent of GDP in 2007 to a deficit of 4.1 percent in 2015. Debt capacity has deteriorated in these economies as well: debt has on average risen from 37 percent of GDP in 2007 to 44 percent of GDP in 2015. In more than one-third of EM, government debt has increased by more than 10 percentage points of GDP since 2007 and in one-quarter of them government debt levels are in excess of 60 percent of GDP. Overall, sustainability gaps-the difference between actual deficits and debt-stabilizing deficits-are negative (i.e. fiscal debt is set to rise steadily) in about half of EM.

The sharp drop in oil prices since mid-2014 has contributed to further deterioration in the fiscal positions of oil-exporting EM, as government revenues have fallen sharply. This fiscal deterioration has also been reflected in weakening credit ratings among oil-exporting countries. Several commodity-exporting countries have tightened fiscal policy even as their growth slowed (Brazil, Malaysia). In oil-importing countries, however, shrinking fiscal vulnerabilities may have created some space. In countries with sizeable fuel subsidies and low energy taxation, lower oil prices have also presented an opportunity for subsidy and tax reform to re-build buffers against future cyclical downturns, or to expand spending on infrastructure investment and poverty-reducing activities (e.g. Egypt, India, and Indonesia).

Most EM appear to have little to no room to implement fiscal stimulus over any but the shortest period.

- At best, oil exporters that have entered the oil price slump of 2014 with large surpluses and low debt (Qatar, Saudi Arabia, United Arab Emirates) can smooth the adjustment of their economies to a "new normal" of persistently low oil prices. However, in most oil-exporting EM, surpluses have already turned into sizeable deficits, and debt is rising in 2015.

- In several non-oil commodity-exporting EM (Brazil, Chile, Colombia, Peru), deficits have widened from a less favorable starting position by more than a percentage point and debt has risen above 50 percent of GDP in 2015 (Brazil, Colombia).

- In 2010, several commodity-importing economies entered the EM growth slowdown with deficits above 4 percent of GDP and debt above 50 percent of GDP (Egypt, Hungary, India, Poland), and their debt and deficits remain elevated despite consolidation efforts.

\section{Monetary policy}

Like fiscal stimulus, monetary policy could help boost growth amidst a cyclical slowdown in activity through a number of channels: by reducing interest rates on government securities, interbank borrowing and bank lending; by weakening the exchange rate; by increasing asset prices (especially equity and house prices) and thus by inflating the value of collateral for borrowing. Monetary policy tends to be more effective when financial markets are deeper and more developed. 


\section{Figure 18. Fiscal policy buffers}

Fiscal space is necessary to ensure that fiscal policy is effective. Among EM, fiscal space on average has shrunk significantly since the crisis, as rising government debt and fiscal deficits have weakened debt sustainabilitysharply in some countries. This has also been reflected in deteriorating credit ratings.

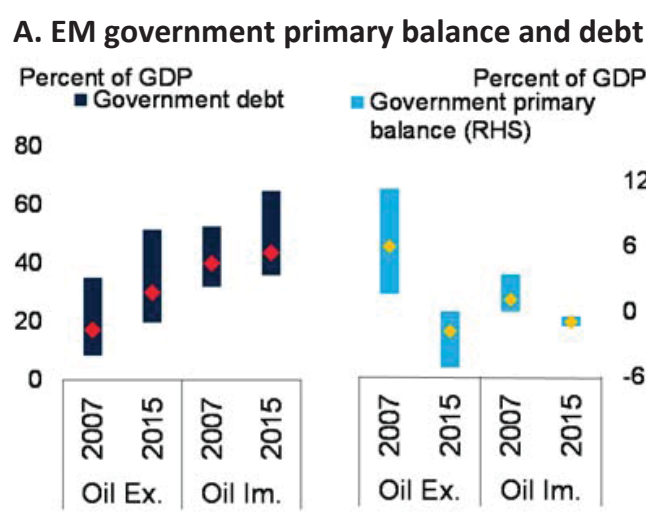

\section{Fiscal multipliers after two years}

Value

3

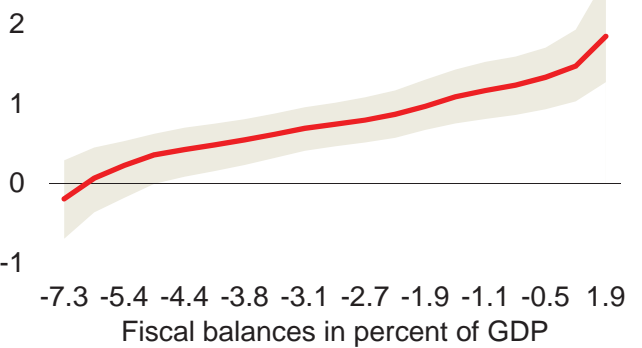

\section{B. EM fiscal sustainability}

Share of EM, in percent

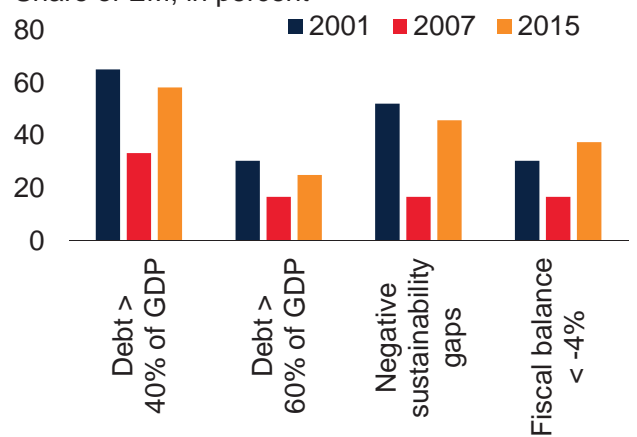

D. Sovereign credit ratings of EM

Credit rating Index BBB- -Average EM sovereign rating (LHS) 120

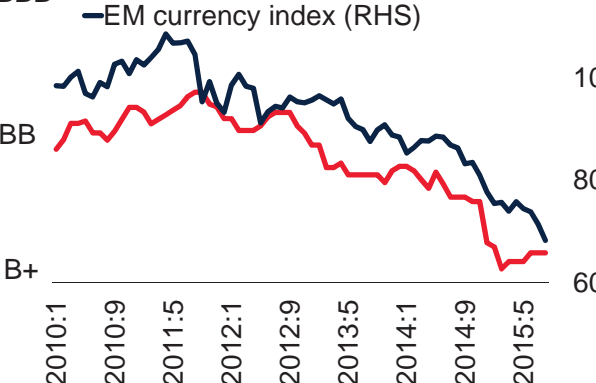

Source: World Bank (2015a), IMF World Economic Outlook, Haver Analytics.

A. Bars show the interquartile ranges. Dots show the median values.

B. EM with general government debt above 60 percent of GDP in 2015 include Brazil, Egypt, Hungary, India, Morocco, Pakistan. Sustainability gap is defined as the difference between the actual overall fiscal balance and the debt-stabilizing fiscal balance at current growth rates. A negative sustainability gap indicates an unsustainable stock of debt and deficit. EM with negative sustainability gaps in excess of -2 percent of GDP in 2015 include Brazil, Egypt, India, Pakistan, and Saudi Arabia.

C. Fiscal multipliers for different levels of fiscal balance (in percent of GDP) after two years, estimated from an IPVAR model using a sample of 15 emerging and frontier markets. Values on the $x$-axis correspond to percentiles of the fiscal balance; solid line represents the median; shaded area is the $16-84$ percent confidence band.

D. The sovereign rating is calculated as the simple average of long-term foreign-currency credit ratings of countries with Standard \& Poor's Rating Service. The latest observation is August 2015. 


\section{Figure 19. Monetary frameworks and currency regimes}

EM's ability to implement independent monetary policy has strengthened, as they have increasingly shifted away from exchange rate targeting towards flexible exchange rate regimes and inflation targeting monetary policy frameworks.

\section{A. EM with inflation-targeting monetary policy frameworks}

Share, in percent

80

60

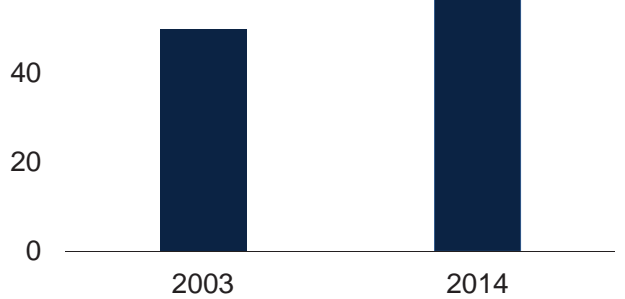

\section{B. EM with floating exchange rate regimes}

\author{
Share, in percent
}

80

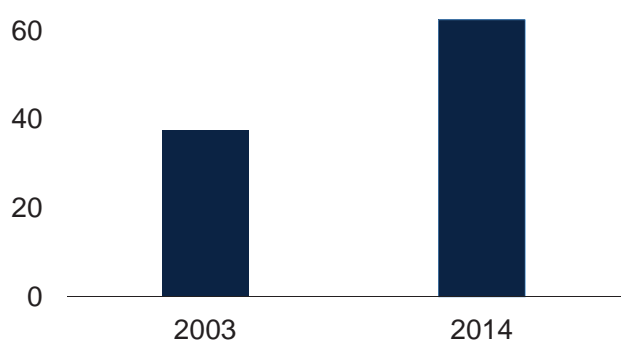

Source: Hammond (2012), Central Bank News, World Bank, Haver Analytics, IMF AREAER.

A. Economies with inflation targeting frameworks in 2014 are Brazil, Chile, China, Colombia, Czech Republic, Hungary, India, Indonesia, Mexico, Pakistan, Peru, Phillipines, Poland, Russia, South Africa, South Korea, Thailand, and Turkey. Includes formal and informal inflation targeting.

B. Includes freely or indendepently floating exchange rate regimes. Excludes currency boards, conventional pegs, stabilized arrangements, crawling pegs, crawl-like arrangements, pegged exchange rates with horizontal bands, and other managed arrangements (IMF $2015 \mathrm{~b}$ ). Economies with floating exchange rate regimes in 2014 are Brazil, Chile, Colombia, Hungary, India, Indonesia, Korea, Mexico, Peru, Philippines, Poland, Russia, South Africa, Thailand, and Turkey.

However, EM typically have less developed financial systems than AE, which constrains the effectiveness of monetary policy. Policymakers in EM face a variety of challenges that differ significantly from those facing their counterparts in advanced economies, including a susceptibility to rapid reversals in capital flows and the risk of financial contagion; a minimal influence on global markets combined with timevarying external credit constraints; an inability to borrow internationally in domestic currency; the management of international reserves; higher degree of pass-through from exchange rate fluctuations to domestic prices; and usually pro-cyclical fiscal policies (Lane 2003; Devereux, Lane, and Xu 2006; Chinn 2014; Mishra et al. 2014).

Monetary policy frameworks have improved significantly across EM over the past decade. In particular, EM have increasingly shifted towards flexible exchange rate regimes over the 2000s (Figure 19). In the process, many of them have oriented their monetary policy regimes towards inflation targeting. By 2014, about 75 percent of EM had inflation targeting frameworks. Inflation targeting frameworks can help stabilize business cycles provided medium-term inflation expectations remain anchored and central banks are able to change short-term interest rates without triggering offsetting shifts in long-term interest rates (Lane 2003).

Notwithstanding strengthened monetary frameworks, financial stability concerns may remain a constraint on monetary policy in EM with the rise in the share of foreign currency debt from 30 percent of GDP in 2007 to 36 percent of GDP in 2014. Concerns about the inflationary impact of depreciation and foreign currency exposures in private and public balance sheets may prevent central banks from implementing accommodative monetary policies to support growth. 


\section{Figure 20. Monetary policy buffers}

Among oil-importers, the oil price drop has reduced inflation below target levels and made room for policy accommodation. Among oil exporters, recent depreciations have been associated with higher inflation. In many commodity exporters, current policy rates are below levels implied by a Taylor rule, whereas in many commodity importers, current policy rates are above those levels.

\section{A. Inflation}

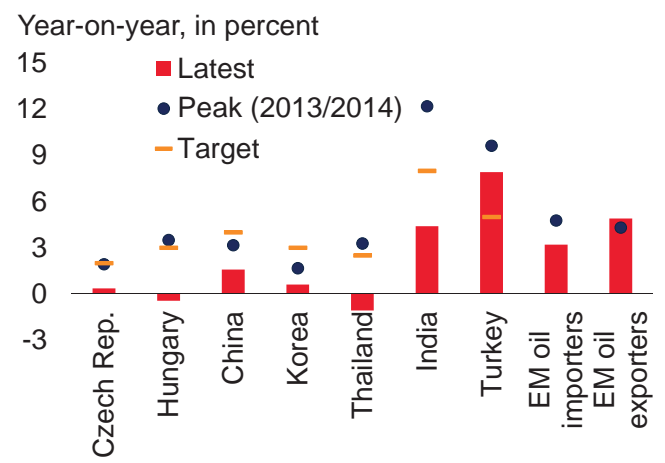

\section{Monetary policy rate changes in EM}

Number of hikes and cuts

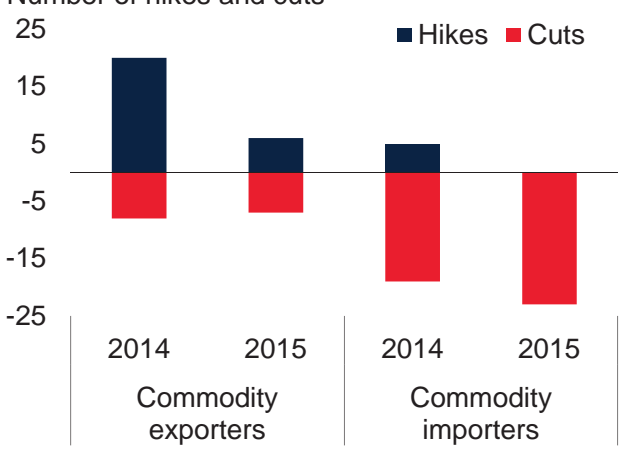

\section{B. Foreign currency debt}

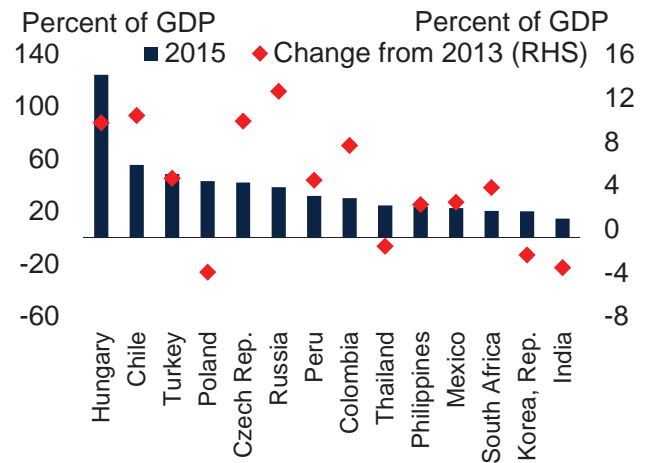

D. Monetary policy rates and Taylor rule rates

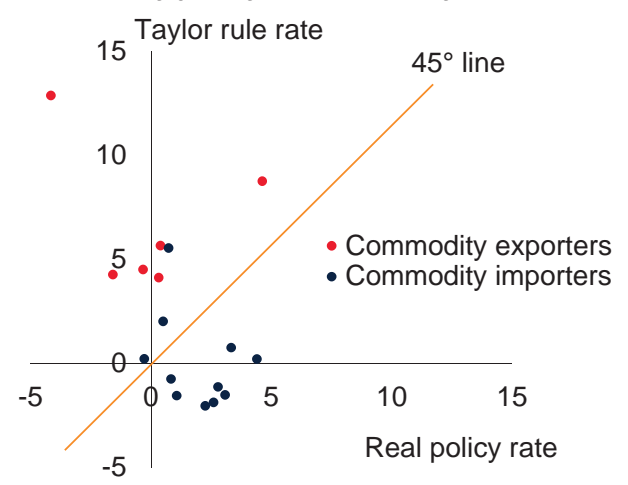

Source: Hammond (2012), Central Banking News, World Bank, Haver Analytics, Consensus Forecasts.

A. Latest observation is September 2015. Includes both formal and informal inflation targets.

C. Hikes and cuts refer to central bank rate decisions, including base rate, policy rate, repo rate, Selic rate, discount rate, reference rate, lending rate, refinancing rate and benchmark rate. The number of rate cuts is shown with a negative sign. There are 11 commodity exporters and 13 commodity importers.

D. Real policy rate refers to the nominal policy rate less inflation, reflecting the latest available data as of Sept/Oct 2015. Taylor rule rate is a real rate calculated as 1.353* (Expected Inflation - Inflation Target) +2.233 , in which the coefficients on inflation gap and the constant are based on estimated Taylor rules of EM inflation targeting economies by Ostry, Ghosh, and Chamon (2012).

The room to maneuver in the short-run and EM monetary policy buffers-well-anchored inflation expectations, low foreign currency exposures, low short-term external debt-have diverged between commodity exporters and importers (Figure 20). A Taylor-rule illustrates the gap between real policy rates and real interest rates implied by expected inflation and inflation targets (Figure 20). Most commodityexporting EM have limited monetary policy space, whereas many commodity-importing EM have some room to counteract shocks with further interest rate cuts and thus stimulate economic activity. 
- In the majority of commodity-exporting countries, monetary policy is constrained by either fixed exchange rate regimes (Qatar, Saudi Arabia, United Arab Emirates) or above-target inflation (Brazil, Colombia, Russia), partly as a result of weakening investor sentiment accompanied by depreciation. Central banks in those countries are balancing the need to support growth, stabilize inflation, and temper currency pressures (including containing financial stability risks from foreign currency exposures). In fact, real policy rates in some EM are already well below those implied by a Taylor rule. ${ }^{23}$

- In contrast, lower oil prices have temporarily reduced inflation in oil-importing countries and opened up room for monetary policy rate cuts to support activity (Egypt, India). Compared with rates implied by a Taylor rule, there might even be further room to cut rates in several commodityimporting EM. However, this room may dissipate quickly once oil prices stabilize.

\section{B. Structural policies}

The sustained and broad-based growth slowdown raises the specter of a growth trap looming in emerging markets. In general, during their development process, countries may go through an extended period of slow growth that leaves them stagnating within a certain interval of per capita income, typically at middleincome levels. This phenomenon has been dubbed the "middle-income trap" (Gill and Kharas 2007, 2015; Annex II). Measured by the threshold income advocated by Eichengreen, Park, and Shin (2012), about one-third of EM could be in a middle-income trap as of 2014. In fact, several EM share characteristics typically associated with the middle-income trap, such as slowing TFP growth, rising investment cost, unfavorable demographic features, and rising income inequality (Anand et al. 2014, Cubeddu et al. 2014; De Gregorio 2015). Evidence suggests that escaping the middle-income trap requires a variety of structural reforms ranging from improvements in the market-enabling environment, to strengthening policy capacity to the functioning of labor markets (while maintaining adequate labor protections), to closing of gaps in the formation of human and physical capital (Agénor and Canuto 2012; Aiyar et al. 2013).

Emerging markets are known to have discontinuous growth paths, lurching from sudden stops into growth spurts (Pritchett 2000). Improvements in structural characteristics are strongly associated with episodes of growth takeoffs and expansions (Abiad et al. 2012; Berg, Ostry, and Zettelmeyer 2012; IMF 2013). As a result, structural reforms could help mitigate the sources of the recent growth slowdown. Institutional reforms in the conduct of monetary and fiscal policies can also do much to improve the capacity to stabilize cyclical fluctuations. In addition to these long-term benefits, the implementation of structural reforms can lift investor confidence in growth prospects in the short run. Moreover, growth gains from structural reforms could be particularly large in $\mathrm{EM}$ and $\mathrm{FM}$, as compared to $\mathrm{AE}$, for two reasons. First, emerging and frontier market economies tend to display higher inter-sectoral dispersion in productivity than advanced economies (Dabla-Norris et al. 2013; Anand et al. 2014). Second, misallocation of capital and labor is pervasive in a number of emerging and frontier markets (Hsieh and Klenow 2009; IADB 2013). Indeed, greater market and financial sector access have been associated with stronger TFP growth during 2010-12 compared with 2003-07 (Qureshi, Diaz-Sanchez, and Varoudakis 2014).

\footnotetext{
${ }^{23}$ Taylor rule rate is a real rate calculated as 1.353*(Expected Inflation - Inflation Target) +2.233 , in which the coefficients on inflation gap and the constant are based on estimated Taylor rules of EM inflation targeting economies by Ostry, Ghosh, and Chamon (2012).
} 


\section{Fiscal, labor, and product market reforms}

In many EM, unfavorable demographic trends may lend urgency to structural reforms to support growth (Dabla-Norris et al. 2013; Anand et al. 2014). Reforms to lift labor productivity and mobility to ease demographic pressures have also been identified as major priorities by the Group of Twenty (G20 2015). Policy priorities to address the challenges created by population aging include implementing labor market, pension, and product market reforms to improve the efficiency of resource allocation and strengthen fiscal sustainability (World Bank 2015g). ${ }^{24}$

- Pension reforms can raise growth by increasing the labor supply and increasing savings. For example, Karam et al. (2010) find that pension reforms not only boost consumption in the short run, but also increase investment in the long run by lowering government debt. For the Euro Area, Cournède and Gonand (2006) show that a gradual rise in the retirement age, once combined with constraints on non-aging related expenditures, helps raise growth. In addition, pension reforms strengthen fiscal sustainability by reducing expenditures on benefits and improving debt dynamics (Barrel, Hurst, and Kirby 2009). This could help widen fiscal space and allow the effective implementation of fiscal stimulus to support activity.

- Labor market reforms can raise growth by lowering unemployment and encouraging a more efficient allocation of labor (Blanchard, Jaumotte, and Loungani 2013). Incentives for greater or longer labor force participation may offset demographic pressures and, by reducing benefits and increasing social contributions, widen fiscal space. ${ }^{25}$ Payroll tax reductions and collective bargaining decentralization in Chile appear to have helped lower unemployment (Edwards and Edwards 2000). Less restrictive employment protection legislation to increase labor market flexibility is associated with higher productivity (e.g. Bassanini and Venn 2008). In China, eliminating hukou restrictions may increase real worker incomes over the long-term (Bosker, Deichmann, and Roberts 2015). Labor market reforms combined with other reforms, including financial sector reforms, could significantly raise growth and reduce unemployment in economies in the Middle East and North Africa (Agénor et al. 2007).

- Product market reforms can raise growth by improving productivity and increasing firm entry India's delicensing reforms in the 1980s (Srivastava 1996) and services sector deregulation in the 1990s (Arnold et al. Forthcoming) have significantly raised firm productivity in those sectors most affected by the licensing reform. These growth-enhancing effects of product market deregulations are higher under more flexible labor markets and in conjunction with other reforms (Aghion et al. 2008; Pelkmans et al. 2008). Evidence from OECD's Product Market Regulation (PMR) indicators suggests that the largest EM, including BRICS, have additional room for product market reforms relative to $\mathrm{AE} .{ }^{26}$

\footnotetext{
24 Increases in savings and investment by the amount of its saving gap have been estimated to potentially raise growth in Brazil by 0.3 percentage point (World Bank 2015g).

${ }^{25}$ Unemployment insurance reforms in Germany in 2005 have reduced long-term unemployment by about 1.4 percentage points (Krebs and Scheffel 2013).

${ }^{26}$ For more about the impact of product market reforms, see Nicoletti and Scarpetta (2003); Blanchard and Giavazzi (2003); Wölfl et al. (2010); Prati, Onorato, and Papageorgiou (2012). The OECD's economy-wide Product Market Regulation indicator is a measure of the overall level of restrictiveness in any given country's product markets, and is constructed based on survey questions related to three aspects: barriers to entrepreneurship, barriers to trade and investment, and state control (Koske et al. 2015).
} 


\section{Improving the business environment}

Whereas labor market and pension reforms support growth by increasing the labor force and improving the allocation of labor, improvements to the business environment may also raise total productivity growth. A growing literature has documented the long-term benefits associated with business environment reforms in emerging and frontier markets:

- Promote growth. Large improvements in business environments are also associated with a significant increase in per capita growth (Divanbeigi and Ramalho 2015). Even modest improvements in business environments have been associated with higher growth and lower macroeconomic volatility. ${ }^{27}$ Especially an easing of financial constraints has been credited with raising growth at the firm, sector, and macroeconomic levels (King and Levine 1993; Rajan and Zingales 1998; Beck and Demirguc-Kunt 2006).

- Leverage infrastructure investment. Business environment reforms combined with infrastructure investment can have especially potent growth effects. The increase in firm start-ups and farm productivity as a result of land reform in China was larger in villages with lower travel time to the nearest city (Deininger et al. 2015). Across a large set of countries, power sector reforms appear to have improved the quality of electricity supply more in countries where regulators were more independent (Jamasb, Nepal, and Timilsina 2015). In Uganda, poor access to power supply decreased firm investment and productivity (Reinikka and Svensson 2002). ${ }^{28}$

- Increase job creation, firm productivity, and formality. Lower startup costs, easier registration requirements, improved management practices, and better access to finance have been linked to more firm entry, employment creation, and productivity improvement in a range of countries. ${ }^{29}$ Trade liberalization in India (Topalova and Khandelwal 2011) and bankruptcy reform in Brazil (Ponticelli 2015) have boosted firm productivity and growth. Reforms to strengthen property rights have also led to a shift towards more formal activity in the retail sector in Brazil (Monteiro and Assunção 2012).

\section{Governance reforms}

Enterprise surveys suggest that a major obstacle to growth in EM relates to governance, especially corruption (Figure 21). ${ }^{30}$ To varying degrees in South Asia, Sub-Saharan Africa, the Middle East and North Africa, and Latin America and Caribbean, corruption is facilitated by burdensome practices for licenses and permits; inefficient tax administration; heavy-handed customs and trade regulations; and weak judicial system that fail to robustly protect investor and property rights.

\footnotetext{
27 See Claessens and Laeven (2003); Cooley, Marimon, and Quadrini (2004); Loayza, Oviedo, and Servén (2005); Djankov, McLiesh, and Ramalho (2006); Dethier, Hirn, and Straub (2008); and Hanusch (2012).

28 Drawing policy conclusions at the national level from micro-studies faces two limitations. First, a change in de jure constraints may not be reflected in de facto business constraints. Second, data based on questionnaires and surveys may target a limited subset of the corporate or household sector.

29 See Desai, Gompers, and Lerner (2003); Klapper, Laeven, and Rajan (2006); McKenzie and Woodruff (2015); Klapper and Love Forthcoming; including Mexico (Bruhn 2011, 2013; Bruhn and Love 2014) and Portugal (Branstetter et al. 2014).

30 For evidence on the negative relationship between corruption and growth, see Mauro (1995); Tanzi and Davoodi (1997); and $\mathrm{Li}, \mathrm{Xu}$, and Zhou (2000). Pritchett and Summers (2014) cite governance as a constraint to uninterrupted growth for China and India.
} 
Figure 21. Reform needs

Structural reforms are needed to address infrastructure bottlenecks, especially in energy, and strengthen institutions, partly to reduce corruption. Large EM still possess room for product market reforms.

\section{A. Major constraints to firm activities}

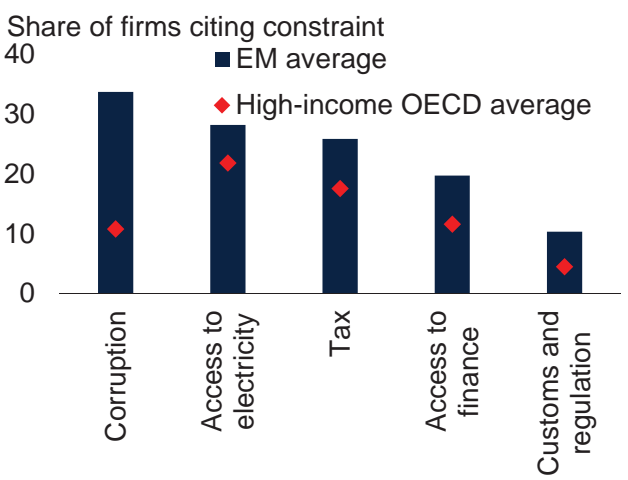

\section{B. Product market regulations, 2013}

Index

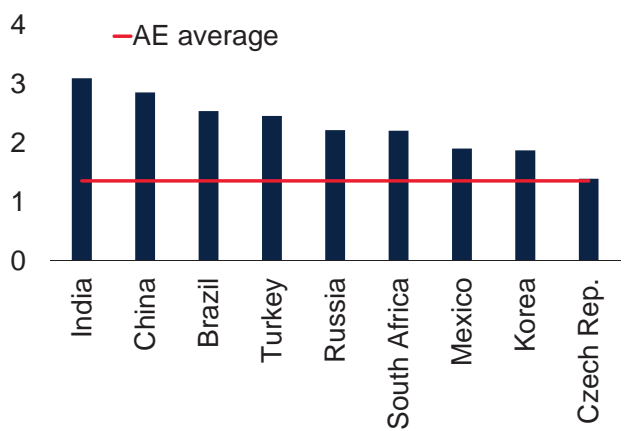

Source: World Bank Enterprise Surveys, OECD Product Market Regulations index.

A. For each indicator, each bar shows the EM average of the country-specific percentage of firms citing that indicator as a major contraint. Each diamond shows that indicator for high-income OECD economies. The averages are computed across data of the latest available year starting in 2009 in each country. Korea, Malaysia, Thailand, Qatar, Saudi Arabia, South Africa, and the United Arab Emirates are not available. Indicator for "Tax" denotes the average of the indicators of constraints to tax rate and tax administration. Customs and regulation refer to constraint in customs and trade regulation.

B. Each bar shows the index in the degree of restrictiveness in economy-wide product market regulations, as measured by survey responses to questions on barriers to entrepreneurship, barriers to trade and investment, and state control. The index ranges from 1 to 6 , where $1=l e a s t$ restrictive and $6=$ most restrictive. Among $\mathrm{AE}$, data are not available for Hong Kong, Malta, Singapore, and the U.S. The latest available data is for the year 2013.

Using the Worldwide Governance Indicators, an event study is conducted to illustrate the differential growth outcomes associated with periods of reform spurts and setbacks. ${ }^{31}$ The analysis, which controls for country time-invariant and global factors, identifies 50 episodes of significant reform spurts and 47 episodes of reform setbacks among the sample of $64 \mathrm{EM}$ and FM between 1996 and 2014. A reform spurt episode is defined as a two-year interval in which a country's index on the Worldwide Governance Indicators improves in at least one of the four areas of interest (regulatory quality, control of corruption, rule of law, or government effectiveness).

The improvement needs to be of at least two standard deviations. ${ }^{32}$ A reform setback episode is analogously defined: a two-year interval in which a country's index on the Worldwide Governance Indicators deteriorates in at least one of the four areas of interest by at least two standard deviations.

\footnotetext{
31 The Worldwide Governance Indicators (available 1996-2014; Kaufmann, Kraay, and Mastruzzi 2010) summarize a number of underlying indicators from a wide range of sources into indices of regulatory quality, government effectiveness, control of corruption, and the rule of law. The indicators extract the principal component from a wide range of indicators using a rich set of sources. Each indicator is based on rescaling and aggregating data from a variety of government and private institutions.

32 Reform spurts that are accompanied by simultaneous setbacks in one of the other three indicators are excluded. Analogously, reform setbacks that are accompanied by reform spurts in one of the other three indicators are excluded. Reform spurts that took place under an IMF program-perhaps more exogenous than indigenous reform programs-are considered separately. Reform spurts covered by an IMF program were associated with a larger growth differential.
} 


\section{Figure 22. Growth and governance reforms}

Significant reforms in governance are positively associated with growth performance. During the most recent slowdown period, countries that were able to increase the quality of governance more appeared to experience milder slowdowns.

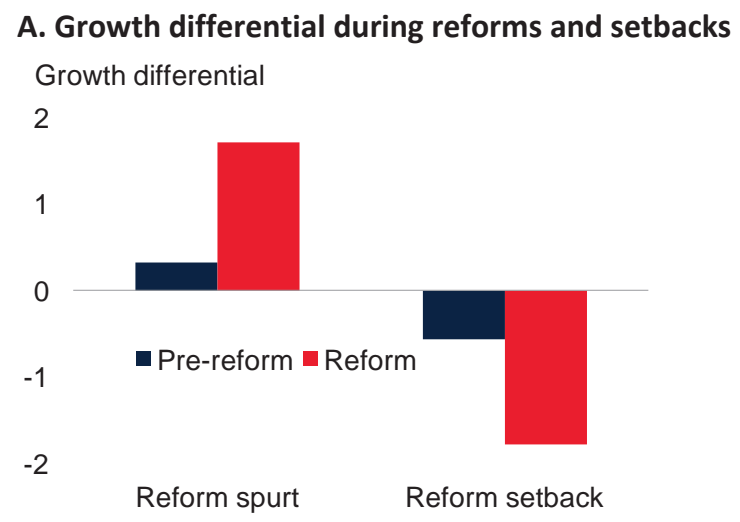

\section{B. Change in growth and governance quality: 2010-14}

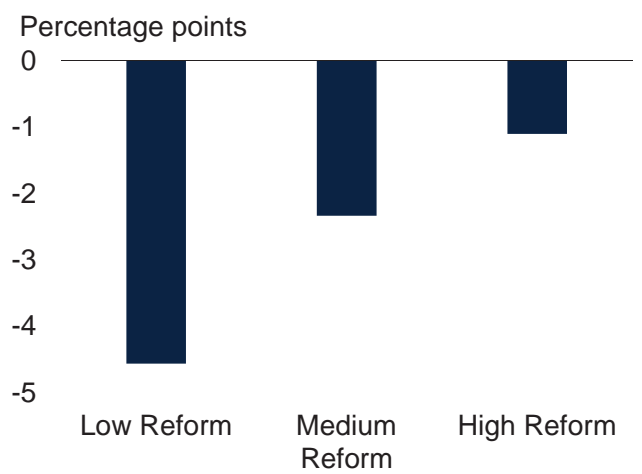

Source: World Bank's Worldwide Governance Indicators (WGI).

A. The columns show the cumulative growth differential of economies during and prior to an reform spurt or setback episode, relative to those that experienced neither spurts nor setbacks. Spurt (setback) is defined by a two-year increase (decrease) by two standard deviations in one or more of the following four measures of the WGI index: regulatory quality, government effectivness, rule of law, and control of corruption. Differentials are based on estimates from a panel data regression with time and country fixed effects. The sample spans 64 EM and FM over 19962014. Annex III provides additional details about the empirical exercise.

B. The bars show the changes in growth during 2010-14. Low, medium, and high reform refer to the $25^{\text {th }}, 25^{\text {th }}-75^{\text {th }}$, and $75^{\text {th }}$ percentiles of the distribution in changes in average governance of EM from 2010-2014. Average governance is defined as the unweighted average of each economy's regulatory quality, government effectivness, rule of law, and control of corruption index in the WGI indicators. The WGI indicators are principal components of a wide range of survey-based and other indicators.

Growth during reform spurt episodes rose more than 1 percentage points above growth during nonreform periods and growth during reform setbacks declined by about the same magnitude (Figure 22). Isolating one particular episode, the EM slowdown of 2010-14, the decline in growth was indeed lower in countries with the largest improvements in economic governance (Figure 22). The sample of $24 \mathrm{EM}$ is split into three groups: the top $25^{\text {th }}, 25^{\text {th }}-75^{\text {th }}$, and bottom $25^{\text {th }}$ percentiles of countries with the largest improvements in the average index on four Worldwide Governance Indicators during 2010-14. Growth in the "high reformers" in the top quartile slowed by 1 percentage point during 2010-14, whereas growth decelerated on average by 4 percentage points among the "low reformers" in the bottom quartile.

\section{Status of structural reforms}

Reform momentum towards a market-enabling environment has been mixed throughout the 2000s across EM, with no concerted reform drive during the post-crisis period (Figure 23). Since the crisis, reforms have focused on regulatory reforms, such as reducing the burden of tax compliance or registering a startup business, as well as reforms that facilitate infrastructure investment, such as construction permits and electricity supplies. ${ }^{33}$ However, legislative reforms, for example to ensure contract enforcement, have lagged (Figure 23).

\footnotetext{
33 Reform progress is measured as the distance to frontier score in the Doing Business indicators. Doing Business Indicators (available 2004-2015 at best) summarize expert surveys on the ease of starting and closing businesses, registering property, getting credit, enforcing contracts, dealing with construction permits, accessing electricity, trading across borders, and paying taxes. Each indicator is an aggregate based on simple unweighted averages of a series of sub-indicators arising from survey questionnaires. The frontier is defined as the country-year observation over the full sample period that indicates the easiest
} 
An arguably unwelcome effect of the crisis has been the setback in reform momentum towards trade and financial liberalization. During 2006-09, the ease of cross-border trading, as measured by the World Bank's Doing Business indicators, improved significantly in EM. ${ }^{34}$ Since then, however, the pace of improvements has slowed substantially, by about two-thirds and several EM have put in place outright trade restrictions (WTO 2015). Trading internationally in EM is still, on average, about 11 percent more "difficult" (as captured in the number of documents, days and cost spent to comply with regulations) than in advanced economies. EM's temporary trade barriers on imports have also increased. On the financial front, in the aftermath of the global financial crisis, a number of EM have put in place capital account restrictions limiting off-balance sheet activities and foreign exchange exposures in the banking sector or imposing sanctions. Heightened uncertainty about capital flows in the subsequent few years has led EM to be hesitant in significantly relaxing their capital account restrictions. ${ }^{35}$

While many EM have implemented reforms in specific areas, a few have announced comprehensive structural reform plans, including China, India, and Mexico (World Bank 2015h). Although the pace of implementation remains a concern, these plans have been well received by investors. China continues to gradually implement its November 2013 reform agenda, which spans from financial, fiscal, state-owned enterprise, land and labor reforms to social and environmental measures. India formally adopted inflation targeting in 2015, thus strengthening the credibility of the central bank; reduced barriers to FDI in insurance, telecommunications, railways, and retail; eliminated diesel subsidies while raising excise duties on petroleum and diesel fuel; approved the introduction of a harmonized goods and services tax; and committed to increasing public investment. Mexico approved major reforms in 2013-14 that include opening up deep water and shale oil fields to the private sector, increasing competition in the telecommunications sector, widening the tax base, and easing some employment restrictions.

\footnotetext{
business environment. The ease of starting a business is higher the lower the number of days and procedures and the cost of starting business. The ease of access to credit is higher the more extensive coverage of credit bureaus and the stronger collateral and bankruptcy laws. The ease of paying taxes is greater, the fewer days and forms are needed to file taxes, the fewer taxes exist, and the lower the profit tax rate and other business fees.

34 The World Bank's Doing Business indicator on ease of trading across borders measures the average distance to the frontier of the number of documents required for exports and imports (for banks, customs clearance, port and terminal handling, and transport), the number of days and cost required to comply with regulations (for obtaining, filling and submitting all documents, inland transport and handling, customs clearance and inspections, and port and terminal handling excluding sea transport time). 35 Areas for further reform needs and priorities vary across regions as well. In East Asia and Pacific (EAP) as well as Europe and Central Asia, substantial room exists for reforms in state-owned enterprises and the banking sector to promote competition, improve governance, and facilitate financial development. Reforms to increase labor market flexibility are needed in Latin America; Middle East and North Africa; and South Asia to address structural unemployment. EAP, South Asia, and Sub-Saharan Africa can also benefit from fiscal reforms to reduce poorly targeted subsidies and improve fiscal space. Subsequently, this would enhance the ability to remove infrastructure bottlenecks, a significant growth constraint facing most parts of the world (World Bank, 2015a and 2015f).
} 


\section{Figure 23. Reform progress}

Reform momentum has been mixed during the 2000s. The crisis brought a series of reforms to ease tax burdens and access to credit. Since then, reforms have been most pronounced in the areas related to business regulations, construction permits, and electricity access. The pace of easing financial and trade restrictions has also slowed.

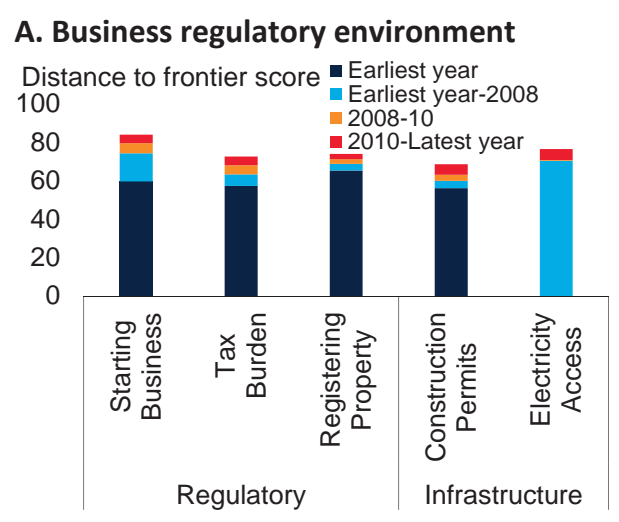

C. EM with higher capital account restrictions Number of countries

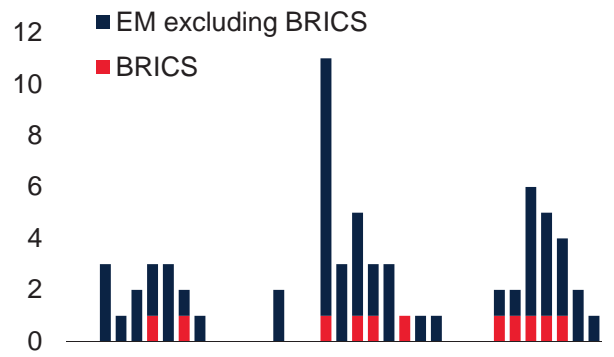

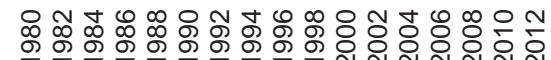

\section{B. Financial legislative protection environment}

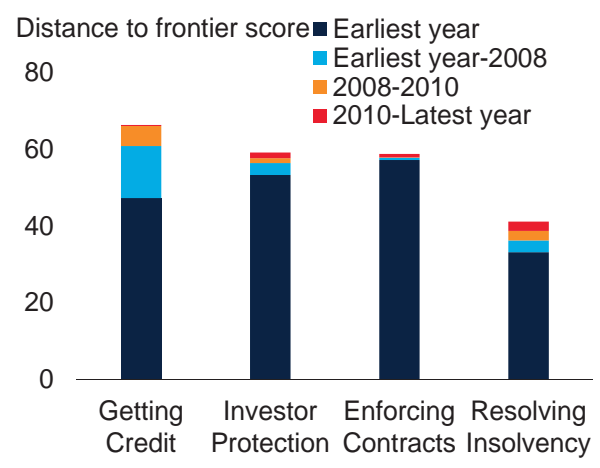

D. Ease of trading: Average improvement

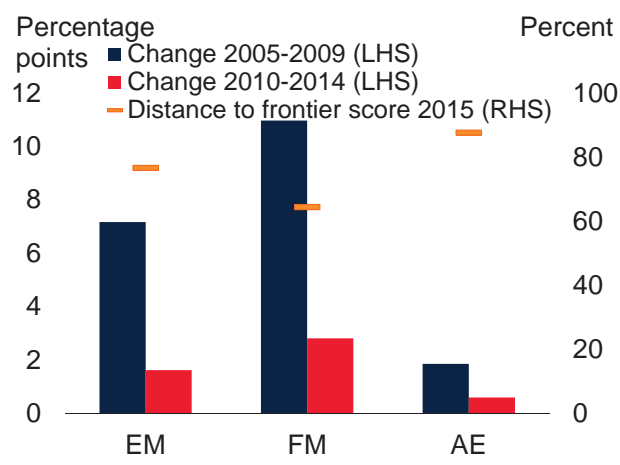

Source: World Bank Doing Business Indicators, Chinn and Ito (2006).

A.B. Ease of starting a business, enforcing contracts, and resolving insolvency indicators start in 2003. Ease of registering property and getting credit start in 2004. Investor protection, tax burden, and dealing with construction permits start in 2005. Electricity access starts in 2009. Ease of obtaining credit, investor protection, and resolving insolvency end in 2012. All other indicators end in 2014. EM excludes Qatar. The dark blue bars denote the distance to frontier score in the earliest year (except electricity access: the earliest year was 2009 and denoted by the light blue bar). All other bars denote changes over time. Each year refers to June of previous year to June of current year.

C. Number of countries with a decline in the Chinn-Ito index from the previous year.

D. Unweighted average across EM, FM, and AE countries of the indicator in ease of trading across borders. Distance to frontier score refers to the best performance among more than 150 economies for 2005-2014. Ease of trading across border refers to the time and cost of exporting and importing a standard cargo of goods by sea and is measured based on surveys from legal experts. Bahrain, Malta, and Qatar are excluded. Each year refers to June of previous year to June of current year.

\section{Risks down the road}

\section{A. Growth: A perfect storm?}

The recent slowdown in EM has been taking place against the background of rising risks. These include setbacks in the recovery in major advanced countries; a hard landing in China; and large swings in oil prices and the possibility of bouts of financial market turmoil, whether triggered by central bank actions in advanced economies or eroding credit worthiness in EM, and further weakness in commodity prices. These risks (more fully discussed in World Bank 2015f) could threaten growth in EM and have significant global repercussions. 


\section{Figure 24. Growth risks down the road}

Persistent growth slowdowns in EM and FM have been associated with an increased likelihood of contractions. Deteriorating external conditions increase the risk of sudden stops, which may have substantial growth consequences.

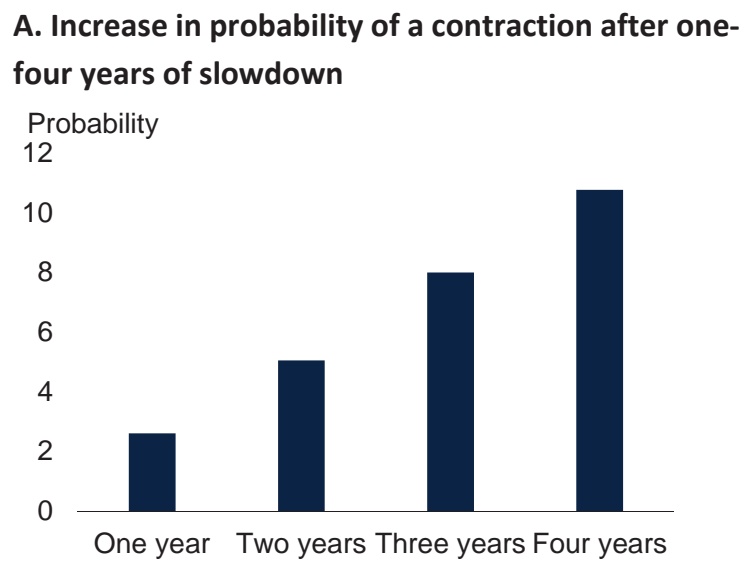

\section{B. Sudden stops and GDP growth}

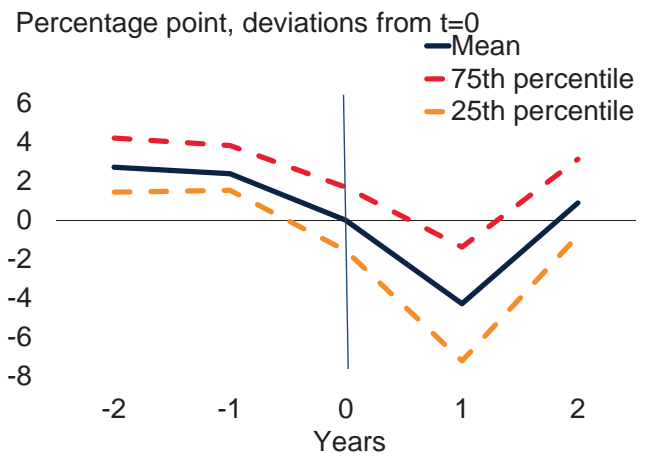

Source: IMF World Economic Outlook, World Bank, Arteta et al (2015).

A. Each column shows the increase in likelihood of entering a contraction in the current year if a growth slowdown of one-four years has begun in the previous year. Estimates are based on a linear probability model. A contraction is defined as negative growth rates, and a slowdown is defined as a lower growth rate than that of the previous year. Estimation includes year fixed-effects to control for the impact of global common shocks. The unconditional sample probability of a contraction is 0.13 . The sample spans $64 \mathrm{EM}$ and FM over 1985-2014. Annex III provides additional details on the empirical exercise. Probability is expressed as percent.

B. Blue line denotes averages for emerging and frontier economies that experienced systemic sudden stops. Dotted lines indicate the $75^{\text {th }}$ and $25^{\text {th }}$ percentiles. A systemic sudden stop is a period when capital flows fall one standard deviation below their historical mean and, at the same time, the VIX index surpasses by one standard deviation its historical mean. The calculations include 21 nonconsecutive systemic sudden stop episodes for 58 emerging and frontier economies in 1995-2014.

Although the U.S. interest rate liftoff and subsequent tightening cycle is expected to proceed smoothly, there is a risk that they lead to abrupt changes in market expectations that could, in turn, prompt a spike in U.S. long-term interest rates, volatility in global financial markets, and a sharp increase in borrowing cost for emerging markets-similar to the way initial discussions of U.S. monetary policy normalization triggered the "taper tantrum" of May-June 2013. If, in response to the liftoff, U.S. long-term bond yields were to jump 100 basis points (as they did during the taper tantrum), capital inflows to emerging markets could decline by up to 2.2 percentage points of GDP over the following year.

Deteriorating external conditions, perhaps resulting from U.S monetary policy tightening or elevated uncertainty about growth prospects in a major EM, could potentially combine with domestic factors into a "perfect storm" by sparking a sudden stop in capital inflows to multiple emerging markets. Especially at risk are countries where vulnerabilities have increased or where there has been uncertainty about policy direction, or where long-term growth prospects have deteriorated significantly (Arteta et al. 2015). Sudden stops in capital flows could thus compound the slowdown already underway in EM (e.g. Becker and Mauro 2006; Hutchison and Noy 2006). The short-run costs of such "systemic" sudden stops can be substantial. In a larger sample of emerging and frontier markets, Arteta et al. (2015) report that output growth declined, on average, almost 7 percentage points and investment growth declined more than 21 percentage points in the two years following a systemic sudden stop (Figure 24).

The protracted growth slowdown in emerging markets since 2010 also raises concerns that it could itself trigger financial stress with significant global implications. A sustained growth slowdown in EM erodes the reserves in private and public sector balance sheets. Eventually, this could lead to a loss of investor 
confidence in the prospects and resilience of these economies and trigger a sharp contraction. Indeed, with every year of slowing growth, the probability of an economic contraction rises (Figure 24). ${ }^{36}$ The spillovers from a slowdown in BRICS to other EM, and from EM to each other and frontier markets may be sizeable (World Bank Forthcoming). In turn, a slowdown in EM could have the potential to derail the fragile global recovery.

\section{B. Poverty: Gains at risk?}

During the 2000s, a rising tide of growth has brought prosperity to many of the world's poorest. In 2000, 37 percent of the global population lived in a low-income country (LIC); today only 8 percent does. A large share of the global population now lives in middle-income countries: 76 percent in 2015, up from 48 back in 2000. Importantly, poverty rates fell sharply during the 2000s such that the Millennium Development Goal on reducing extreme poverty was reached ahead of time, in 2011: the share of the population living on $\$ 1.90$ per day (in constant prices) fell from 29 percent in 1999 to 14 percent in 2011 (Figure 25; World Bank 2015g).

The growth slowdown in major emerging and frontier markets since 2011 thus raises concerns that the significant decline in poverty achieved recently may not be repeated over the next decade or may even be reversed. Even if growth could be sustained at rates over the decade since 2004, the global poverty rate would be around 4 percent. If, however, growth remained at historical average rates-close to currently expected growth rates - until 2030, the global poverty rate would be close to 6 percent (World Bank 2015g). Under most plausible scenarios, the World Bank's goal of lowering the share of the global population living in extreme poverty (on less than $\$ 1.90$ per day) to 3 percent by 2030 would be a challenge to achieve.

\section{Conclusion}

A sustained growth slowdown has been underway in emerging markets since 2010. It has been associated with bouts of financial market volatility, partly as a result of uncertainty about growth prospects. This raises the risk that various adverse developments combine with a weak growth environment to precipitate an episode of intense financial market stress among some EM, which could also derail the still-fragile recovery in advanced economies. Faster growth is also needed to continue progress towards reducing poverty.

The recent slowdown in EM has generated an intense debate about the characteristics, sources, and policy implications of the slowdown. This PRN examines these issues and addresses major questions on the slowdown.

What are the main characteristics of the slowdown? The EM slowdown has been unusually synchronous and protracted. The current slowdown is comparable only to previous episodes of global turmoil, even though this time it is taking place against a backdrop of a weak, but not a stressed external environment.

What are the major drivers of the slowdown? The EM slowdown has been driven by a wide range of external and domestic factors. Among the external developments are weak world trade, low commodity

\footnotetext{
${ }^{36} \mathrm{~A}$ linear regression is estimated of the probability of a contraction in output on dummies indicating the entry into one, two, three, or four years of slowdown in the previous year, controlling for global factors with year dummies. The sample uses annual data for 64 EM and FM over 1985-2014. Annex III provides details of the empirical exercise.
} 


\section{Figure 25. Poverty implications}

EM have accounted for a large share of global poverty reduction over the past 25 years. Slower-than-expected EM growth would add to challenges to reach the World Bank's goal of eradicating extreme poverty-by reducing the share of people living on $\$ 1.90$ per day below 3 percent-by 2030.

\section{A. Evolution of global poverty}

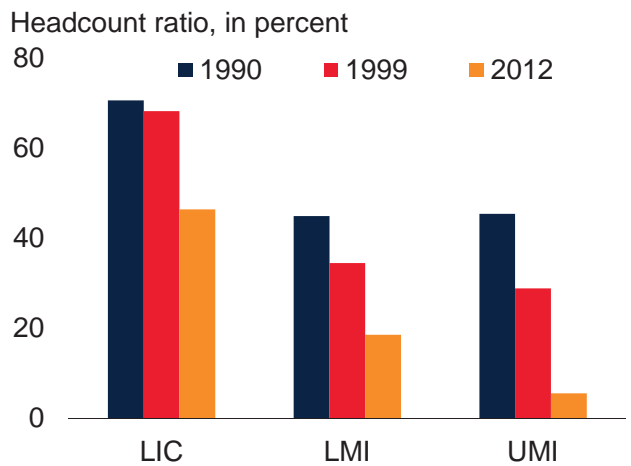

B. Global poverty in 2030 in different growth scenarios

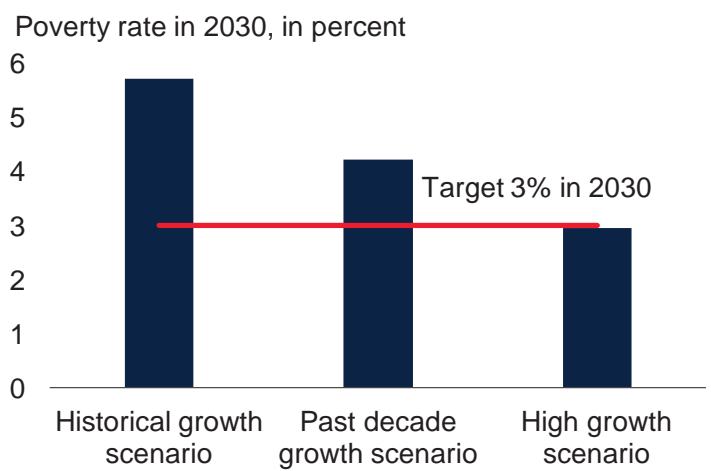

Source: World Bank (2015g)

A. Headcount ratio denotes the share of the population living on less than \$1.90 per day (2011 PPP prices). LIC, LMI, and UMI stand for "Low income Economies," "Lower-middle-income Economies," and "Upper-middle-income Economies," respectively.

B. The "High-growth" scenario is based on the assumption of annual GDP growth of 4.4 percent and household income growth of 3.9 percent, and is the scenario under which the World Bank's poverty reduction goal of a 3 percent poverty rate by 2030 can be achieved. The "past decade growth" scenario assumes that each country grows at the country-specific average rate observed over 2004-2013. The "historical growth" scenario assumes that each country grows at the country-specific average rate observed over 1994-2013.

prices, and the prospects for tightening financial conditions. These external factors have coincided with a cyclical weakening in EM following a short-lived, post-crisis rebound and with domestic structural bottlenecks. Slowing productivity growth and heightened policy uncertainty are domestic challenges that are also shared by many EM. The erosion of policy buffers after the global financial crisis has made it increasingly difficult to stem the growth slowdown through expansionary policies in many countries.

Which policies are available to stimulate growth? The appropriate policy response to slowing growth depends on the degree to which the deceleration stems from cyclical or structural causes. Uncertainty around such an assessment suggests that the optimal mix requires both policy buffers that allow cyclical policy (if available and needed) as well as structural policies to improve medium- and long-term growth prospects. The combination of countercyclical and structural policies could be mutually reinforcing. That said, the room for accommodative cyclical policies is limited in many EM, lending urgency to putting in place structural policies to upgrade governance structures, improve business environments, and manage demographic pressures.

A rough patch or prolonged weakness? EM registered record-high growth rates prior to the global financial crisis. They were also able to manage the global financial crisis well by implementing effective countercyclical fiscal and monetary policies. However, EM now find themselves at a crossroads. The growth slowdown since 2010 could be a rough patch before they recharge their batteries of growth; alternatively, it could signal the start of an era of weak growth, especially, given repeated forecast downgrades and the persistent nature of the factors that have driven the slowdown so far. In light of the significant global risks going forward, EM need urgently to strengthen policies to promote growth. 


\section{Annex I. Country Classification}

Emerging market economies (EM) generally include countries with a long-established record of significant access to international financial markets. Frontier market economies (FM) include countries that are usually smaller and less financially developed than EM, and with more limited access to international capital markets. EM include 24 countries that are classified as Emerging Markets in at least two of the three stock indexes by S\&P, FTSE, and MSCl. FM include 40 countries that are classified as Frontier Markets by at least two of the same three indexes.

\section{Table Al.1. List of Countries}

\begin{tabular}{|c|c|c|c|c|c|c|}
\hline \multicolumn{2}{|c|}{ Emerging markets } & \multicolumn{3}{|c|}{ Frontier markets } & \multicolumn{2}{|c|}{ Advanced economies } \\
\hline Brazil & Morocco & Argentina & Ghana & Panama & Australia & Japan \\
\hline Chile & Pakistan & Azerbaijan & Guatemala & Paraguay & Austria & Luxembourg \\
\hline China & Peru & Bahrain & Honduras & Romania & Belgium & Malta \\
\hline Colombia & Philippines & Bangladesh & Jamaica & Senegal & Canada & Netherlands \\
\hline Czech Rep. & Poland & Bolivia & Jordan & Serbia & Denmark & New Zealand \\
\hline Egypt & Qatar & Botswana & Kazakhstan & Sri Lanka & Finland & Norway \\
\hline Hungary & Russia & Bulgaria & Kenya & Tunisia & France & Portugal \\
\hline India & Saudi Arabia & Costa Rica & Kuwait & Ukraine & Germany & Singapore \\
\hline Indonesia & South Africa & Côte d'Ivoire & Lebanon & Uruguay & Greece & Spain \\
\hline Korea & Thailand & Croatia & Mauritius & Venezuela & Hong Kong & Sweden \\
\hline Malaysia & Turkey & Ecuador & Mongolia & Vietnam & Iceland & Switzerland \\
\hline \multirow[t]{3}{*}{ Mexico } & UAE & El Salvador & Namibia & Zambia & Ireland & United Kingdom \\
\hline & & Gabon & Nigeria & & Italy & United States \\
\hline & & Georgia & Oman & & & \\
\hline
\end{tabular}




\section{Annex II. The Middle-Income Trap: A Brief Literature Review}

The growth slowdown in EM raises concerns that many of these middle-income countries would be unable to generate sufficiently high growth to emerge to high-income status. Indeed, as documented by Gill and Kharas $(2007,2015)$, most middle-income economies have failed to converge to the US in per capita income over 1960-2012 and remained in a "middle-income trap". A large literature (Table A2.1) has explored the factors that drive countries into the middle-income trap and those that lift them out of it. This Annex presents a brief review of the literature to address the following questions. First, what is the middle-income trap? Second, what are the causes of the middle-income trap? Third, which policies could help avert or exit the middle-income trap?

What is the middle-income trap? The term "middle income trap" was coined by Gill and Kharas (2007). It describes an extended period of stagnation at a certain level of per capita income. Growth appears to slow by 2-3 percentage points when per capita income reaches around $\$ 16,700-\$ 17,000$ (in 2005 prices; Eichengreen, Park, and Shin 2012). Eichengreen, Park, and Shin (2013) argue that high growth in middleincome countries may decelerate in discrete steps in two ranges of per capita incomes $(\$ 10,000-\$ 11,000$ and $\$ 15,000-\$ 16,000$, in 2005 prices). Other authors have interpreted the middle-income trap as a result of misguided policies rather than a statistical pattern around key income thresholds. A policy focus on maintaining fast growth in middle-income countries may lead to unsustainable policies that eventually create the "trap-like" pattern of low growth (Im and Rosenblatt 2013).

What are the causes of the middle-income trap? The middle-income trap has been attributed to slowing productivity growth and rising factor input cost as per capita income grows. About 85 percent of the growth slowdowns in middle-income countries can be explained by slowing total factor productivity growth, which partly reflects diminishing gains from sectoral reallocation of labor and capital and from reliance on imported foreign technology (Agénor and Canuto 2012; Eichengreen, Park, and Shin 2012). As per capita income rises, labor cost (Agénor and Canuto 2012) increases, which slows the shift towards higher value-added products and reduces competitiveness (Lin and Treichel 2012). The determinants of growth appear to differ at low and high-income levels: capital accumulation becomes a less effective growth strategy as economies transition to high-income status (Bulman, Eden, and Nguyen 2014).

Which policies could help avert or exit the middle-income trap? Policy recommendations have focused on improving competitiveness, sustaining technological upgrading, and ensuring macroeconomic stability. Policies to strengthen competitiveness include establishing better institutions and macroeconomic policies, more flexible labor markets, stronger property rights and more modern infrastructure (Hall and Jones 1999; Roller and Waverman 2001; Berg, Ostry, and Zettelmeyer 2012; Lin and Treichel 2012; Aiyar et al. 2013; Gill and Kharas 2015). Greater trade integration in the high-tech sector and openness to foreign direct investment can facilitate technological spillovers from advanced countries (Berg, Ostry, and Zettelmeyer 2012; Aiyar et al. 2013; Eichengreen, Park, and Shin 2013; Arias and Wen 2015; Gill and Kharas 2015). Improved education system, more dynamic R\&D activity, and less high-skilled outward migration could further help absorb and develop technological advances (Sala-i-Martin, Doppelhofer, and Miller 2004; Weinberg 2011; Lin and Treichel 2012; Eichengreen, Park, and Shin 2013). Finally, the sustainability of growth is key to avoiding a growth slowdown at middle-income levels. This includes avoiding exchange rate misalignments (Berg, Ostry, and Zettelmeyer 2012; Eichengreen, Park, and Shin 2012) and maintaining fiscal and external sustainability (Zhuang, Vandenberg and Huang 2012). 
Table All.1. Middle-Income Trap: Selected Studies

\begin{tabular}{|c|c|c|}
\hline Authors & Methodology & Objectives and Results \\
\hline $\begin{array}{l}\text { Agénor and } \\
\text { Canuto, } 2012\end{array}$ & $\begin{array}{l}\text { Theoretical Model. } \\
\text { Two-period } \\
\text { overlapping } \\
\text { generations model }\end{array}$ & $\begin{array}{l}\text { Evidence for middle-income trap in a two-period overlapping generations model of growth with } \\
\text { endogenous occupational choices. } \\
\text { - Improved access to advanced infrastructure may help exit from the middle-income growth trap. } \\
\text { - Policy recommendations include property rights protection and flexible labor markets. }\end{array}$ \\
\hline $\begin{array}{l}\text { Agénor, Canuto, } \\
\text { and Jelenic, } \\
2014\end{array}$ & $\begin{array}{l}\text { Theoretical Model. } \\
\text { Two-period } \\
\text { overlapping } \\
\text { generations model }\end{array}$ & $\begin{array}{l}\text { Impact of financial access, product innovation, and labor supply on the likelihood of entering the } \\
\text { middle-income trap using an OLG model with endogenous distribution and credit market frictions. } \\
\text { - Multiple equilibria may emerge in the model, one of which is a middle-income trap characterized } \\
\text { by low wages in the design sector, a low share of the labor force engaged in innovation activity, } \\
\text { and low growth. } \\
\text { - Policies aimed at promoting the production of ideas and improving incentives to invest in skills } \\
\text { may allow a country to move away from the middle-income trap. }\end{array}$ \\
\hline $\begin{array}{l}\text { Aiyar, Duval, } \\
\text { Puy, Wu, and } \\
\text { Zhang, } 2013\end{array}$ & $\begin{array}{l}\text { Probit regression \& } \\
\text { Bayesian Model } \\
\text { Averaging }\end{array}$ & $\begin{array}{l}\text { Determinants of the middle-income trap. } \\
\text { - The middle-income trap is defined as a special case of growth slowdowns and is identified as a } \\
\text { large sudden and sustained deviation from the growth path predicted by a basic conditional } \\
\text { convergence framework. } \\
\text { - Roles of institutions, demography, infrastructure, the macroeconomic environment, output } \\
\text { structure and trade structure are important in driving the likelihood of middle-income traps. }\end{array}$ \\
\hline $\begin{array}{l}\text { Berg, Ostry, and } \\
\text { Zettelmeyer, } \\
2012\end{array}$ & $\begin{array}{l}\text { Identify structural } \\
\text { breaks in economic } \\
\text { growth in } 140 \\
\text { countries \& } \\
\text { regression analysis }\end{array}$ & $\begin{array}{l}\text { Drivers of sustained growth. } \\
\text { - Growth duration is positively associated with these factors: the degree of equality in income } \\
\text { distribution; democratic institutions; export orientation (higher propensities to export } \\
\text { manufactures, greater openness to FDI, and avoidance of overvalued exchange rates); } \\
\text { macroeconomic stability. }\end{array}$ \\
\hline
\end{tabular}




\begin{tabular}{|c|c|c|}
\hline Authors & Methodology & Objectives and Results \\
\hline $\begin{array}{l}\text { Bulman, Eden, } \\
\text { and Nguyen, } \\
2014\end{array}$ & Regression Analysis & $\begin{array}{l}\text { Pattern of growth at middle-income levels. } \\
\text { - Find evidence that the determinants of growth at low and high-income levels differ. } \\
\text { - Middle-income countries may need to change growth strategies to transition smoothly to high- } \\
\text { income status, but this does not imply the existence of a middle-income trap. }\end{array}$ \\
\hline $\begin{array}{l}\text { Eichengreen, } \\
\text { Park, and Shin, } \\
2012\end{array}$ & $\begin{array}{l}\text { Regression analysis } \\
\text { using international } \\
\text { data starting in } 1957\end{array}$ & $\begin{array}{l}\text { Growth patterns of middle income countries, with a focus on structural slowdowns. } \\
\text { - Rapidly growing economies slow down significantly: growth rate downshifts by at least } 2 \\
\text { percentage points when their per capita incomes reach around } \$ 17,000 \text { in } 2005 \text { constant } \\
\text { international prices. } \\
\text { - Growth slowdowns are more likely in countries that maintain undervalued real exchange rates. }\end{array}$ \\
\hline $\begin{array}{l}\text { Eichengreen, } \\
\text { Park, and Shin, } \\
2013\end{array}$ & $\begin{array}{l}\text { Regression analysis } \\
\text { using international } \\
\text { data starting in } 1957\end{array}$ & $\begin{array}{l}\text { Incidence and correlates of growth slowdowns in fast-growing middle-income countries. } \\
\text { - A number of countries appear to have experienced two slowdowns, one in the } \$ 10,000-\$ 11,000 \\
\text { range (based on } 2005 \text { constant international prices) and another in the } \$ 15,000-\$ 16,000 \text { range. } \\
\text { - Slowdowns are less likely in countries that have relatively high levels of secondary and tertiary } \\
\text { education and in which high-technology products account for a relatively large share of exports. }\end{array}$ \\
\hline $\begin{array}{l}\text { Felipe, Kumar, } \\
\text { and Galope, } \\
2014\end{array}$ & $\begin{array}{l}\text { Cross country case } \\
\text { study }\end{array}$ & $\begin{array}{l}\text { Historical transitions across income groups. } \\
\text { - Historically, it has taken a "typical" economy } 55 \text { years to graduate from lower middle income } \\
\text { (\$2,000 in } 1990 \text { purchasing power parity [PPP] dollars) to upper-middle income }(\$ 7,250 \text { in } 1990 \\
\text { PPP \$). } \\
\text { - Historically, it has taken } 15 \text { years for an economy to graduate from upper-middle income to high } \\
\text { income (above } \$ 11,750 \text { in } 1990 \text { PPP dollars). } \\
\text { - As of } 2013 \text {, there were } 10 \text { (out of } 39 \text { ) lower-middle-income economies and } 4 \text { (out of } 15 \text { ) upper- } \\
\text { middle income economies that were experiencing slow transitions (i.e., above } 55 \text { and } 15 \text { years, } \\
\text { respectively). }\end{array}$ \\
\hline
\end{tabular}




\begin{tabular}{|c|c|c|}
\hline Authors & Methodology & Objectives and Results \\
\hline $\begin{array}{l}\text { Felipe, Abdon } \\
\text { and Kumar, } \\
2012\end{array}$ & $\begin{array}{l}\text { Cross country case } \\
\text { study based on } 124 \\
\text { countries that have } \\
\text { consistent data for } \\
\text { 1950-2010 }\end{array}$ & $\begin{array}{l}\text { Working definition of the middle-income trap and threshold number of years for a country to stay in } \\
\text { the middle-income trap. } \\
\text { - A country that becomes lower middle-income (i.e., reaches } \$ 2,000 \text { per capita income in } 1990 \text { PPP } \\
\text { dollars) has to attain an average annual per capita income growth rate of at least } 4.7 \text { percent to } \\
\text { avoid falling into the lower middle-income trap (i.e., to reach } \$ 7,250 \text {, the upper middle-income } \\
\text { level threshold). } \\
\text { - A country that becomes upper middle-income (i.e., reaches } \$ 7,250 \text { per capita income) has to } \\
\text { attain an average annual per capita income growth rate of at least } 3.5 \text { percent to avoid falling } \\
\text { into the upper middle income trap (i.e., to reach } \$ 11,750 \text {, the high-income level threshold). }\end{array}$ \\
\hline $\begin{array}{l}\text { Lin and Treichel, } \\
2012\end{array}$ & Case study & $\begin{array}{l}\text { Causes of the middle-income trap in Latin America and Caribbean; challenges and opportunities that } \\
\text { China's rise brings for Latin America. } \\
\text { - Countries in Latin America and Caribbean are caught in a middle-income trap due to their inability } \\
\text { to upgrade from low value-added to high value-added products. } \\
\text { - The region could achieve dynamic growth through continuous structural upgrading in sectors } \\
\text { intensive in factors such as natural resources, scientific knowledge, and unskilled labor. This } \\
\text { would require investments in education, research and development, and physical infrastructure. }\end{array}$ \\
\hline $\begin{array}{l}\text { Zhuang, } \\
\text { Vandenberg, } \\
\text { and Huang, } \\
2012\end{array}$ & Case study & $\begin{array}{l}\text { How China can avoid the middle-income trap. } \\
\text { - Avoiding the middle-income trap requires continuous industrial upgrading through innovation } \\
\text { and moving from a low-cost to a high-value economy. } \\
\text { - Moving from a low-cost to a high-value economy requires a critical mass of firms with strong } \\
\text { incentives for innovation. It also requires the government to create a conducive macroeconomic } \\
\text { and market environment. }\end{array}$ \\
\hline
\end{tabular}




\section{Annex III. Empirical Methodology}

\section{A. Bayesian VAR Estimation - External vs domestic Shocks (Figure 8)}

The estimation consists of a nonstructural Bayesian VAR (BVAR) for $18 \mathrm{EM}$. The baseline model has 8 variables: real GDP growth, 5 external variables and 3 domestic variables. The model quantifies the growth effects of the external shocks and domestic shocks.

External variables include the following:

US real GDP growth (pp -- log difference)

US 10-yr Treasury Bond rate (pp)

China GDP growth (pp -- log difference)

EMBI Yield (pp)

Terms-of-trade growth (pp -- log difference)

Domestic variables include the following:

Domestic inflation rate ( $p p$-- log difference)

Rate of real exchange rate appreciation versus USD ( $\mathrm{pp}$-- log difference)

Domestic short-term interest rate $(\mathrm{pp})$

The Cholesky decomposition is used to identify shocks, with ordering of the variables above.

The data series are quarterly, ranging from 1998:Q1 to 2015:Q2. The model is estimated for each of the 18 countries in the sample. The sample includes the following countries: Brazil, Chile, China, Colombia, Czech Republic, Hungary, India, Indonesia, Korea, Malaysia, Mexico, Peru, Philippines, Poland, Russia, South Africa, Thailand, Turkey.

\section{B. Growth effects of reforms (Figure 22A)}

Values in columns of Figure 22A are based on a panel data regression in which the dependent variable is real GDP growth. A spurt (setback) is defined as a two-year increase (decrease) by two standard deviations in one or more of the following four measures of the WGI index: regulatory quality, government effectiveness, rule of law, and control of corruption. The WGI indicators are principal components of a wide range of survey-based and other indicators. For each index, the standard deviation is measured as the average of the standard errors of the WGI index in the beginning and at the end of each two-year interval. Episodes in which there were improvements in one measure and simultaneous setbacks in another are excluded. The sample spans 64 EM and FM over 1996-2014.

Let $t$ denote the end of a two-year spurt or setback. The coefficients are dummy variables for spurts and setbacks over the $[t-3, t+2]$ window around these episodes. In figure 22A, "Reform" denotes the $t=[-1,0]$ window (i.e. during the two years of improvement/deterioration). "Pre-reform" denotes the $t=[-3,-2]$ window. For each window, each column shows the sum of coefficients. Reform spurts associated with (and without, though not shown in chart) an IMF program are estimated in a separate regression. All coefficients show the growth differential of economies during an episode compared to those that experienced neither improvements nor setbacks. All estimates include time fixed effects to control for global common shocks and country fixed effects to control for time-invariant heterogeneity at the country-level. Under robust standard errors, estimates during the reform spurt window are jointly significant at the 10 percent level, and likewise for the reform setback window. The growth differentials during reform spurts associated with IMF programs are jointly significant at the 1 percent level. 


\section{Probability of contraction (Figure 24A).}

The estimates in the columns of figure $24 \mathrm{~A}$ are based on a linear regression in which the dependent variable equals to 1 if an economy has experienced a contraction in growth in year $t$. The independent variables equal to 1 if in the previous year (t-1), growth has begun to slow down for the number of consecutive years denoted in the column, and 0 otherwise. A slowdown in growth is defined as a lower growth rate than that of the previous year. The following table shows the regression estimates.

\begin{tabular}{lc}
\hline Dependent variable: & \\
$=1$ if economy experiences a contraction in year $\mathrm{t}$ \\
\hline & \\
One-year slowdown [t-1] & 0.026 \\
& $(0.018)$ \\
Two-year slowdown [t-1] & $0.051^{* *}$ \\
& $(0.025)$ \\
Three-year slowdown [t-1] & $0.080^{*}$ \\
& $(0.042)$ \\
Four-year slowdown [t-1] & $0.108^{*}$ \\
& $(0.058)$ \\
& \\
$\mathrm{R}^{2}$ & \\
Observations & 0.10 \\
\hline
\end{tabular}

Note: The coefficient estimates show the increase in likelihood of entering a contraction in the current year if a slowdown of one-four years has begun in the previous year. Robust standard errors are in parentheses. ${ }^{* *}$ and $*$ denote significance at the 5 and 10 percent levels, respectively. Estimation includes year fixed effects. The unconditional sample probability of a contraction is 0.13 . The sample spans $1985-2014$ across 64 EM and FM. 


\section{REFERENCES}

Abiad, A., J. Bluedorn, J. Guajardo, and P. Topalova. 2012. "The Rising Resilience of Emerging Market and Developing Economies." Working Paper 12/300, International Monetary Fund, Washington, DC.

Agénor, P-R., M. K. Nabli, T. Yousef, and H.T. Jensen. 2007. "Labor Market Reforms, Growth, and Unemployment in Labor-Exporting Countries in the Middle East and North Africa." Journal of Policy Modeling 29 (2): 277-309.

Agénor, P-R., and O. Canuto. 2012. “Middle-Income Growth Traps.” Policy Research Working Paper 6210, World Bank, Washington, DC.

Agénor, P-R., O. Canuto, and M. Jelenic. 2014. “Access to Finance, Product Innovation and Middle-Income Traps." Policy Research Working Paper 6767, World Bank, Washington, DC.

Aghion, P., R. Burgess, S. J. Redding, and F. Zilibotti. 2008. "The Unequal Effects of Liberalization: Evidence from Dismantling the License Raj in India." American Economic Review, 98 (4): 1397-1412.

Ahmed, S., M. Appendino, and M. Ruta. 2015. "Depreciations without Exports? Global Value Chains and the Exchange Rate Elasticity of Exports." Policy Research Working Paper 7390, World Bank, Washington, DC.

Aiyar, S. and A. Mody. 2011. "The Demographic Dividend: Evidence from the Indian States." Working Paper 11/38, International Monetary Fund, Washington, DC.

Aiyar, S., R. Duval, D. Puy, Y. Wu, and L. Zhang. 2013. "Growth Slowdowns and the Middle-Income Trap." Working Paper 13/71, International Monetary Fund, Washington, DC.

Aksoy, Y., H. S. Basso, T. Grasl, and R. P. Smith. 2015. "Demographic Structure and Macroeconomic Trends." Working Paper 1501, Birkbeck Department of Economics, Mathematics \& Statistics, University of London, London.

Anand, R., K. C. Cheng, S. Rehman, and L. Zhang. 2014. "Potential Growth in Emerging Asia." Working Paper 14/2, International Monetary Fund, Washington, DC.

Arias, M.A., and Y. Wen. 2015. "Trapped: Few Developing Countries Can Climb the Economic Ladder or Stay There." The Regional Economist, Oct 2015. St. Louis: Federal Reserve Bank of St. Louis.

Arnold, J., B. Javorcik, M. Lipscomb, and A. Mattoo. Forthcoming. "Services Reform and Manufacturing Performance: Evidence from India." The Economic Journal.

Arteta, C., M. A. Kose, F. Ohnsorge, and M. Stocker. 2015. "The Coming U.S. Interest Rate Tightening Cycle: Smooth Sailing or Stormy Waters?” Policy Research Note 2, World Bank, Washington, DC.

Aslund, A. 2013. "Why Growth in Emerging Economies is Likely to Fall." Working Paper 13-10, Peterson Institute for International Economics, Washington, DC.

Baffes, J., M. A. Kose, F. Ohnsorge, and M. Stocker. 2015. "The Great Plunge in Oil Prices: Causes, Consequences, and Policy Responses." Policy Research Note 1, World Bank, Washington DC.

Baker, S. R., N. Bloom, and S. J. Davis. 2013. "Measuring Economic Policy Uncertainty." Research Paper 13-02, Chicago Booth School of Business, Chicago. 
Barrell, R., I. Hurst, and S. Kirby. 2009. "How to Pay for the Crisis or Macroeconomic Implications of Pension Reform." Discussion Paper 333, National Institute of Economic and Social Research, London.

Barro, R. 1991. "Economic Growth in a Cross Section of Countries." The Quarterly Journal of Economics 106 (2): 407-443.

Bassanini, A., and D. Venn. 2008. "The Impact of Labour Market Policies on Productivity in OECD Countries." International Productivity Monitor 17(Fall): 3-15.

Beck, T., and A. Demirguc-Kunt. 2006. "Small and Medium-Size Enterprises: Access to Finance as a Growth Constraint." Journal of Banking and Finance 30(11): 2931-2943.

Becker, T., and P. Mauro. 2006. "Output Drops and the Shocks that Matter." Working Paper 06/172, International Monetary Fund, Washington, DC.

Berg, A., J. D. Ostry, and J. Zettelmeyer. 2012. "What Makes Growth Sustained?” Journal of Development Economics 98 (2): 149-166.

Blanchard, O., F. Jaumotte, and P. Loungani. 2013. "Labor Market Policies and IMF Advice in Advanced Economies during the Great Recession." Staff Discussion Note 13/02, International Monetary Fund, Washington, DC.

Blanchard, O., and F. Giavazzi. 2003. "Macroeconomic Effects of Regulation and Deregulation in Goods and Labor Markets." The Quarterly Journal of Economics 118 (3): 879-907.

Bloom, D., and D. Canning. 2004. "Global Demographic Change: Dimensions and Economic Significance." Working Paper 10817, National Bureau of Economic Research, Cambridge.

Bloom, D., D. Canning, and J. Sevilla. 2003. The Demographic Dividend: A New Perspective on the Economic Consequences of Population Change. Santa Monica: RAND Corporation.

Bom, P. R. D., and J. E. Ligthart. 2014. "What Have We Learned From Three Decades of Research on the Productivity of Public Capital?" Journal of Economic Surveys 28 (5): 889-916.

Bosker, M., U. Deichmann, and M. Roberts. 2015. "Hukou and Highways: The Impact of China's Spatial Development Policies on Urbanization and Regional Inequality." Policy Research Working Paper 7350, World Bank, Washington, DC.

Bown, C. P. 2014. "Temporary Trade Barriers Database." The World Bank, June, available at http://econ.worldbank.org/ttbd/.

Branstetter, L., F. Lima, L. J. Taylor, and A. Venâncio. 2014. “Do Entry Regulations Deter Entrepreneurship and Job Creation? Evidence from Recent Reforms in Portugal." The Economic Journal 124 (577): 805-832.

Brender, A., and A. Drazen. 2008. "How Do Budget Deficits and Economic Growth Affect Reelection Prospects? Evidence from a Large Panel of Countries." American Economic Review 98 (5): 2203-20.

Bruhn, M. 2011. "License to Sell: The Effect of Business Registration Reform on Entrepreneurial Activity in Mexico." The Review of Economics and Statistics 93 (1): 382-86.

Bruhn, M. 2013. "A Tale of Two Species: Revisiting the Effect of Registration Reform on Informal Business Owners in Mexico." Journal of Development Economics 103: 275-283. 
Bruhn, M., and I. Love. 2014. "The Real Impact of Improved Access to Finance: Evidence from Mexico." Journal of Finance 69 (3): 1347-1376.

Bulman, D., M. Eden, and H. Nguyen. 2014. "Transitioning from Low-Income Growth to High-Income Growth. Is There a Middle Income Trap?" Policy Research Working Paper 7104, World Bank, Washington, DC.

Burns, A., T. J. van Rensburg, K. Dybczak, and T. Bui. 2014. "Estimating Potential Output in Developing Countries." Journal of Policy Modeling 36 (4): 700-716.

Calderón, C., and L. Servén. 2008. "Infrastructure and Economic Development in Sub-Saharan Africa." Policy Research Working Paper 4712, World Bank, Washington, DC.

Calderón, C., and L. Servén. 2010. "Infrastructure in Latin America." Policy Research Working Paper 5317, World Bank, Washington, DC.

Calderón, C., and L. Servén. 2014. "Infrastructure, Growth, and Inequality: an Overview." Policy Research Working Paper 7034, World Bank, Washington, DC.

Carrière-Swallow, Y., and L. F. Céspedes. 2013. "The Impact of Uncertainty Shocks in Emerging Economies." Journal of International Economics 90 (2): 316-325.

Chinn, M. D. 2014. "Central Banking: Perspectives from Emerging Economies." Working Paper 2014-006, La Follette School of Public Affairs Working Paper Series, University of Wisconsin, Madison.

Chinn, M. D., and H. Ito. 2006. "What Matters for Financial Development? Capital Controls, Institutions, and Interactions." Journal of Development Economics 81 (1): 163-192.

Claessens, S., and L. Laeven. 2003. "Financial Development, Property Rights, and Growth." Journal of Finance 58 (6): 2401-2436.

Cooley, T., R. Marimon, and V. Quadrini. 2004. "Aggregate Consequences of Limited Contract Enforceability." Journal of Political Economy 112 (4): 817-847.

Constantinescu, C., A. Mattoo, and M. Ruta. 2014. “Global Trade Slowdown: Cyclical or Structural?” Paper presented at Third International Monetary Fund/World Bank/World Trade Organization Workshop, Washington, DC, November 6-7.

Cournède, B., and F. Gonand. 2006. "Restoring Fiscal Sustainability in the Euro Area: Raise Taxes or Curb Spending." Economics Department Working Paper 520, Organisation for Economic Co-operation and Development, Paris.

Cubeddu, L., et al. 2014. "Emerging Markets in Transition: Growth Prospects and Challenges." Staff Discussion Note 14/06, International Monetary Fund, Washington, DC.

D’Auria, F., et al. 2010. "The Production Function Methodology for Calculating Potential Growth Rates and Output Gaps." Economic Paper 420. Directorate-General for Economic and Financial Affairs, European Commission, Brussels.

Dabla-Norris, E., G. Ho, K. Kochhar, A. Kyobe, and R. Tchaidze. 2013. "Anchoring Growth: The Importance of Productivity-Enhancing Reforms in Emerging Market and Developing Economies." Staff Discussion Note 13/08, International Monetary Fund, Washington, DC. 
De Gregorio, J. 2015. "From Rapid Recovery to Slowdown: Why Recent Economic Growth in Latin America has been Slow." Policy Brief 15-6, Peterson Institute for International Economics, Washington, DC.

De la Torre, A., T. Didier, A. Ize, D. Lederman, and S. Schmukler. 2015. Latin America and the Rising South: Changing World, Changing Priorities. Washington, DC: World Bank.

Deininger, K., S. Jin, S. Liu, T. Shao, and F. Xia. 2015. “Impact of Property Rights Reform to Support China's Rural-Urban Integration: Village-Level Evidence from the Chengdu National Experiment." Policy Research Working Paper 7389, World Bank, Washington, DC.

Dervis, K. 2014. "Tailspin or Turbulence?" Project Syndicate, February 17.

Dervis, K. 2015. “Will Technology Kill Convergence." Project Syndicate, October 15.

Desai, M., P. Gompers, and J. Lerner. 2003. "Institutions, Capital Constraints and Entrepreneurial Firm Dynamics: Evidence from Europe." Working Paper 10165, National Bureau of Economic Research, Cambridge.

Dethier, J-J., M. Hirn, and S. Straub. 2008. "Explaining Enterprise Performance in Developing Countries with Business Climate Survey Data." Policy Research Working Paper 4792, World Bank, Washington, DC.

Devereux, M., P. R. Lane, and J. Xu. 2006. "Exchange Rates and Monetary Policy in Emerging Market Economies." The Economic Journal 116 (April): 478-506.

Dinkelman, T. 2011. "The Effects of Rural Electrification on Employment: New Evidence from South Africa." American Economic Review 101 (7): 3078-3108.

Divanbeigi, R., and R. Ramalho. 2015. "Business Regulations and Growth." Policy Research Working Paper 7299, World Bank, Washington, DC.

Djankov, S., C. McLiesh, and R. Ramalho. 2006. "Regulation and Growth." Economics Letters 92 (3): 395401.

Edwards, S., and A. C. Edwards. 2000. "Economic Reforms and Labour Markets: Policy Issues and Lessons from Chile." Economic Policy 15 (30): 181-230.

Eichengreen, B., D. Park, and K. Shin. 2012. "When Fast-Growing Economies Slow Down: International Evidence and Implications for China." Asian Economic Papers 11 (1): 42-87.

Eichengreen, B., D. Park, and K. Shin. 2013. "Growth Slowdowns Redux: New Evidence on the MiddleIncome Trap." Working Paper 18673, National Bureau of Economic Research, Cambridge.

Emmott, B. 2015. "The Great Emerging-Market Bubble." Project Syndicate, August 17.

Estache, A., E. Ianchovichina, R. Bacon, and I. Salamon. 2013. Infrastructure and Employment Creation in the Middle East and North Africa. Washington, DC: World Bank.

Estevão, M., and I. Samake. 2013. "The Economic Effects of Fiscal Consolidation with Debt Feedback." Working Paper 13/136, International Monetary Fund, Washington, DC.

European Bank for Reconstruction and Development. 2015. "Regional Economic Prospects in EBRD Countries of Operations May 2015. In the Cross-currents of Diverging Monetary Policies and Russia's Recession." European Bank for Reconstruction and Development, London. 
Fayad, G., and R. Perrelli. 2014. "Growth Surprises and Synchronized Slowdowns in Emerging Markets An Empirical Investigation." Working Paper 14/173, International Monetary Fund, Washington, DC.

Felipe, J., A. Abdon, and U. Kumar. 2012. "Tracking the Middle-Income Trap: What is it, Who is in it, and Why?" Working Paper 715, Levy Economics Institute, Bard College, New York.

Felipe, J., U. Kumar, and R. Galope. 2014. “Middle-Income Transitions: Trap or Myth?” Economics Working Paper 421, Asian Development Bank, Manila.

Fernald, J. G. 1999. "Roads to Prosperity? Assessing the Link between Public Capital and Productivity." American Economic Review 89 (3): 619-638.

Feyen, E., K. Kibuuka, and I. Ötker-Robe. 2012. "Bank Deleveraging: Causes, Channels, and Consequences for Emerging Market and Developing Countries." Policy Research Working Paper 6086, World Bank, Washington, DC.

Francois, J., and M. Manchin. 2013. "Institutions, Infrastructure, and Trade." World Development 46: 165175.

Gill, I. S., and H. Kharas. 2007. An East Asian Renaissance: Ideas for Economic Growth. Washington DC: World Bank.

Gill, I. S., and H. Kharas. 2015. "The Middle-Income Trap Turns Ten." Policy Research Working Paper 7403. World Bank, Washington, DC.

Gonzalez-Navarro, M., and C. Quintana-Domeque. 2010. "Street Pavement: Results from an Infrastructure Experiment in Mexico." Working Paper 556, Princeton University Industrial Relations Section, New Jersey.

Gourio, F., M. Siemer, A. Verdelhan. 2014. "Uncertainty and International Capital Flows." Unpublished manuscript, Massachusetts Institute of Technology, Cambridge.

Group of Twenty. 2015. Fostering Strong, Sustainable and Balanced Growth in 2016 and Beyond: A Reflection on Potential Priorities for the Framework Working Group. Group of Twenty, Cannes.

Gruss, B. 2014. "After the Boom-Commodity Prices and Economic Growth in Latin America and the Caribbean." Working Paper 14/154, International Monetary Fund, Washington, DC.

Gupta, P., and A. Panagariya. 2014. "Growth and Election Outcomes in a Developing Country." Economics \& Politics 26 (2): 332-354.

Gupta, S., A. Kangur, C. Papageorgiou, and A. Wane. 2014. "Efficiency-Adjusted Public Capital and Growth." World Development 57: 164-178.

Hall, R. E., and C. I. Jones. 1999. "Why Do Some Countries Produce So Much More Output Per Worker Than Others?" The Quarterly Journal of Economics 114 (1): 83-116.

Hammond, G. 2012. State of the Art of Inflation Targeting-2012. Handbook 29, Centre for Central Banking Studies, London: Bank of England.

Hanusch, M. 2012. "The Doing Business Indicators, Economic Growth and Regulatory Reform." Policy Research Working Paper 6176, World Bank, Washington, DC.

Hausmann, R. 2013. "The End of the Emerging-Market Party." Project Syndicate, August 30.

Henry, P.B. 2013. Turnaround: Third World Lessons for First World Growth. Philadelphia: Basic Books. 
Higgins, M. 1998. "Demography, National Savings, and International Capital Flows." International Economic Review 39 (2): 343-369.

Hsieh, C.-T. and P. Klenow. 2009. "Misallocation and Manufacturing TFP in China and India." The Quarterly Journal of Economics 124 (4): 1403-1448.

Hutchison, M. M., and I. Noy. 2006. "Sudden Stops and the Mexican Wave: Currency Crises, Capital Flow Reversals and Output Loss in Emerging Markets." Journal of Development Economics 79 (1): 225-248.

Ilzetzki, E., E. G. Mendoza, and C. A. Végh. 2013. "How Big (Small?) are Fiscal Multipliers?” Journal of Monetary Economics 60 (2): 239-254.

Im, F. G., and D. Rosenblatt. 2013. "Middle-Income Traps: A Conceptual and Empirical Survey." Policy Research Working Paper 6594, World Bank, Washington, DC.

Inter-American Development Bank. 2013. Rethinking Reforms: How Latin America and the Caribbean can Escape Suppressed World Growth. 2013 Latin American and Caribbean Macroeconomic Report. Washington, DC: Inter-American Development Bank.

International Monetary Fund. 2005. Global Imbalances: A Saving and Investment Perspective. World Economic Outlook, Appendix 2.1, Chapter 2, Sept 2015. Washington, DC: International Monetary Fund.

International Monetary Fund. 2013. Breaking through the Frontier: Can Today's Dynamic Low-Income Countries Make It? World Economic Outlook, Chapter 4, April 2013. Washington, DC: International Monetary Fund.

International Monetary Fund. 2014a. On the Receiving End? External Conditions and Emerging Market Growth Before, During, and After the Global Financial Crisis. World Economic Outlook, Chapter 4, April 2014. Washington, DC: International Monetary Fund.

International Monetary Fund. 2014b. Is it Time for an Infrastructure Push? The Macroeconomic Effects of Public Investment. World Economic Outlook, Chapter 3, October 2014. Washington, DC: International Monetary Fund.

International Monetary Fund. 2015a. Where are We Headed? Perspectives on Potential Output. World Economic Outlook, Chapter 3, April 2015. Washington, DC: International Monetary Fund.

International Monetary Fund. 2015b. Annual Report on Exchange Arrangements and Exchange Restrictions 2015. Washington, DC: International Monetary Fund.

Jamasb, T., R. Nepal, and G. R. Timilsina. 2015. "A Quarter Century Effort Yet to Come of Age: A Survey of Power Sector Reforms in Developing Countries." Policy Research Working Paper 7330, World Bank, Washington, DC.

Julio, B., and Y. Yook. 2012. "Political Uncertainty and Corporate Investment Cycles." Journal of Finance 67 (1): 45-83.

Julio, B., and Y. Yook. 2013. "Policy Uncertainty, Irreversibility, and Cross-Border Flows of Capital." Finance and Economics Discussion Series Working Paper 2013-64, Board of Governors of the Federal Reserve System, Washington, DC.

Karam, P., D. Muir, J. Pereira, and A. Tuladhar. 2010. "Macroeconomic Effects of Public Pension Reforms." Working Paper 10/297, International Monetary Fund, Washington, DC. 
Karolyi, G.A. 2015. Cracking the Emerging Markets Enigma. Oxford: Oxford University Press.

Kaufmann, D., A. Kraay, and M. Mastruzzi. 2010. "The Worldwide Governance Indicators: Methodology and Analytical Issues." Policy Research Working Paper 5430, World Bank, Washington, DC.

Kee, H. L., and H. Tang. 2014. "Domestic Value Added in Exports: Theory and Firm Evidence from China." Mimeo, Word Bank, Washington, DC.

Khandker, S. R., and G. B. Koolwal. 2007. "Are Pro-Growth Policies Pro-Poor? Evidence from Bangladesh." Unpublished manuscript, World Bank, Washington, DC.

Khandker, S. R., and G. B. Koolwal. 2010. "How Infrastructure and Financial Institutions Affect Rural Income and Poverty: Evidence from Bangladesh." The Journal of Development Studies 46 (6): 1109-1137.

King, S. D. 2010. Losing Control: The Emerging Threats to Western Prosperity. New Haven: Yale University Press.

King, R., and R. Levine. 1993. "Finance and Growth: Schumpeter Might be Right." The Quarterly Journal of Economics 108 (3): 717-737.

Klapper, L., and I. Love. Forthcoming. "The Impact of Business Environment Reforms on New Registrations of Limited Liability Companies." World Bank Economic Review.

Klapper, L., L. Laeven, and R. Rajan. 2006. "Entry Regulation as a Barrier to Entrepreneurship." Journal of Financial Economics 82 (3): 591-629.

Kose, M. A., S. Kurlat, and F. Ohnsorge. Forthcoming. "A Cross-Country Database of Fiscal Space." Policy Research Working Paper, World Bank, Washington, DC.

Kose, M. A., and E. Prasad. 2010. Emerging Markets: Resilience and Growth amid Global Turmoil. Washington, DC: Brookings Institution Press.

Kose, M. A., and M. Terrones. 2015. Collapse and Revival: Understanding Global Recessions and Recoveries. Washington, DC: International Monetary Fund.

Koske, I., I.Wanner, R. Bitetti, and O. Barbiero. 2015. "The 2013 Update of the OECD's Database on Product Market Regulation: Policy Insights for OECD and Non-OECD Countries." Economics Department Working Paper 1200, Organisation for Economic Co-operation and Development, Paris.

Kraay, A., and L. Servén. 2013. "Fiscal Policy as a Tool for Stabilization in Developing Countries." Background Note for the 2014 World Development Report: Managing Risk for Development, World Bank, Washington, DC.

Krebs, T., and M. Scheffel. 2013. "Macroeconomic Evaluation of Labor Market Reform in Germany." Working Paper 13/42, International Monetary Fund, Washington, DC.

Lane, P.R. 2003. "Business Cycles and Macroeconomic Policy in Emerging Market Economies." International Finance 6 (1): 89-108.

Li, H., L. C. Xu, and H. Zhou. 2000. "Corruption, Income Distribution, and Growth." Economics \& Politics 12

(2): $155-182$ 
Lin, J. Y., and V. Treichel. 2012. "Learning from China's Rise to Escape the Middle-Income Trap: A New Structural Economics Approach to Latin America." Policy Research Working Paper 6165, World Bank, Washington DC.

Litterman, R. 1986. "Forecasting with Bayesian Vector Autoregression - Five Years of Experience." Journal of Business Economic Statistics 4 (1): 25-38.

Loayza, N. V., A.M. Oviedo, and L. Servén. 2005. "Regulation and Macroeconomic Performance." Policy Research Working Paper 3469, World Bank, Washington, DC.

Magnus, G. 2010. Uprising: Will Emerging Markets Shape or Shake the World Economy? Hoboken: John Wiley and Sons.

Mauro, P. 1995. "Corruption and Growth." The Quarterly Journal of Economics 110 (3): 681-712.

McKenzie, D., and C. Woodruff. 2015. "Business Practices in Small Firms in Developing Countries." Policy Research Working Paper 7405, World Bank, Washington, DC.

Mishra, P., P. Montiel, P. Pedroni, and A. Spilimbergo. 2014. "Monetary Policy and Bank Lending Rates in Low-Income Countries: Heterogeneous Panel Estimates." Journal of Development Economics 111: 117131.

Monteiro, J. C. M., and J. J. Assunção. 2012. "Coming Out of the Shadows? Estimating the Impact of Bureaucracy Simplification and Tax Cut on Formality in Brazilian Microenterprises." Journal of Development Economics 99 (1): 105-115.

Mu, R., and D. P. Van de Walle. 2007. "Rural Roads and Local Market Development in Vietnam." Policy Research Working Paper 4340, World Bank, Washington, DC.

Nicoletti, G., and S. Scarpetta. 2003. "Regulation, Productivity and Growth: OECD Evidence." Economic Policy 18 (36): 9-72.

O'Neill, J. 2011. The Growth Map: Economic Opportunity in the BRICS and Beyond. New York: Portfolio/Penguin.

Ostry, J., A. R. Ghosh, and M. Chamon. 2012. "Two Targets, Two Instruments: Monetary and Exchange Rate Policies in Emerging Market Economies." Staff Discussion Note 12/01, International Monetary Fund, Washington, DC.

Pelkmans, J., L. A. Montoya, and A. Maravalle. 2008. "How Product Market Reforms Lubricate Shock Adjustment in the Euro Area." Economic Paper 341, Directorate-General for Economic and Financial Affairs, European Commission, Brussels.

Ponticelli, J. 2015. "Court Enforcement, Bank Loans and Firm Investment: Evidence from a Bankruptcy Reform in Brazil." Fama-Miller Working Paper 14-08, Chicago Booth School of Business, Chicago.

Prati, A., M. G. Onorato, and C. Papageorgiou. 2013. "Which Reforms Work and under What Institutional Environment? Evidence from a New Dataset on Structural Reforms." The Review of Economics and Statistics 95 (3): 946-968.

Pritchett, L. 2000. "Understanding Patterns of Economic Growth: Searching for Hills among Plateaus, Mountains, and Plains." World Bank Economic Review 14 (2): 221-250. 
Pritchett, L., and L. Summers. 2014. "Asiaphoria Meets Regression to the Mean." Working Paper 20573, National Bureau of Economic Research, Cambridge.

Qureshi, Z., J. L. Diaz-Sanchez, and A. Varoudakis. 2014. "The Post-Crisis Growth Slowdown in Emerging Economies and the Role of Structural Reforms." Policy Research Working Paper 7107, World Bank, Washington, DC.

Rajan, R., and L. Zingales. 1998. "Financial Dependence and Growth." American Economic Review 88 (3): 559-586.

Ramos-Francia, M., and S. García-Verdú. 2015. “Is Trouble Brewing for EMEs?” Working Paper 2015-08, Banco de México, Mexico City.

Reinikka, R., and J. Svensson. 2002. "Coping with Poor Public Capital." Journal of Development Economics 69: 51-69.

Reinhart, C. 2015. "The Hidden Debt Burden of Emerging Markets." Project Syndicate, Oct. 9.

Rodrik, D. 1991. "Policy Uncertainty and Private Investment in Developing Countries." Journal of Development Economics 36 (2): 229-242.

Rodrik, D. 2015. "Back to Fundamentals in Emerging Markets." Project Syndicate, Aug 13.

Rogoff, K. 2014. “How Fragile are Emerging Markets." Project Syndicate, February 6.

Roller, L-H., and L. Waverman. 2001. "Telecommunications Infrastructure and Economic Development: A Simultaneous Approach." American Economic Review 91 (4): 909-923.

Roubini, R. 2015. “Emerging Markets After the Fed Hikes Rates.” Project Syndicate, Jun 29.

Rud, J. P. 2012. "Electricity Provision and Industrial Development: Evidence from India." Journal of Development Economics 97 (2): 352-367.

Sala-i-Martin, X., G. Doppelhofer, and R. I. Miller. 2004. "Determinants of Long-Term Growth: A Bayesian Averaging of Classical Estimates (BACE) Approach." American Economic Review 94 (4): 813-835.

Sharma, R. 2012. Breakout Nations: In Pursuit of the Next Economic Miracles. New York: Norton.

Sosa, S., E. Tsounta, and H. S. Kim. 2013. "Is the Growth Momentum in Latin America Sustainable?" Working Paper 13/109, International Monetary Fund, Washington, DC.

Spence, M. 2011. The Next Convergence: The Future of Economic Growth in a Multispeed World. New York: Farrar, Straus, and Giroux.

Spence, M. 2014. “Overshooting in Emerging Markets." Project Syndicate, Feb 20.

Srivastava, V. 1996. Liberalization, Productivity and Competition. Delhi: Oxford University Press.

Tanzi, V., and H.R. Davoodi. 1997. "Corruption, Public Investment, and Growth.” Working Paper 97/139, International Monetary Fund, Washington, DC.

Topalova, P., and A. Khandelwal. 2011. "Trade Liberalization and Firm Productivity: The Case of India." The Review of Economics and Statistics 93 (3): 995-1009. 
Tsounta, E. 2014. “Slowdown in Emerging Markets: Sign of a Bumpy Road Ahead?” Working Paper 14/205, International Monetary Fund, Washington, DC.

Tyson, L. 2015. "The Future for Emerging Markets." Project Syndicate, June 30.

Velasco. A. 2013. “Emerging Markets' Nirvana Lost." Project Syndicate, Sept 11.

Weinberg, B. A. 2011. "Developing Science: Scientific Performance and Brain Drains in the Developing World." Journal of Development Economics 95 (1): 95-104.

Wölfl, A., I. Wanner, O. Röhn, and G. Nicoletti. 2010. "Product Market Regulation: Extending the Analysis Beyond OECD Countries." Economics Department Working Paper 799, Organization for Economic Cooperation and Development, Paris.

World Bank. 2011a. Global Development Horizons 2011-Multipolarity: The New Global Economy.

Washington, DC: World Bank.

World Bank. 2011b. The Changing Wealth of Nations: Measuring Sustainable Development in the New Millennium. Washington, DC: World Bank.

World Bank. 2013. Global Economic Prospects January 2013. Washington, DC: World Bank.

World Bank. 2015a. Having Space and Using It. Global Economic Prospects January 2015. Washington, DC: World Bank.

World Bank. 2015b. East Asia and Pacific Economic Update: Staying the Course, October 2015. Washington, DC: World Bank.

World Bank. 2015c. Getting Prices Right: The Recent Disinflation and its Implications. South Asia Economic Focus, Fall 2015. Washington, DC: World Bank.

World Bank. 2015d. Russia Economic Report: Balancing Economic Adjustment and Transformation. No. 34, September 2015. Washington, DC: World Bank.

World Bank. 2015e. Commodity Markets Outlook July 2015. Washington, DC: World Bank.

World Bank. 2015f. The Global Economy in Transition. Global Economic Prospects June 2015. Washington, DC: World Bank.

World Bank. 2015g. Development Goals in an Era of Demographic Change. Global Monitoring Report 2015/2016. Washington, DC: World Bank.

World Bank. 2015h. Latin America Treads a Narrow Path to Growth: The Slowdown and its Macroeconomic Challenges. Semi-Annual Report of the Office of the Regional Chief Economist, April. Washington, DC: World Bank.

World Bank. 2015i. Migration and Development Brief 25. October 2015. Washington, DC: World Bank.

World Bank. Forthcoming. Global Economic Prospects January 2016. Washington, DC: World Bank.

World Trade Organization. 2015. Report to the TPRB from the Director-General on Trade-Related Developments, Mid-October 2014 to mid-May 2015. Geneva: World Trade Organization. 
United Nations. 2015. World Population Prospects: The 2015 Revision. New York: United Nations, Department of Economic and Social Affairs. Population Division.

Zhuang, J., P. Vandenberg, and Y. Huang. 2012. Growing Beyond the Low-Cost Advantage: How the People's Republic of China can avoid the Middle-Income Trap. Manila: Asian Development Bank. 